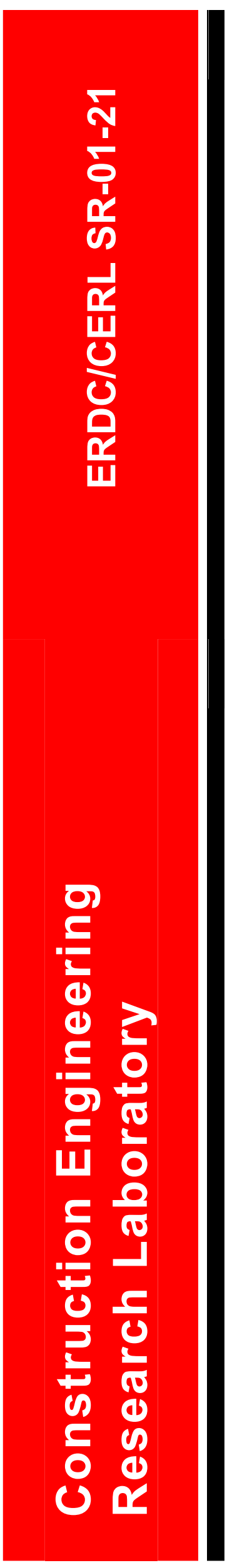

\title{
Proceedings of the Workshop on Environmental Protection for Forces Deployment
}

Edited by Robert Lozar and Charles R. Ehlschlaeger

December 2001 


\section{Foreword}

This research was conducted for the Commander, U.S. Army Corps of Engineers, under 622720A896, "Environmental Quality Technology," Work Unit TY9, "Overseas Forces and Environmental Protection Scoping." The technical monitor was Dr. William D. Severinghaus, Engineer Research and Development Center/Construction Engineering Research Laboratory (ERDC/CERL).

The work was performed by the Ecological Processes Branch (CN-N) of the Installations Division (CN), Construction Engineering Research Laboratory (CERL). The CERL Principal Investigator was Robert C. Lozar. The technical editor was Gloria J. Wienke, Information Technology Laboratory. Stephen E. Hodapp is Chief, CN-N, and Dr. John Bandy is Chief, CN. The associated Technical Director was Dr. William D. Severinghaus, CEERD-CV-T. The staff from many U.S. Army installations provided data. The Director of CERL is Dr. Alan W. Moore.

CERL is an element of the U.S. Army Engineer Research and Development Center (ERDC), U.S. Army Corps of Engineers. The Commander and Executive Director of ERDC is COL John W. Morris III, EN, and the Director is Dr. James R. Houston.

\section{DISCLAIMER}

The contents of this report are not to be used for advertising, publication, or promotional purposes. Citation of trade names does not constitute an official endorsement or approval of the use of such commercial products. All product names and trademarks cited are the property of their respective owners.

The findings of this report are not to be construed as an official Department of the Army position unless so designated by other authorized documents. 


\section{Contents}

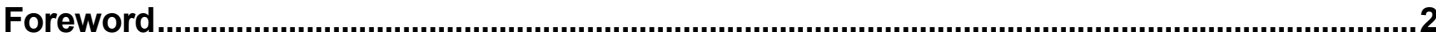

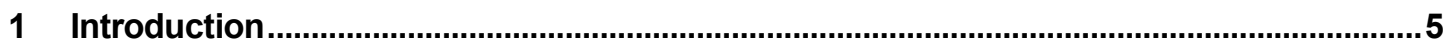

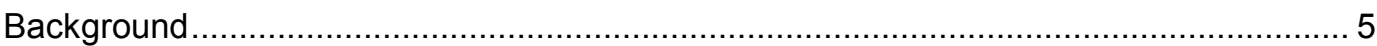

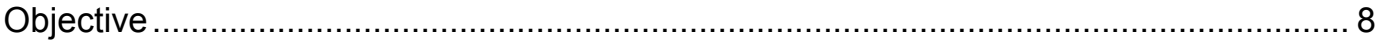

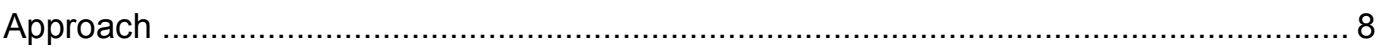

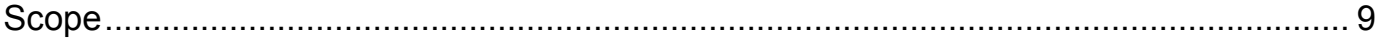

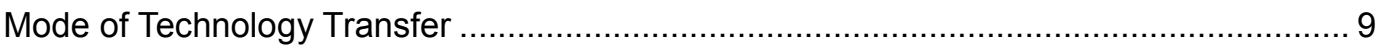

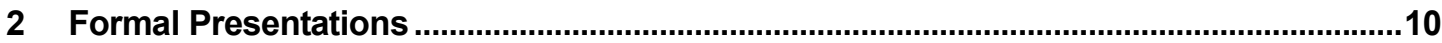

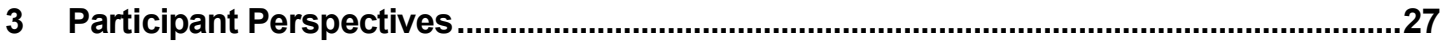

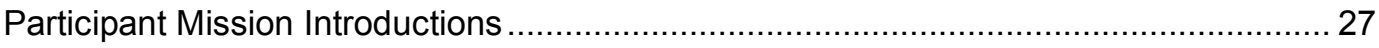

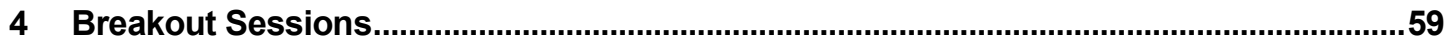

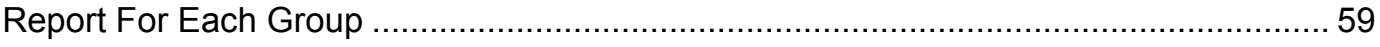

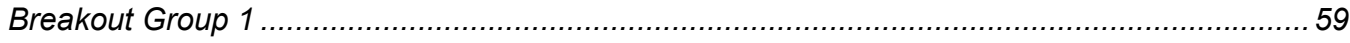

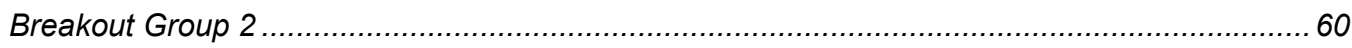

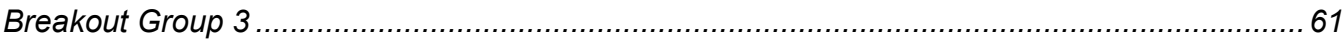

5 Workshop Observations and Recommendations..............................................................64

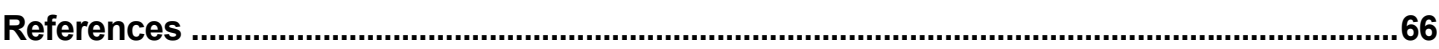

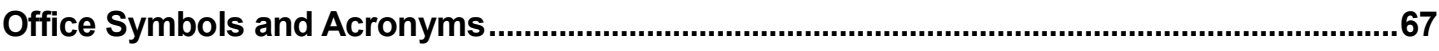

Appendix A: $\quad$ Executive Order on Global Disaster Information Network............................71

Appendix B: $\quad$ List and Addresses of Attendees...............................................................

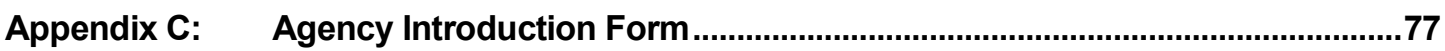

Appendix D: $\quad$ Senior Environmental Leadership Conference Issue Papers ......................78

Appendix E: $\quad$ Overseas Deployment Land Management.....................................................

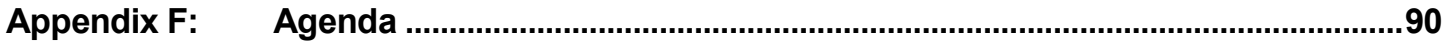


Appendix G: Increasing Environmental Awareness During Overseas

Deployments, an Outsider's Perspective ...........................................................91

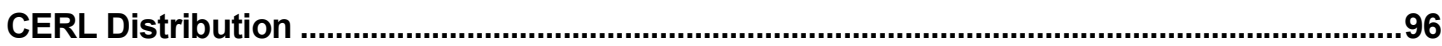

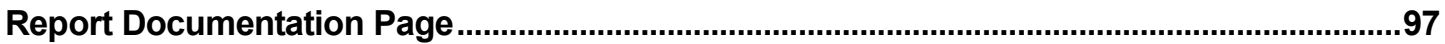




\section{Introduction}

\section{Background}

The Department of Defense (DoD) often must carry out emergency and humanitarian response, training, or tactical activities on lands of other countries. However, these host countries expect that the DoD and other U.S. agencies observe the same care in land management and environmental oversight that they would provide to lands within the United States or, after their departure, the lands be returned to local use in a nondegraded condition. Some impacts may even cause irreversible changes, such as construction that causes loss of archeological sites. Therefore, it is desirable to plan to avoid degradation. When conducting a life cycle cost evaluation for an activity, it is normally less expensive for the United States mission to avoid degradation than to mitigate it later. The United States can avoid potentially controversial issues by knowing about the concerns of host countries.

In 1969, the Congress of the United States passed into public law the National Environmental Policy Act (NEPA) (Public Law [PL] 91-190). This law set the standards by which Federal Government actions are accessed as they relate to the environment within the borders of the United States. A procedure, format for the evaluation, documentation and public notification of significant or controversial actions was set forth. The application of this law remains controversial, yet it has become clear that as a means of systematically evaluating the effects of Federal actions, the documentation (the Environmental Impact Assessment [EIA] and the more robust Environmental Impact Statement [EIS]) has provided a useful model for ensuring thoughtful resource management. There is a long history of support from the U.S. Executive Branch for careful land management and environmental oversight in host countries. In 1979, a Presidential Executive Order (EO 12114, 1979) made the United States responsible for assessing its environmental actions in areas beyond territorial limits. To quote a part of the Purpose:

This directive provides policy and procedures to enable Department of Defense (DoD) officials to be informed and take account of environmental considerations when authorizing or approving certain major federal ac- 
tions that do significant harm to the environment of places outside the United States.

Regulations and policy have extended environmental responsibility to cover land areas where the DoD carries out various actions (AR 200-1, 1997). In addition, the connection to our own national security has been made.

The 1991 National Security Strategy of the United States (NSS) was the first NSS to recognize the environment as a U.S. national security interest; the environmental dimension has been expanded in the 1993 NSS. Its inclusion reflects popular national and international opinion which realizes that environmental issues have a major impact on economics and health, and are increasingly seen as a threat to development and political stability. Environmental issues such as clean air, desertification, and natural resource access have a cross-border component that has contributed to international conflict. By expanding the definition of national security to include the environment, the NSS suggests that traditional national security strategies should expand their focus to include environmental objectives. The military is thus included. (Butts 1993)

Thus, it would seem that the agencies of the U.S. Government and in this case, the Army, have a self interest as well as a responsibility for the environmental consequences of their actions essentially anywhere in the world. Host nations are recognizing this and requesting that the actions of U.S. agencies in host countries incorporate means to effectively carry out land and environmental protection stewardship and restoration when the U.S. military is an invited guest in their county.

The United States Military is increasingly called upon to provide support to missions overseas that are of a nontactical nature, and are not necessarily in unfriendly situations. Examples number in the hundreds to thousands of missions per year and include overseas troop training missions, emergency relief, and humanitarian actions. For each of these, predeployment planning is carried out to ensure a smooth deployment.

For each mission overseas, the local force protection and environment needs to be considered. Health and safety issues for force protection as well as avoiding and minimizing impacts to the local environment provide a payback to the United States in dollar savings. But initial investigation has shown that this planning is dispersed and nonstandardized (particularly between the Services) 
and often not done with the care that is characteristic of other portions of the military deployment planning process.

Yet, in practice, for overseas actions, our military are faced with the need to develop ad-hoc procedures and methods for identifying potential environmental risks. Issues of avoiding or mitigating the time, cost, and controversy associated with actions beyond U.S. territorial limits naturally follow. Programs for establishing training areas (commonly referred to as the Range-in-a-Box program sponsored by the Army Deployable Operations Group) do exist and may provide the model and integration framework for implementing overseas environmental evaluation initiatives (USACE 1990).

The question the military planners face results from military experience (such as from Joint Endeavor and actions in the former Yugoslavia and Albania) that indicates the required spatial and nonspatial information was not available in the planning stages to include environmental management aspects of predeployment, deployment, and postdeployment activities.

Through a concept originated by the Business Area Coordinator at the U.S. Army Engineer Research and Development Center's (ERDC's) Construction Engineering Research Laboratory (CERL), a scoping effort was undertaken. The purpose of the scoping effort is to define the opportunities for procedure improvement among the resources and expertise currently available within the ERDC community. This work is intended to parallel closely the initiatives discussed within the recently emerging government documents: Draft Field Manual (FM) 20-400, Military Environmental Protection, and the TRADOC (Training and Doctrine Command) white paper "Integrating U.S. Army Environmental Strategy into Operational Doctrine." It is expected that this scooping effort will provide a strategic identification of how the Army may better implement the policies within these documents.

Therefore the ERDC conducted a workshop to draw together relevant parties to explore possible solutions to providing required spatial and nonspatial environmental management information to support planning and operations of deployed forces. 


\section{Objective}

This report documents the input and recommendations of the workshop.

The stated objectives of the workshop were:

1. Enhance information exchange among the various agencies working on different aspects of environmental hazards and protection for deployed forces.

2. Identify gaps and redundancies in doctrine, information, programs, coordination, and information technology.

3. Identify existing systems, proponents, and responsibilities.

4. Identify potential Research and Development (R\&D) requirements.

5. Identify necessary command and support relationships.

6. Plan next steps toward solutions.

\section{Approach}

The approach was to coordinate and develop a workshop; gather and document the resources and expertise currently available within the DoD, Army, and ERDC communities; and collate these findings into this document in support of the Scoping Study.

As groundwork needed to put together the workshop, the following Tasks were defined:

- Identify the core critical issues that are of the greatest concern to the military deployment planners

- Prioritize these key issues

- Correlate key issues with agency missions and key personnel

- Document. This material served as the preliminary workshop materials

- Identify a list of potential workshop attendees - both agencies and individuals. These agencies/individuals were invited to participate in the workshop. The participation of the workshop was focused to be 20 to 25 individuals.

- Carry out the Workshop.

- Document:

1. Document the outcome of the workshop in cooperation with the support contractor (who had the responsibility of transcribing the discussions and summarizing 
them). This document will identify the critical issues and responsible agencies discussed at the workshop and in follow-up discussions.

2. Recommend logical direction for the next steps in the development of a customer support and research program within the area of Environmental Overseas Force Protection Support.

\section{Scope}

The purpose of the workshop was to bring together the diverse entities that had some mission in the area of concern for the environment in overseas military deployments. It is not intended that the contents and activities represent the breadth of operations that are occurring or the complete representation of the agencies involved. In fact, this document is clearly limited to the perspectives of those who participated in the workshop. Some of those invited could not attend the workshop, so it is clear that additional perspectives could provide further illumination on a given subject. The workshop was an opportunity for those players in the area to discuss issues openly and come to a consensus. However, in no way is the outcome of the workshop to be considered a complete, nor official representation of the $\mathrm{DoD}$ or any of its agencies. Statements made by workshop participants do not reflect official policy of the Corps of Engineers, the U.S. Army, or the Federal Government.

\section{Mode of Technology Transfer}

This document is intended to provide the framework for the next steps as indicated in the recommendation section of this report.

This report will be made accessible through the World Wide Web (WWW) at URL: http://www.cecer.army.mil 


\section{Formal Presentations}

\section{Workshop Introduction: Robert Lozar}

Military deployments, whether for warfighting or humanitarian operations, can result in environmental degradation. Environmental concerns relate to predeployment site preparation (e.g., road improvements, site clearing, building, or runway construction), deployment operations such as the development of Camp Bondsteel in just a few months (e.g., noise generation, handling and storage of hazardous materials, training or testing operations, or military actions), and postdeployment residual damage (e.g., loss of vegetation and soils, oil and battery acid spills, damage to historic structures, and contaminant residue in soils, ground, or surface waters). These environmental degradations can result in costly mitigation and restoration actions and can be a source of political strain between the United States and the nations in which these deployments occur.

By the attendance it is clear that a great many agencies are highly concerned with the questions that have arisen from the perspective of Environmental Protection for Forces Deployment. Is it a timely issue? Less than a week before this workshop, President Clinton issued a new Executive Order (EO 13151, 27 April 2000) entitled "Global Disaster Information Network." The purpose of this EO (Appendix A) is to establish a Global Disaster Information Network (GDIN) to use information technology more effectively to reduce loss of life and property from natural and man-made disasters. The EO establishes an Interagency Coordinating Committee to provide leadership and oversight for the development of the network. The DoD is second on the list of members of that committee. Clearly, the mission of this workshop is most timely.

In delving into this area (environmental review for overseas deployment) it became clear that there are many agencies that have some set of responsibilities for Environmental Protection for Forces Deployment and that more interaction and coordination might improve the process. Also, many different perspectives exist about how completely served the planning and field commanders are. When consulted, some individuals were of the opinion that all questions were answered, others believed that they were about to be answered, and some felt strongly that no one had even begun to ask the right questions. 
Figure 1 (from TRADOC Draft FM 20-400, figure 1-4) illustrates the variety of military deployment planning perspectives. Most planning is done in deployment and operational situations - where level of environmental protection is agreed to be minimal. Less planning is done in the training, postoperational, mobilization, and redeployment arenas - where level of environmental protection is much higher. This presents a challenge to the workshop participants: to provide the appropriate amount of environmental consideration at each point in the deployment activity.

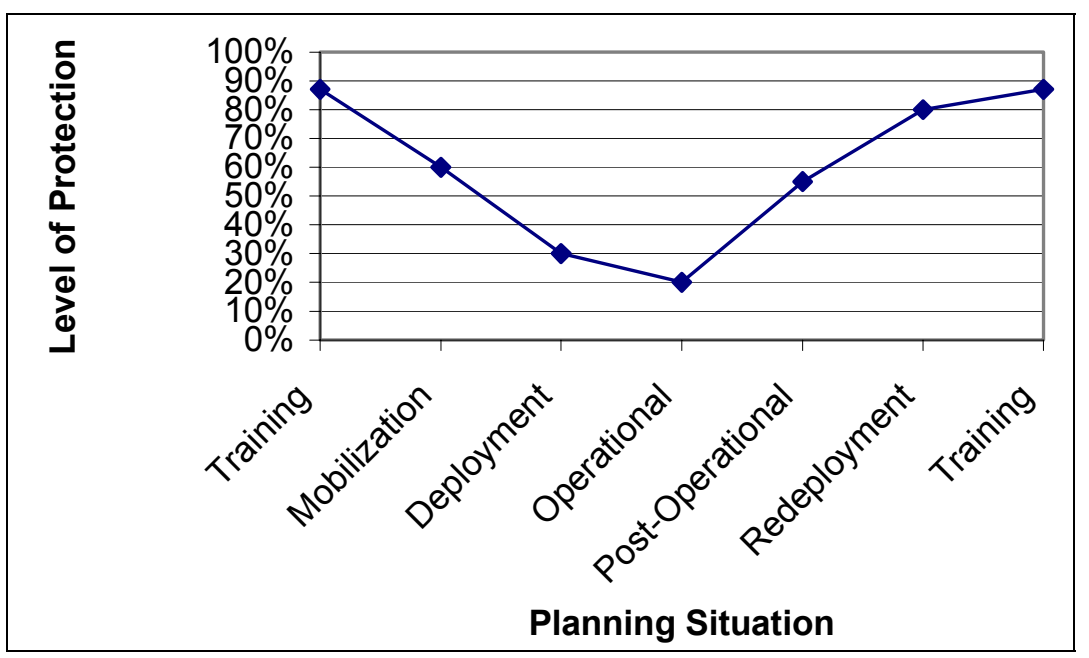

Figure 1. Levels of environmental consideration.

We have come together in this workshop to begin to generate this understanding. We wish to better:

- Understand the setting, players, and mission

- Identify needs as policy and technology (these will be addressed in the working breakout session)

- Identify missions as contingency operations

- Improve our capability for overseas contingency operations per the 27 April 2000 Executive Order.

We will begin with a set of presentations. Then all participants will have the opportunity to introduce themselves and their agency missions. From this we will as a group attempt to develop a consensus and recommendation for what the logical direction should be.

The formal presentations will be given by:

Curtis Bowling - Office of the Deputy Under Secretary of Defense - will provide background from the DoD perspective. 
William Nicholls - U.S. Army Europe (USAREUR) Office of the Deputy Chief of Staff for Engineering (ODCSENG) Environmental Division.

Roy Parks - U.S. Army Corps of Engineers.

Tim Rensema - Army Environmental Policy Institute.

Dr. Bill Severinghaus - U.S. Army Engineer Research and Development Center/Construction Engineering Research Laboratory (ERDC/CERL), Director of Military Land Management. 


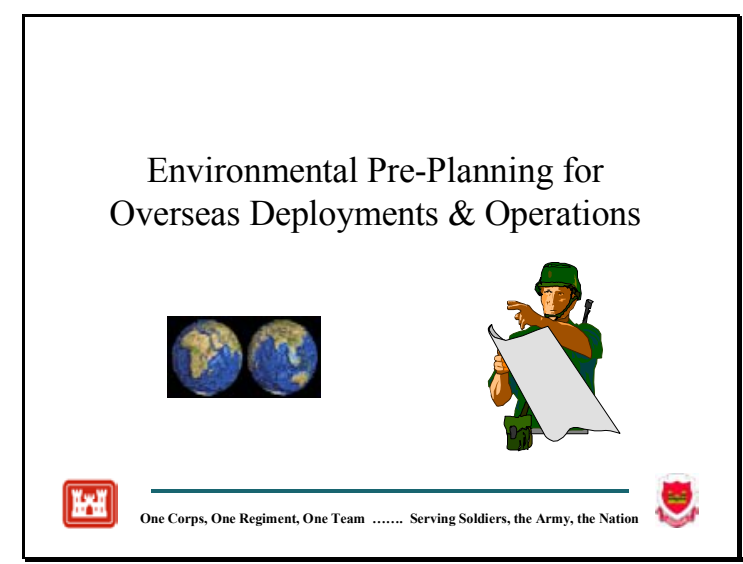

Slide 1

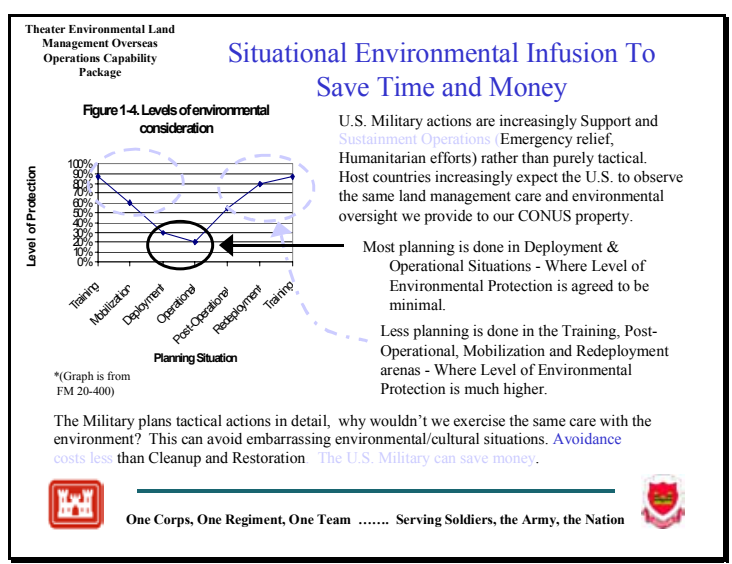

Slide 2

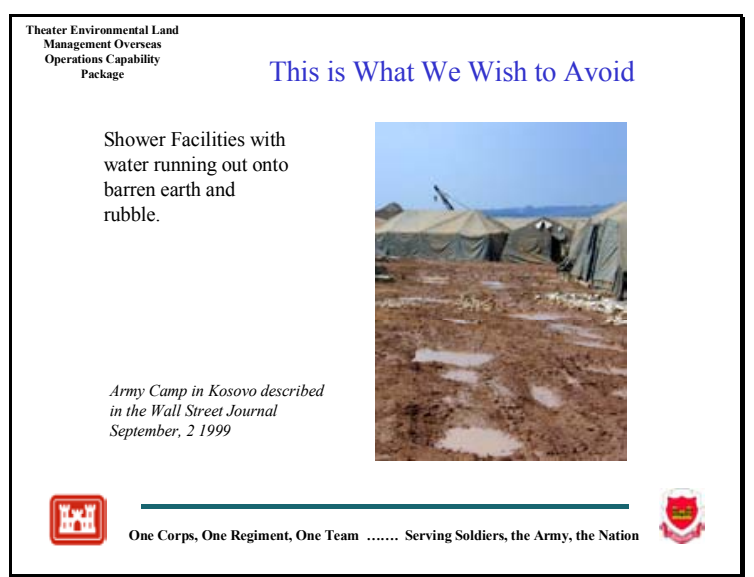

Slide 4

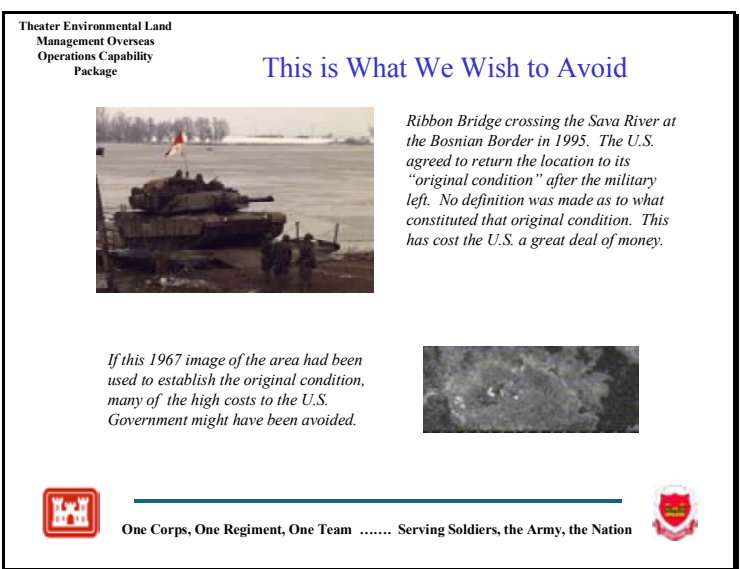

Slide 5

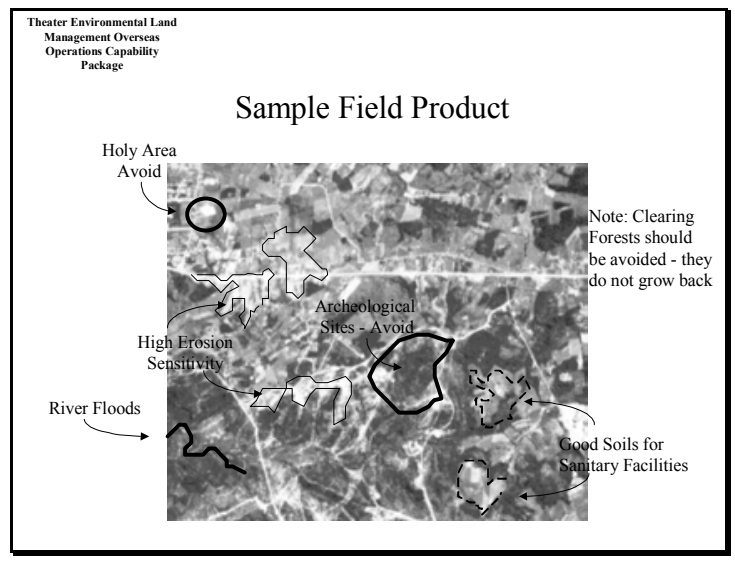

Slide 3

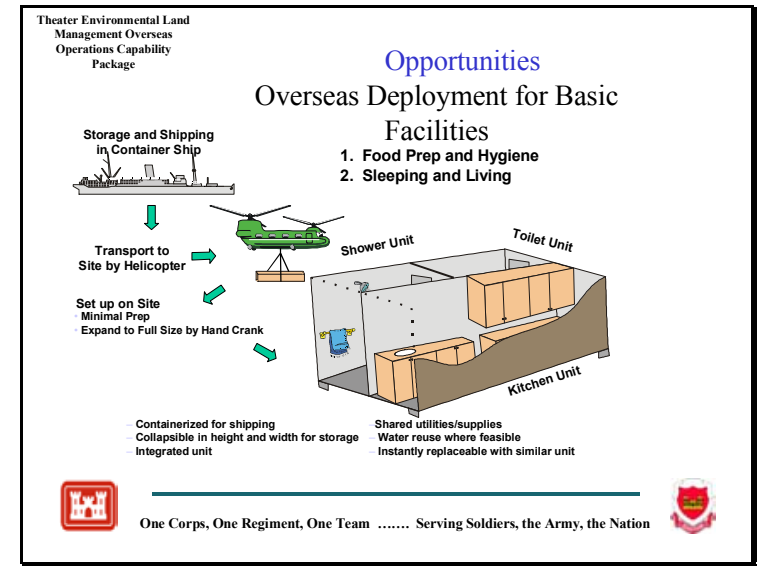

Slide 6 
DUSD-ES, Curtis Bowling - Assistant Deputy Under Secretary of Defense Environmental Security for Force Protection

Address: ODUSD (ES/FP) 3400 Defense Pentagon, Rm 3E791 Washington, DC 20301-3400

Email: Bowlincm@acq.osd.mil

Phone: 703-604-1624

Fax: $\quad 703-607-1244$

The question of overseas deployment is very timely because the DoD is changing its pattern of engagements. The "two major conflict" scenario of the past is being changed to reflect the recent pattern of smaller engagements. An increased number of smaller deployments is expected in the future. The $\mathrm{DoD}$ is a proponent of safety and health operations, and in order to support safety and health in the new pattern, the military will require timely information on environmental conditions for various kinds of humanitarian and emergency deployments, as well as for exercises.

Lessons from the past 10 years, including those gained during the Gulf War, Bosnia, and Kosovo, have shown that Environmental Security is important. The concern about bird migration during the Gulf War is an example of necessary environmental information for fighter pilots. More importantly in that conflict, the environment was used as a weapon when Iraq set the Kuwaiti oil well fires. Also, the Gulf War Syndrome shows that there is a need to understand the environment that the troops are in, what they are exposed to, and the effects of cumulative exposure. Bosnia, for example, was an urban site. Troops were deployed into industrial sites, and into harm's way. If better information had been available, this would not have happened, but information about these sites was not available in time. In Kosovo, televised reports of environmental impacts of the conflict were made while the conflict was taking place. In this case, available technology was employed to try to prevent environmental problems. The Army and the National Imagery and Mapping Agency (NIMA) teamed together to look at potential battlefield damage and contamination, and decided where it was best to deploy troops.

Our cumulative experience shows that without timely information from all agencies involved, adequate environmental protection for forces deployment is impossible. 


\section{USAREUR ODCSENG Environmental Division - William Nicholls}

USAREUR ODCSENG uses data for the following purposes: war, peacemaking, peace enforcement, peacekeeping, humanitarian relief, NEO (noncombatant evacuation operation), and exercises.

This office is trying to develop a land-based GIS [Geographic Information System] environmental system in response to a G2 (intelligence) request. The problem is that commanders in the field need guidance. For example, when deployments are made, the base camp is usually picked by the maneuver commander. He needs to know the environmental information when he makes that choice not a day later, but right at that moment. Positive points are that the commanders believe in environmental questions, and their troops believe in supporting environmental questions. Right now, however, they do not have the information needed to make decisions based on environmental concerns. In order for them to do that, more coordination is needed. When a commander looks at the safety person, he thinks that he is also looking at the medical person and the environmental person; he considers all of these guys the same. Therefore, the people holding these three positions respond as cooperatively as they can.

Department of Defense policy and doctrine need to be refined. The environmental intelligence and the databases that USAREUR ODCSENG can use need to be unclassified so that they can be easily handled wherever they are needed. The question is not whether or not the data is out there; the data is available. The really difficult problem is finding out who has the data, and there also must be a coordinated effort to make it available to the commander in the field. If this environmental deployment is carried out successfully, it will be a great demonstration of how the military and democracy can work well together.

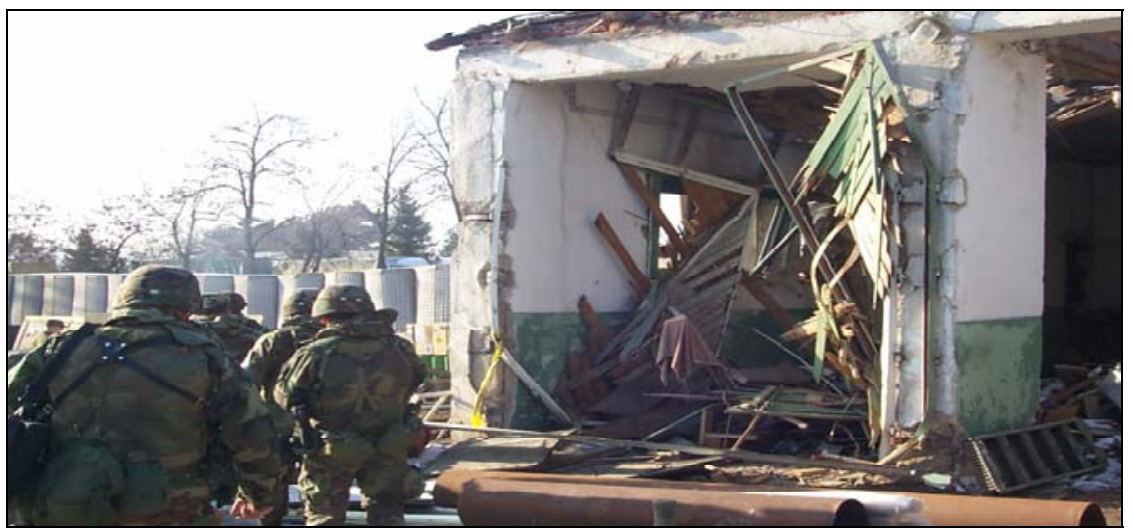

Figure 2. Camp Monteith - building requiring testing/HAZMAT removal. 


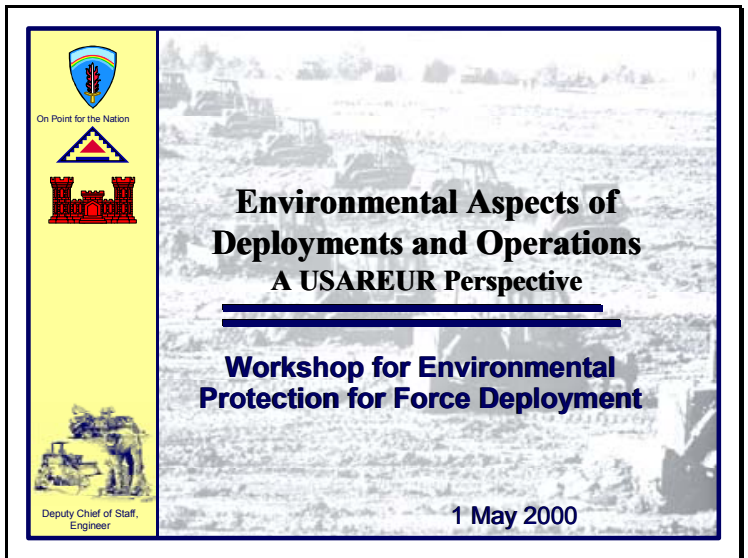

Slide 1

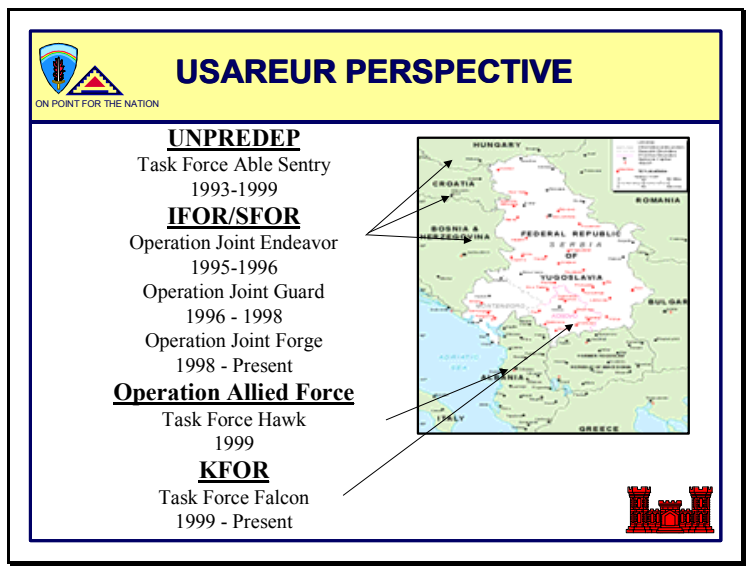

Slide 2

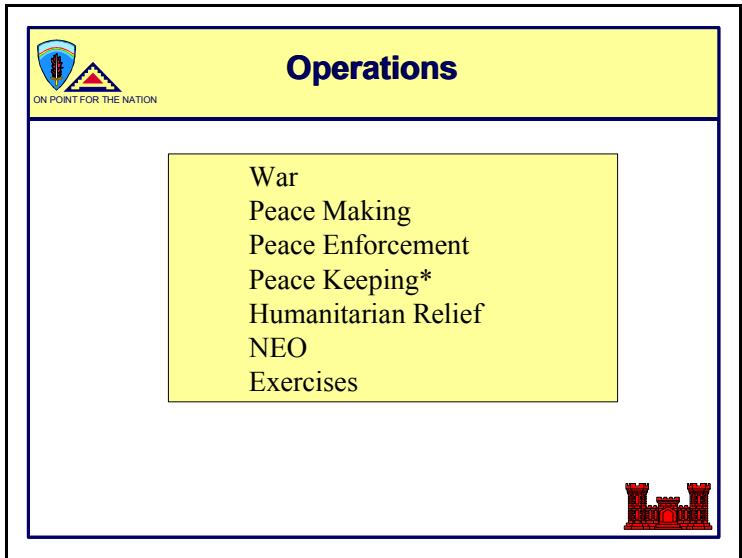

Slide 3

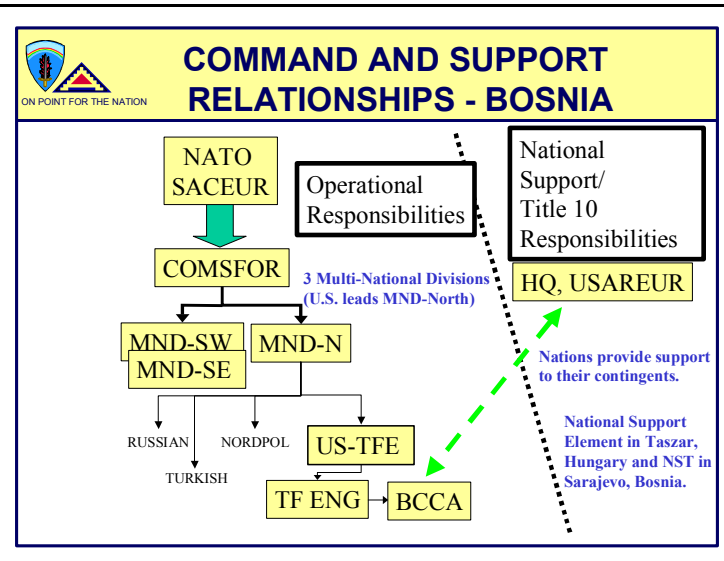

Slide 4

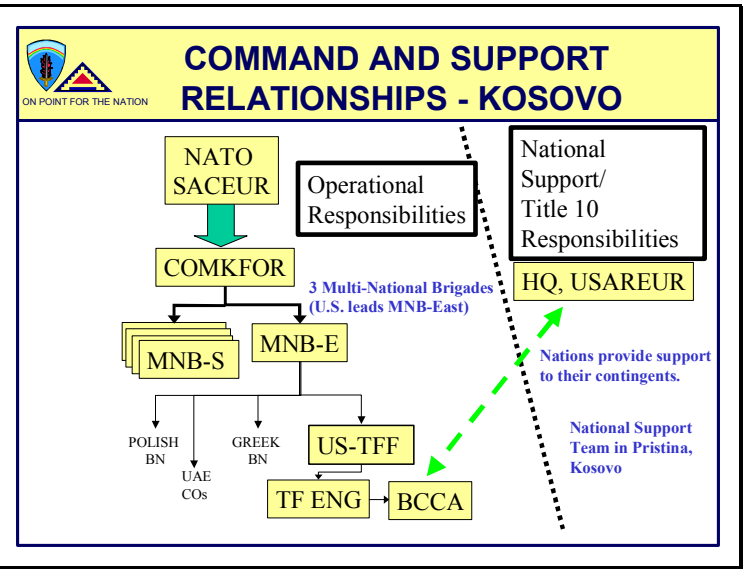

Slide 5

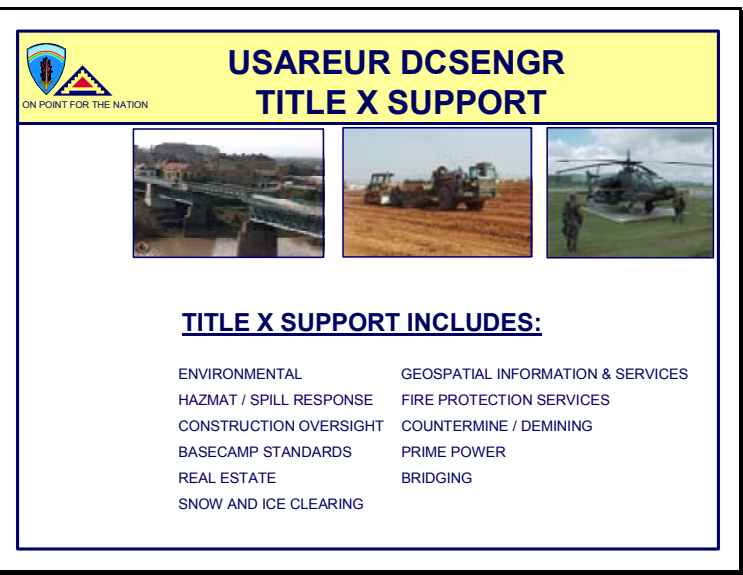

Slide 6 


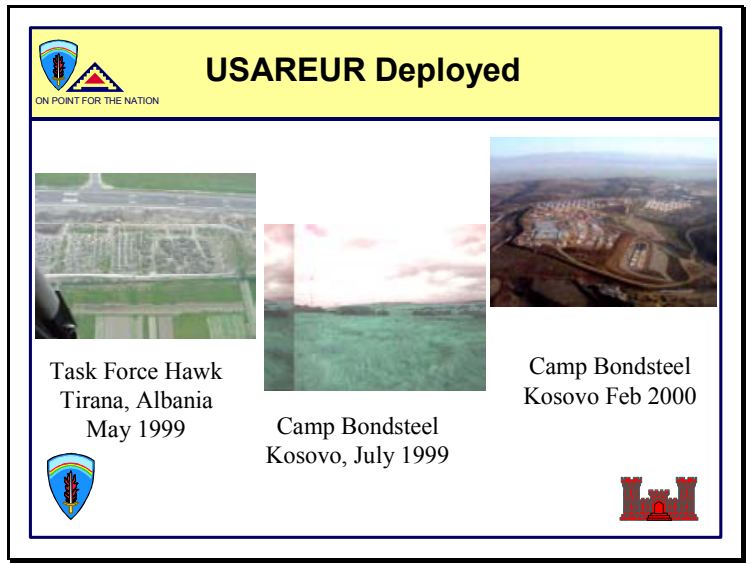

Slide 7

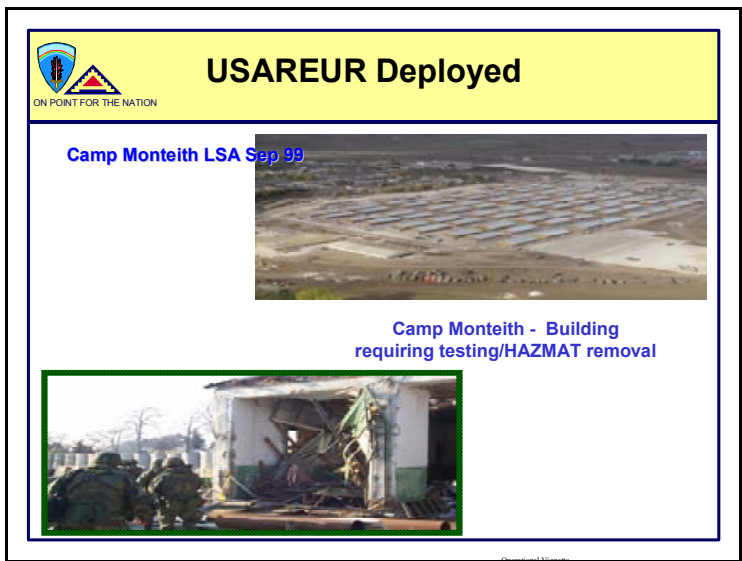

Slide 8

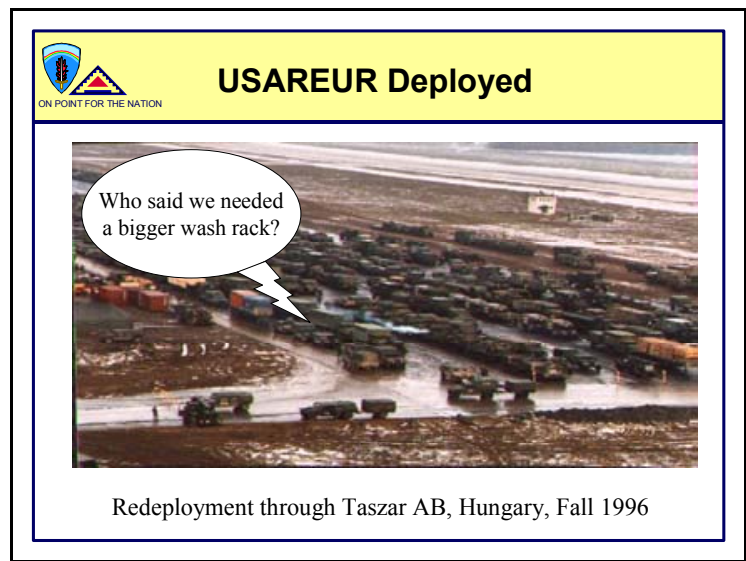

Slide 9

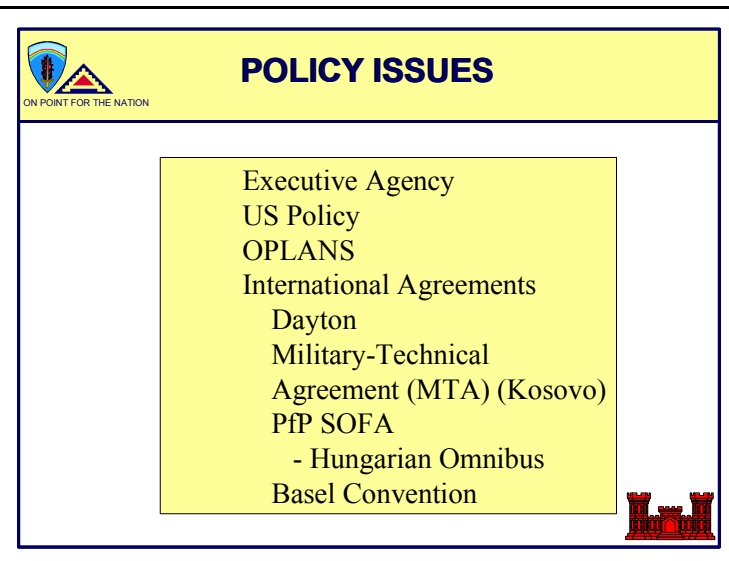

Slide 10

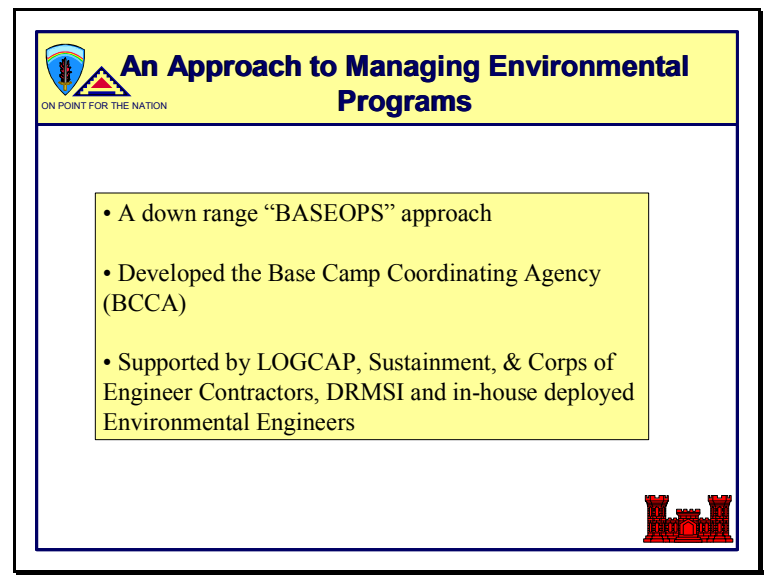

Slide 11

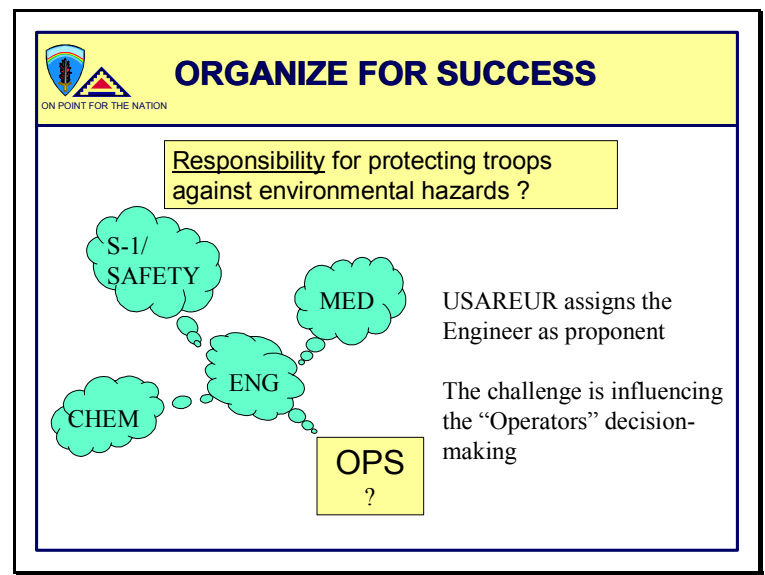

Slide 12 


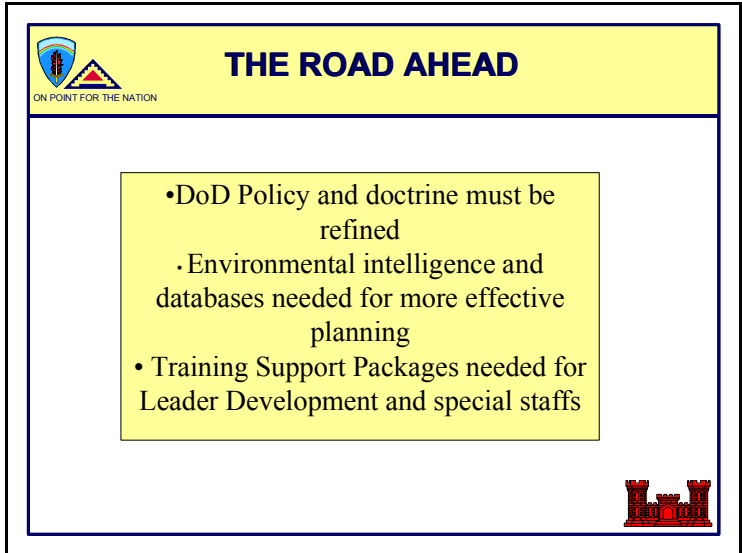

Slide 13

\section{USAREUR - Roy Parks}

Address: USAREUR

CMR 410, Box 4, APO AE 09096

Email: Roy.parks@usace.army.mil

Phone: $\quad 336-2450$; from outside US: 011-49-611-816-2450

Fax: $\quad 336-2453$; from outside US: 011-49-611-816-2453

The Agency Mission of the U.S. Army Corps of Engineers, European District, (EUD) includes planning, design, and construction for USAREUR and USACE military installations in Europe. It is the Corps' forward-deployed district, supporting the permanent USAREUR/USACE forces and infrastructure as well as its more temporary forces. The District is responsible, under the Planning and Environmental Branch, for the execution of a wide range of military Master Planning and Environmental projects, including conservation, pollution prevention, remediation, and compliance. It needs environmental data in support of CONOPS (Concept of Operations) in a timely fashion (prior or coincident with the operation), and a means to foster fusion/integration of tools and data developed in environmental stovepipes. Timely data provides both force and environmental protection, and integration of stovepipe efforts obviously saves the cost of duplication of effort. USAREUR/USACE and numerous other Department of Defense agencies are the District's customers; it works most closely in CONOPS with USAREUR DCSENGR and other Corps Districts to provide deployed engineering expertise and project execution capabilities.

There are plans for a pilot environmental GIS for EUCOM's (European Command) many different contingency operations, with the purpose of getting timely 
information to troops on the ground. Currently, environmental personnel tend to get sent to the field without much information. As a result, decisions impacted by environmental concerns are sometimes made without taking those concerns into consideration. For example, base camp selection is currently based on strategic concerns, but the selection should also take environmental factors into account. In order for commanders to do so, environmental data must be available upon initiation of a contingency operation.

EUCOM's environmental engineers were the first on the ground in Hungary and Macedonia. They were there to set up the contingency operations for the base camps.

In order to get ahead of the game, EUCOM is setting up what is called EUCOM OPS GIS. They have selected a few countries, including Hungary and Macedonia, on which to base the GIS. Robust GIS data is available for Hungary (they have a GIS in ArcView), but there is not much data for Macedonia. The desire is to put data in ESRI [Environmental Systems Research Institute, Inc.] ArcView format on a laptop. The GIS will be standalone, designed to be carried in contingency operations. The data will include planametric information such as topographic data, hydrologic data, and soil data. It will also include HTRW [hazardous, toxic, and radiological waste] support. The environmental protection data will include cultural resources. Because this is a pilot program, only the most important data is currently being included in the GIS. If meteorological and seismic data are considered pertinent, they will eventually be included. Clearly, weather information might be useful. For example, the location of troops in a seasonally dry riverbed in Bosnia is a situation in which climate data would have been useful. At this time, the GIS does not include possible environmental results of targeting (e.g., hitting a chemical dump). Support for the GIS is coming from NIMA and The World Conservation Monitoring Center. Although there are limitations on downloading in the field, the potential for future use is very high because many future operations will deal with the same issues. 


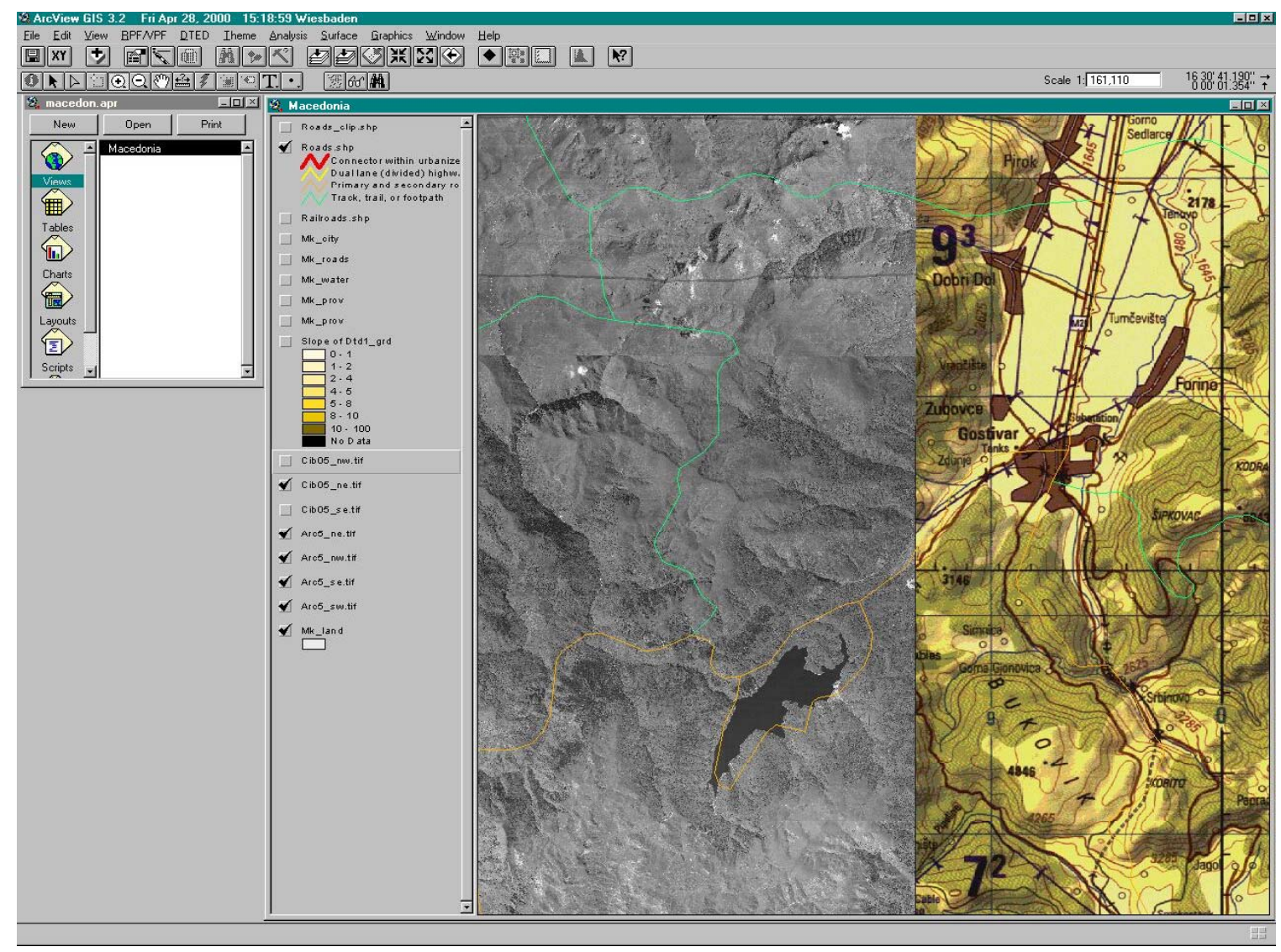

Figure 3. Example of Corps, European District (EUD), planning system. 


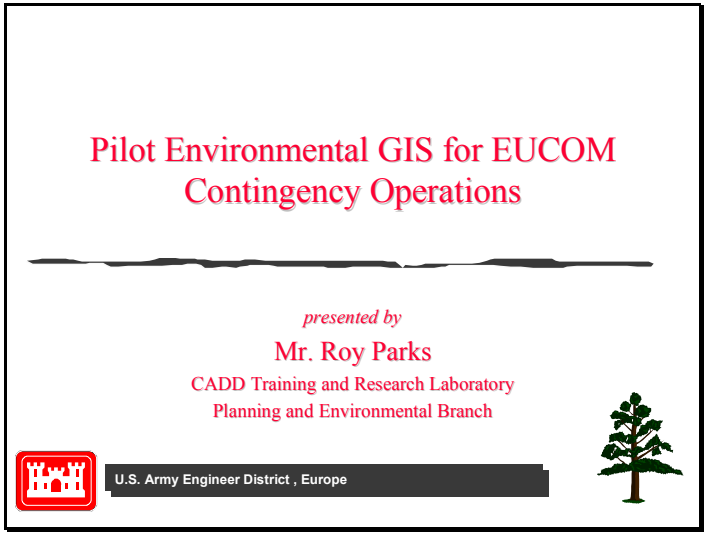

Slide 1

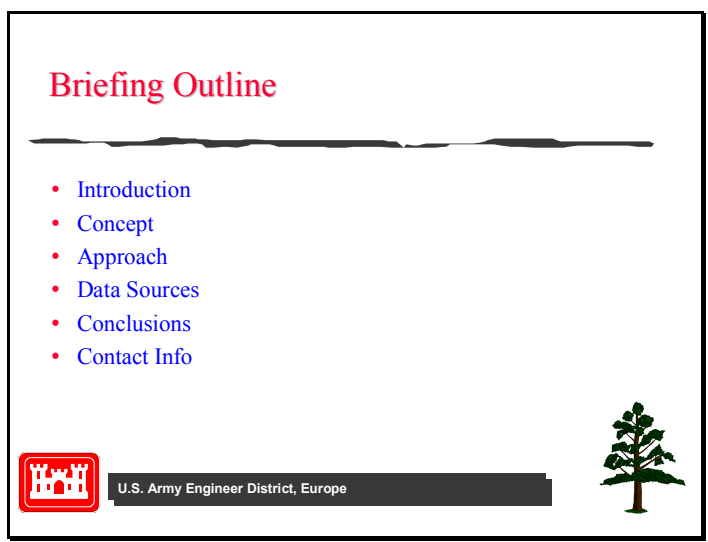

Slide 2

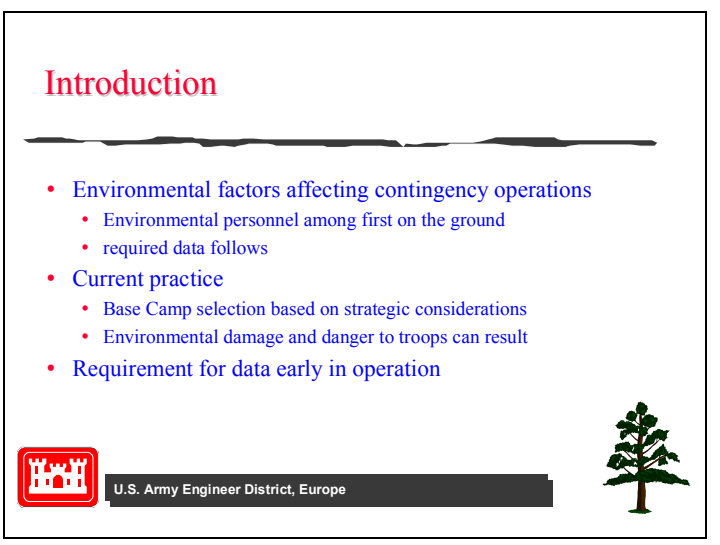

Slide 3

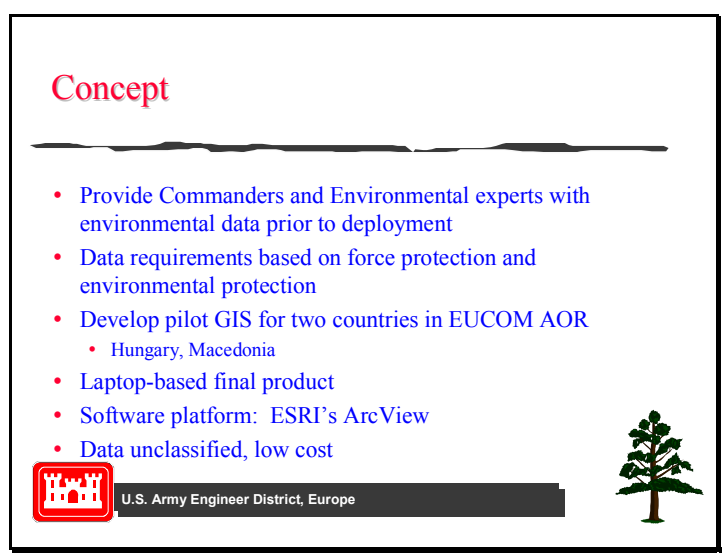

Slide 4

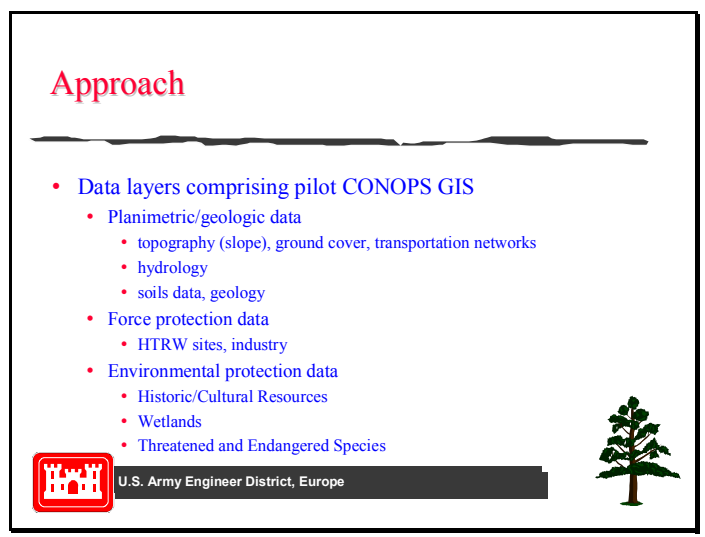

Slide 5

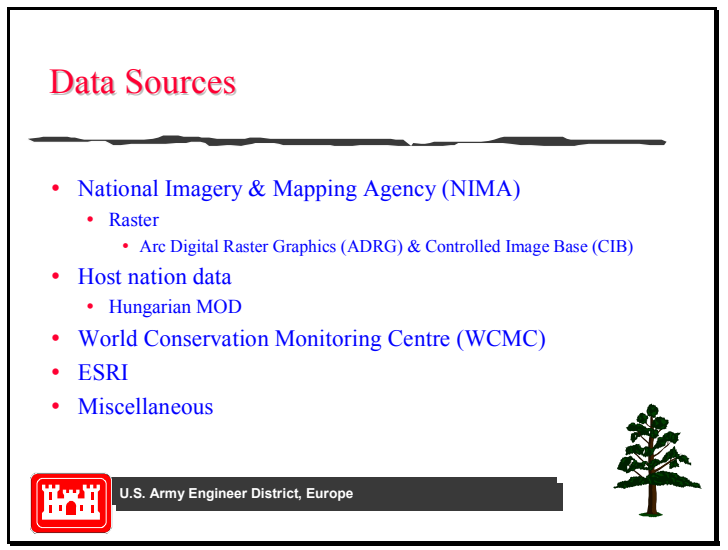

Slide 6 


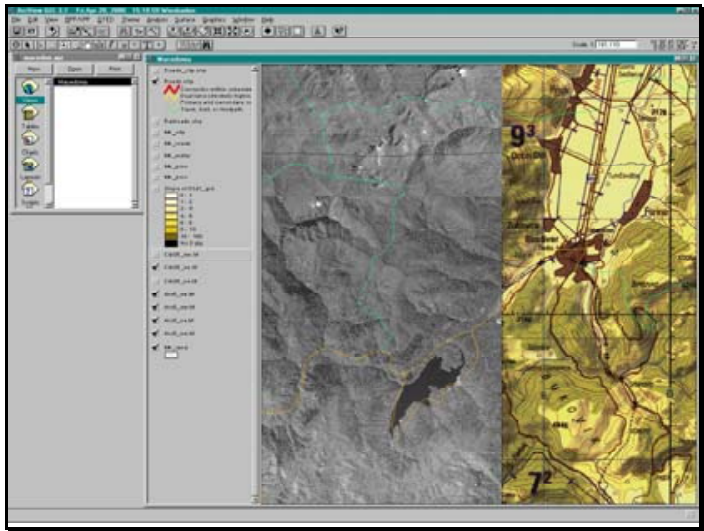

Slide 7

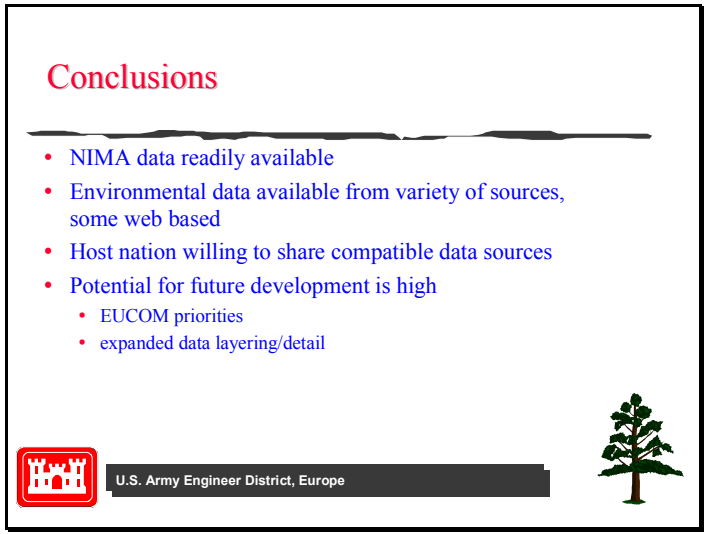

Slide 8

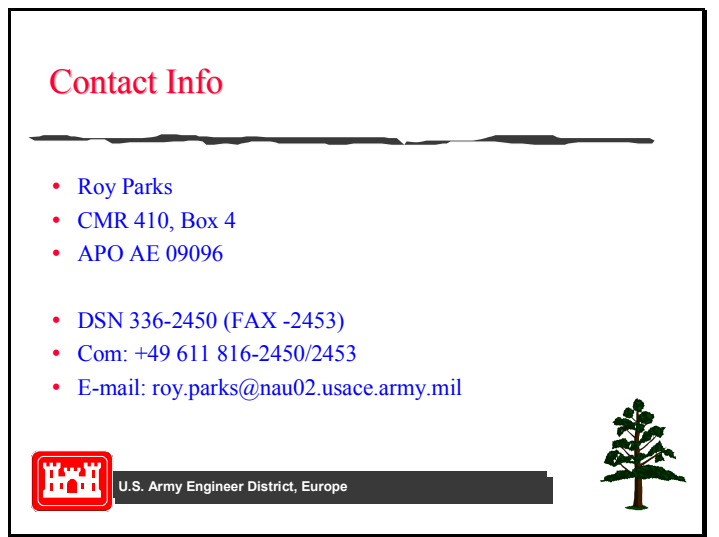

Slide 9

\section{Army Environmental Policy Institute (AEPI) - Tim Rensema}

Address: ARNG Readiness Center

ATTN: NGB-ARE

111 So. George Mason Dr.

Arlington, VA 22204-1382

Email: $\quad$ Trensema@aepi.army.mil (This is his old e-mail; his new e-mail address is not yet operational.)

Phone: (703) 607-7967

The agency's mission is to provide policy/doctrine support to DA (Department of the Army). Its overseas deployment mission is set from doctrine capability. It is responsible for international doctrine investigation. AEPI sees a need for a proponent who is responsible for program/initiative. It most closely cooperates with the Department of the Army, Secretary of the Army (DASA). 
The Army Environmental Policy Institute does strategic and policy planning. It is currently working on incorporating GIS standards on an international basis.

AEPI sees a variety of needs. The Senior Environmental Leadership Conference (SELC), on which AEPI reported, determined two needs. First, commands need environmental security databases. A unified command is also needed so that input from the GIS can be made for risk analysis. It was determined that environmental policy for these operations is fragmentary at best, yet the requirement for both text and spatial data exists. Second, the SELC also determined that redundancy in risk analysis probably exists.

A further need is that environmental personnel on the ground require background environmental information. For example, in Kosovo troops moved into base camps with hazardous materials.

Additionally, there is a need to integrate U.S. environmental standards with those of NATO and/or the UN - ours are generally more stringent - and also to get information from those organizations about environmental conditions left behind when they leave a deployment site. Environmental degradation could lead to conflict. For example, the destruction of a chemical site could come back to haunt you.

Also, particularly with respect to base camp siting, it is necessary to ensure that troops are not being put at risk from environmental factors (e.g., Gulf War Syndrome, Agent Orange).

Comment by Stewart Cannon: There is also a need for environmental decision support tools linked to worldwide environmental databases in contingency operations. These should include natural and industrial hazards. An incident in Kuwait where advanced environmental information would have been useful illustrates the problems faced by deployed troops. The troops arrived at site only to discover a nasty yellow-green film in the staging area. It was later revealed that the location was a highly toxic industrial site. There was a chlorine plant among other things. Sulfur, particulate matter, etc., would have required the troops stay in "Mock 4."

Comment by another workshop participant: Finally, information on a variety of environmentally pertinent subjects is required (e.g., biochemical, biomedical, occupational health, meteorological, etc). The problem is integrating sources. There are pockets of expertise that do not communicate. Everyone is trying to do the right thing; they are just not interacting. 


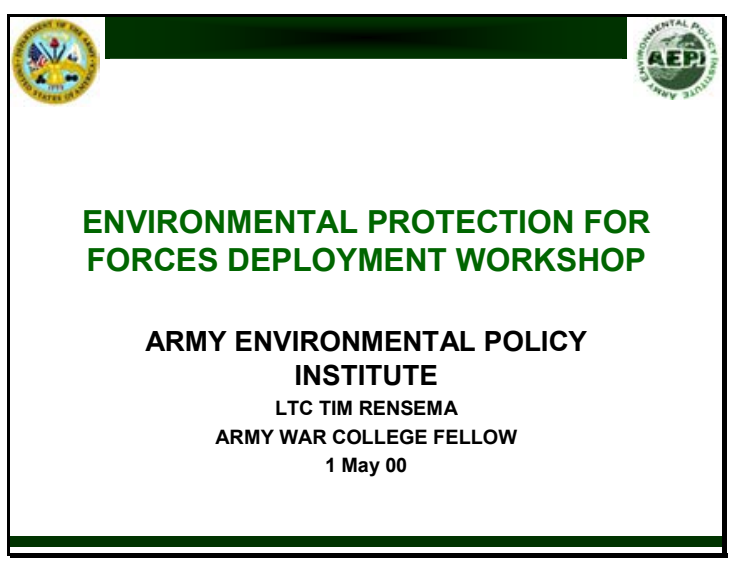

Slide 1

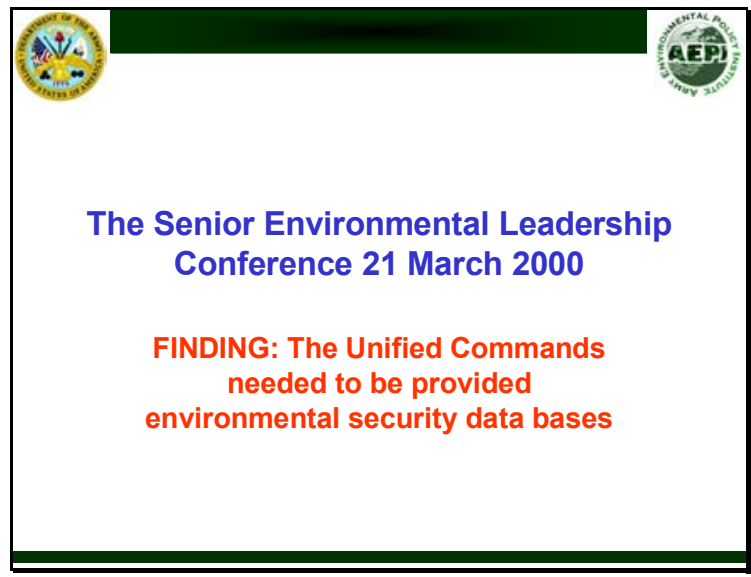

Slide 2

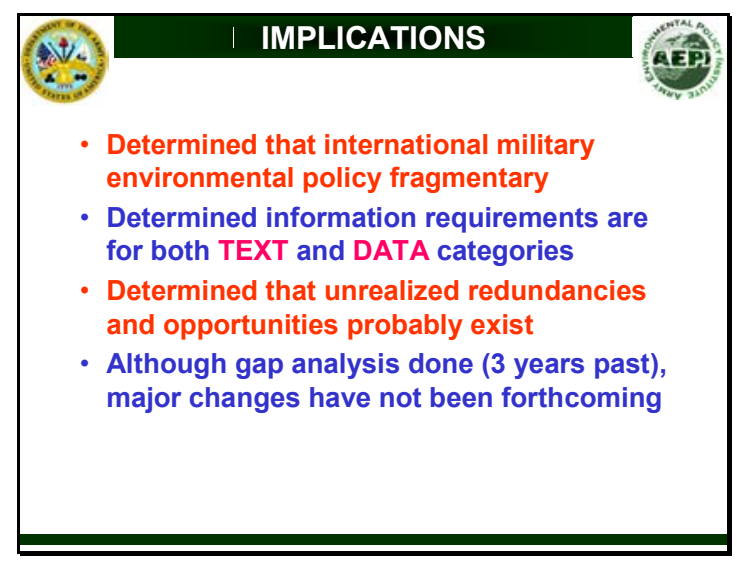

Slide 4

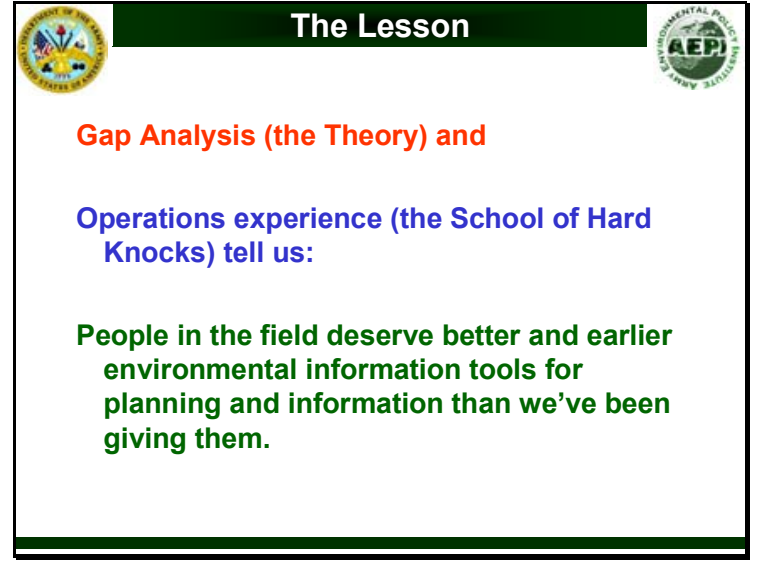

Slide 5

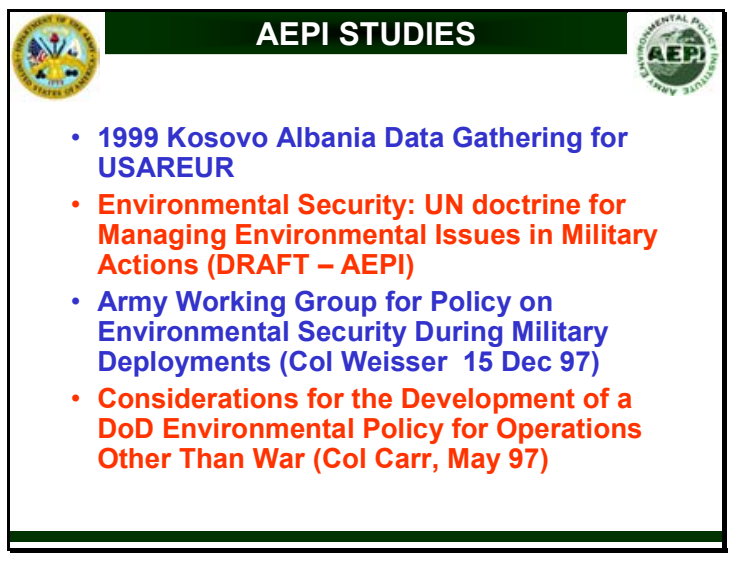

Slide 3 


\section{ERDC/CERL - Dr. Bill Severinghaus}

Email: w-severinghaus@cecer.army.mil

Phone: (217) 352-6511 x6769

ERDC/CERL has developed many different kinds of capabilities over the last 25 years for CONUS (Continental United States) purposes. It is necessary to determine where those research capabilities could be offered in support of overseas deployment questions. Among other things, fixed installations have been studied for many years, and environmental issues have been studied for 30 years. There is a suite of products for fixed facilities that would have been valuable in recent actions (e.g., Kosovo, Bosnia). A problem is determining how to get technologies to where they are needed (i.e., moving technologies into user communities to make sure they are being used). ERDC/CERL's technologies can be used in pre and postoperation planning (e.g., information about installations can be provided through remote sensing and GIS analysis). Various products developed for fixed installations could be applied to contingency operations as well. In addition to limiting troops' exposure to environmental hazards, they can also use these products to avoid creating environmental problems in deployment areas. For example, shower water running down hill or throwing food waste into a hole could be prevented. (Poor hygiene facilities in Kosovo are the kinds of problems that could be prevented.)

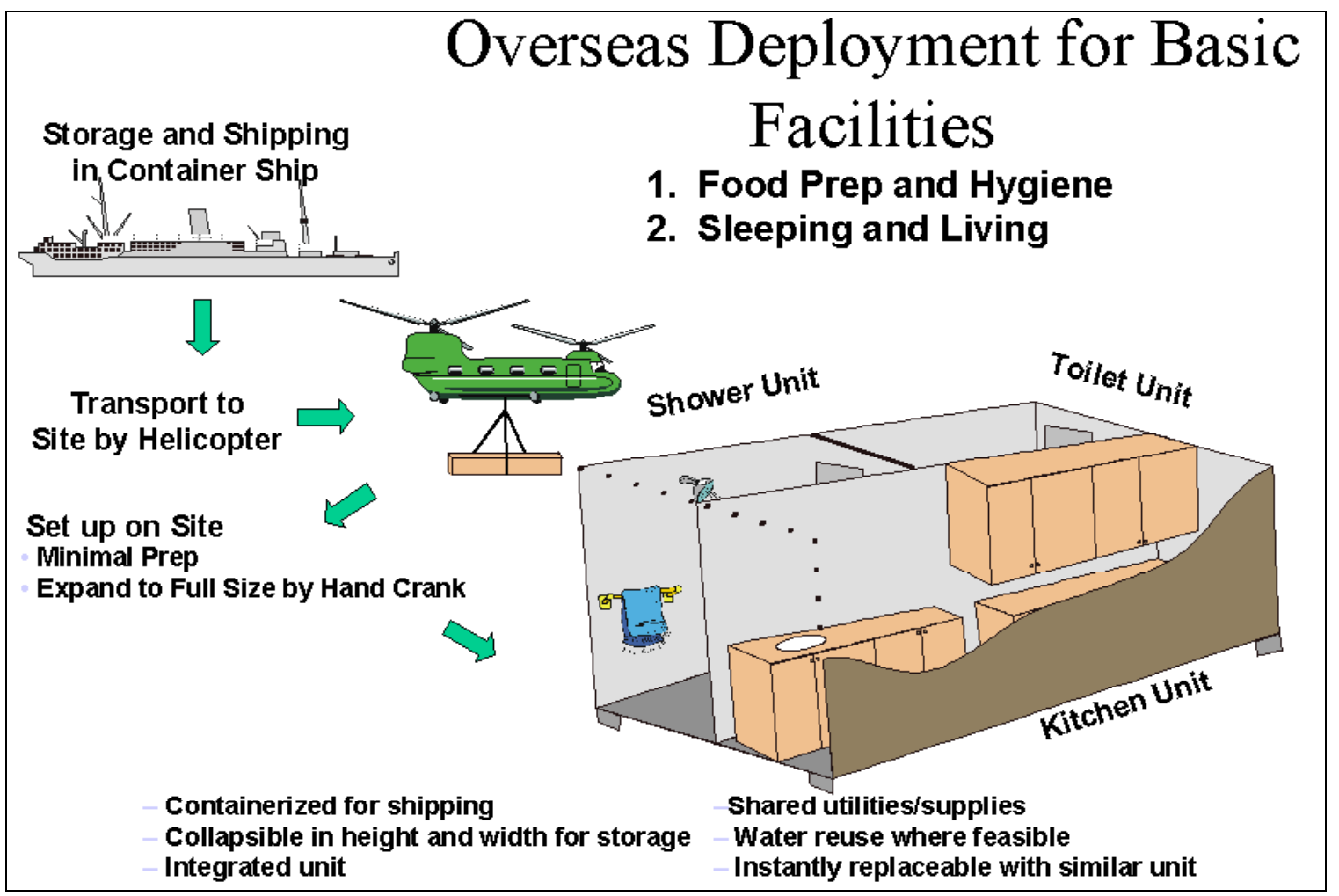

Figure 4. Overseas deployment for basic facilities. 


\section{Sample Field Product}

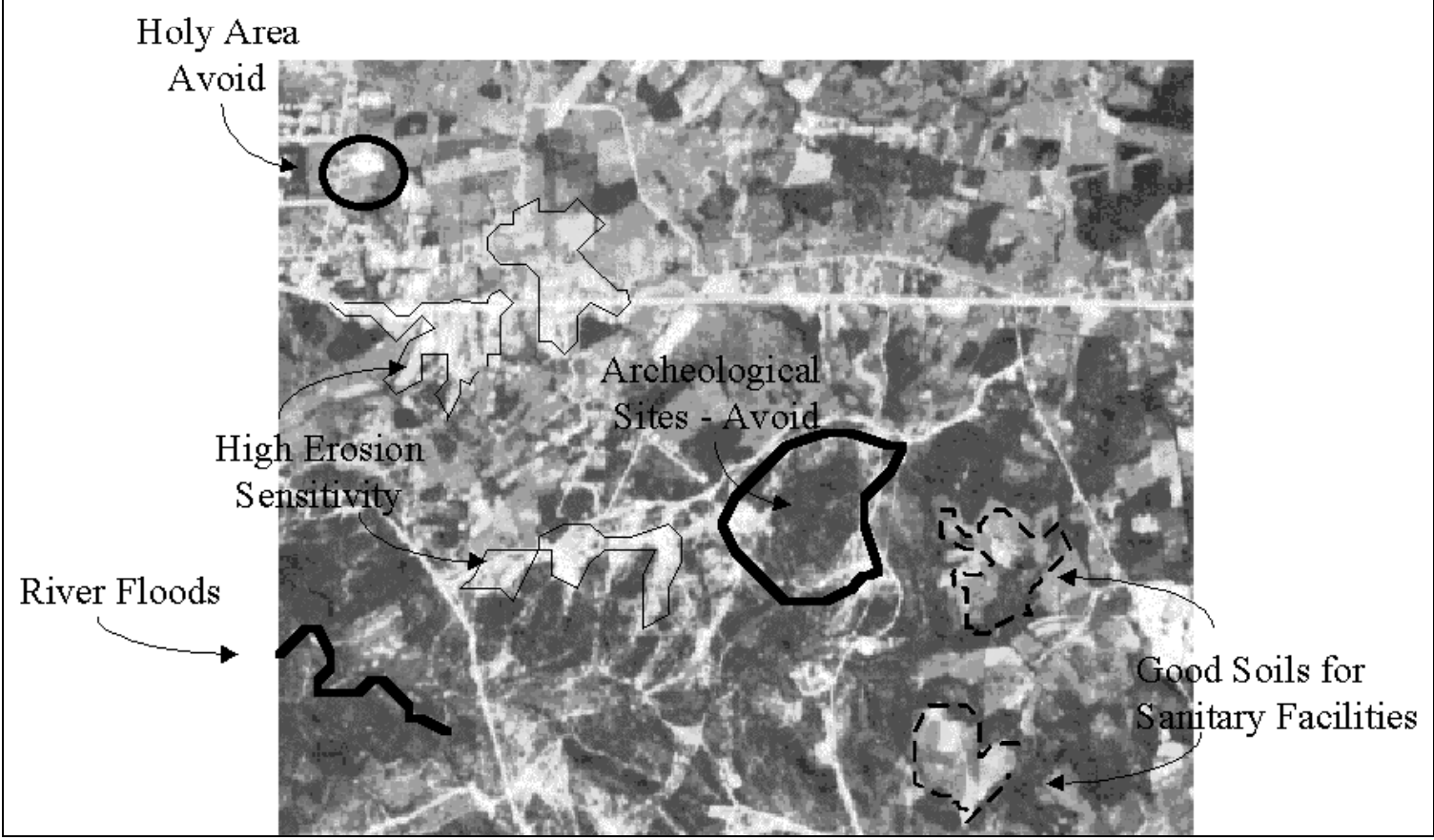

Figure 5. Sample field product. 


\section{Participant Perspectives}

\section{Participant Mission Introductions}

Workshop participants (Appendix B) introduced themselves by following a presentation outline (Appendix C: Agency Introduction Form) designed to encourage a basis for interaction during the afternoon working sessions.

Department of Army, Office of Assistant Secretary, Installations \& Environment - Chris Conrad

Address: ATTN: Chris Conrad

110 ARMY PENTAGON

Washington, DC 20310-0110

Email: $\quad$ Chris.Conrad@hqda.army.mil

Phone: (703) 614-9047

Fax: $\quad$ (703) 614-4057

In order to get Joint Doctrine implemented, it takes approximately 7 years. There needs to be a focus on installations. They need the capacity to deal with environmental operations. There also needs to be more fusion in the G2, and the G2 needs to take on this mission.

\section{U.S. Army Environmental Policy Institute - Tim Rensema}

Address: ARNG Readiness Center

ATTN: NGB-ARE

111 So. George Mason Dr.

Arlington, VA 22204-1382

Email: $\quad$ Timothy.Rensema@ngb.army.mil

Phone: (703) 607-7961

Fax: $\quad$ (703) 607-7993

(At the time of the workshop, Tim Rensema was at AEPI as a fellow on a study assignment from the War College.) 
International security and environmental security are intertwined. GIS provides the ability to evaluate situations in a more interactive manner and can provide an objective base for gap analysis.

\section{U.S. Army Center for Health Promotion and Preventive Medicine (USACHPPM) - Brad Hutchens}

Address: USACHPPM, 5158 Blackhawk Road ATTN: MCHB-TS-EES

Building E1675

Aberdeen Proving Ground, MD 21010-5403

Email: Brad.Hutchens@apg.amedd.army.mil

Phone: $\quad 410-436-8162 / 6096$

Fax: $\quad 410-436-2407$

Mr. Hutchens works for John Resta, Program Manager, Deployment Environmental Surveillance USACHPPM, who was not present.

The agency's mission is to collect and coordinate environmental sampling during deployments and to assess and communicate associated risk. Its overseas mission is to be project officer for the Kosovo operation. The agency is responsible for health threats from the environment, including both short-term and longterm exposures, and threats from BDA (Battle Damage Assessment) data, etc. The agency perceives a need for better sharing of data - USAREUR on the secure site but not on the open Internet. Potential benefits include political issues, health issues, future syndromes, and track exposures. The agency most closely cooperates with AFMIC - gateway to intelligence community; CHPPM-EUR European Sub-command responsible for European operations, EUCOM, USAREUR, and CENTCOM.

USACHPPM has been involved in several Deployment Environmental and Occupational Health Surveillance operations. In the Gulf War, Kuwaiti oil fire "super plumes" were tracked through the use of modeled data verified by remotely sensed images to determine which troops were exposed to oil well fire contaminates. Sampled and modeled air pollution data have also been used to evaluate the health risk to troops or other populations. Specifically, using ArcView they developed a "troop trail" to know where troops were located on a daily basis and modeled what the troops were exposed to (Benzene, etc.), based on their location inside or outside the plume. The Persian Gulf War was modeled after the fact, and there was only marginal success in providing pertinent environmental safety information to planners ahead of time for the Operation Joint Endeavor. For example, troops in Bosnia were deployed to industrial sites be- 
cause information was not available when needed, although they had tried to be more proactive. They have done environmental sampling at 30 to 40 base camps in the Bosnia area of operations to include areas in the Russian sector of Bosnia. (The U.S. has the technology that other countries do not.) GIS could be used to evaluate the effect on troops or other populations of potential natural disasters or terrorist actions. The inclusion of "medical surveillance" is new in deployments.

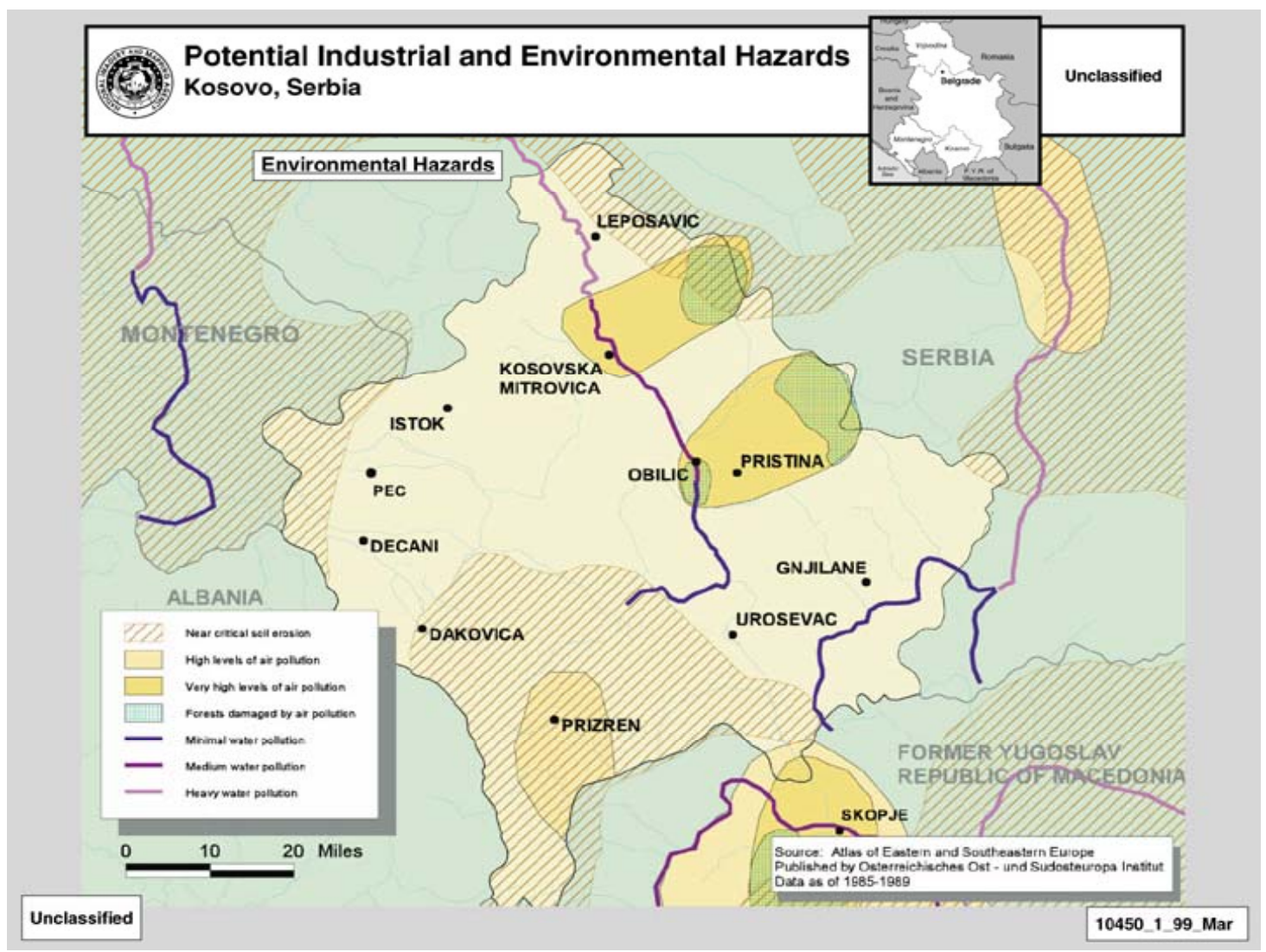

Figure 6. Potential industrial and environmental hazards, Kosovo, Serbia.

The needs and problems of using GIS include the following:

- a possible scheme for presenting environmental information to commanders in a format best suited for quick decisionmaking - matrix of risks characterized as "high," "low," etc.; (there have been some successes with air pollution in Kosovo).

- the problem of classified data - it is difficult both to acquire and to disseminate.

- the need to develop more portable sampling equipment for field operations.

- the need to identify contaminants and what standards to test for because U.S. standards are often not applicable due to the fact that there are chemicals which exist in other countries but which the EPA does not have to deal with anymore because they are outlawed in the United States. 
The financial aspect is cutting liability costs, and the personal aspect is the ability to tell troops what they are exposed to.

See Appendix D: Senior Environmental Leadership Conference Issue Papers, Appendix E: Overseas Deployment Land Management; Appendix F: Agenda; and Appendix G: Increasing Environmental Awareness During Overseas Deployment, an Outsider's Perspective. 


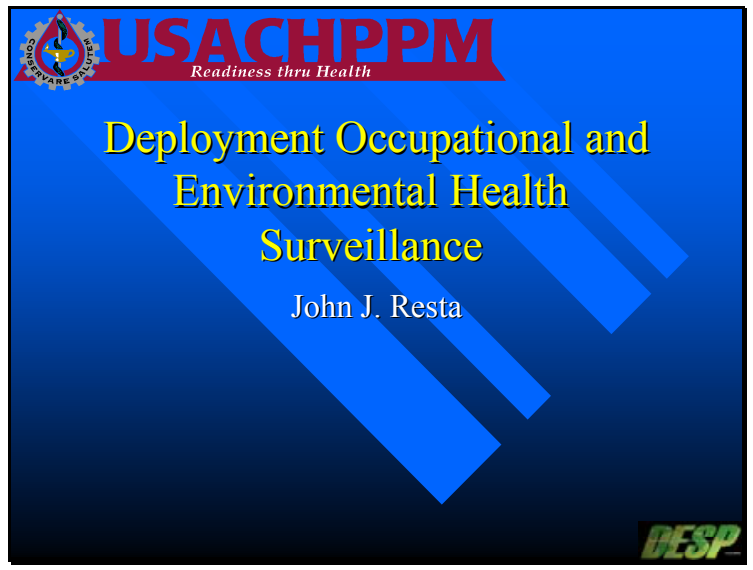

Slide 1

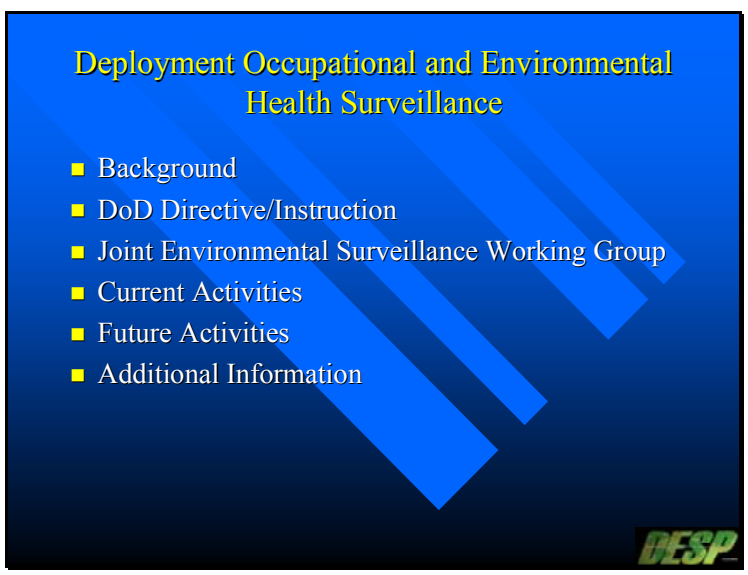

Slide 2

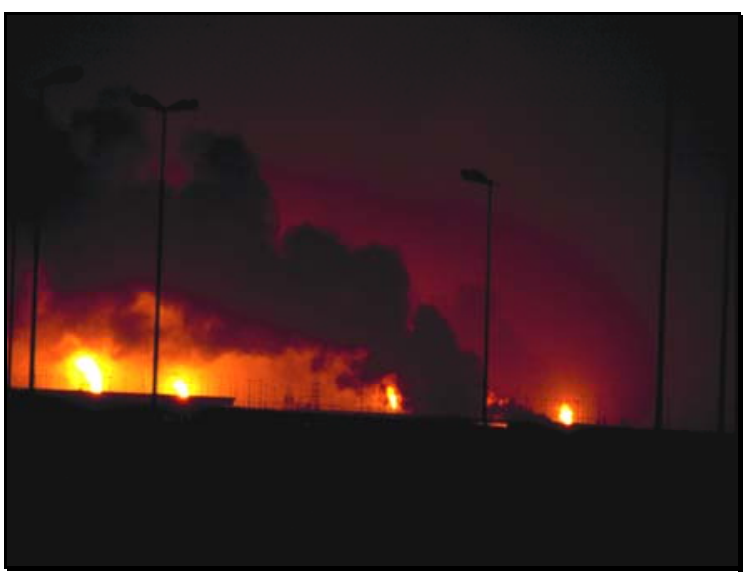

Slide 3

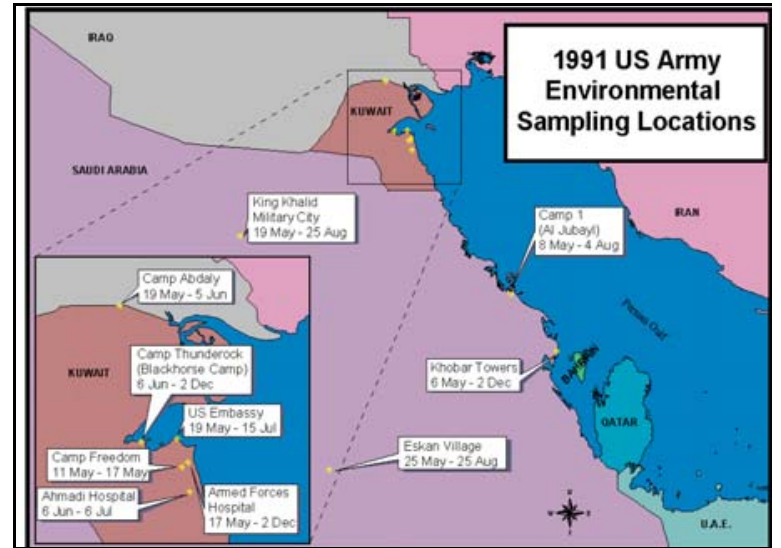

Slide 4

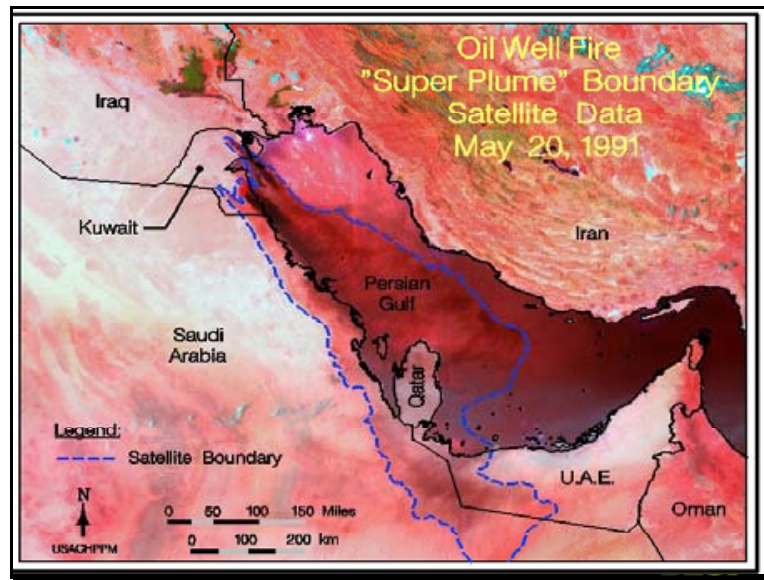

Slide 5

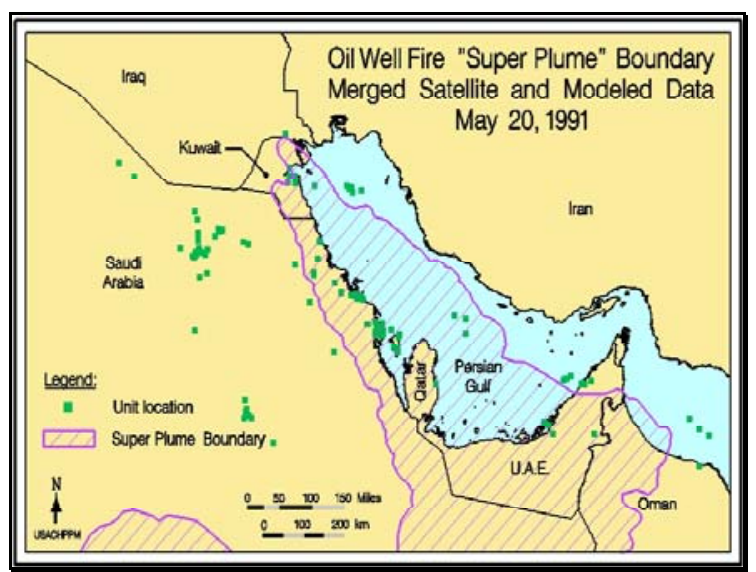

Slide 6 


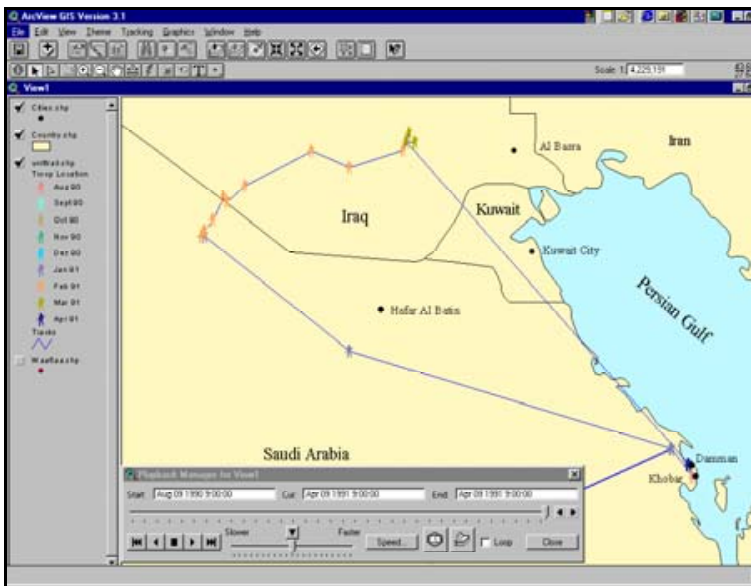

Slide 7

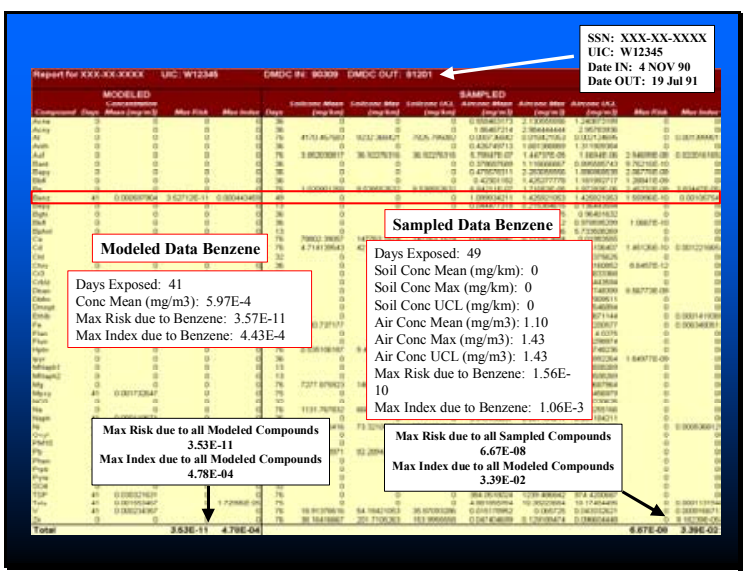

Slide 8

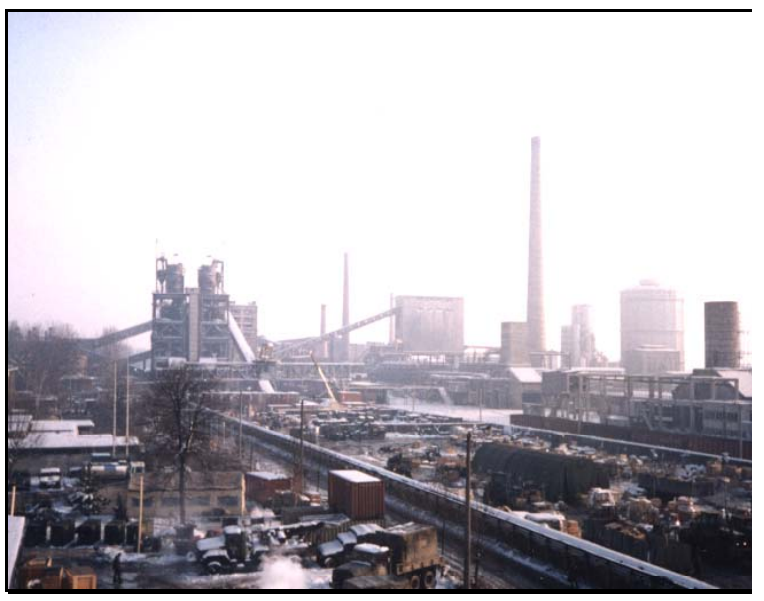

Slide 9

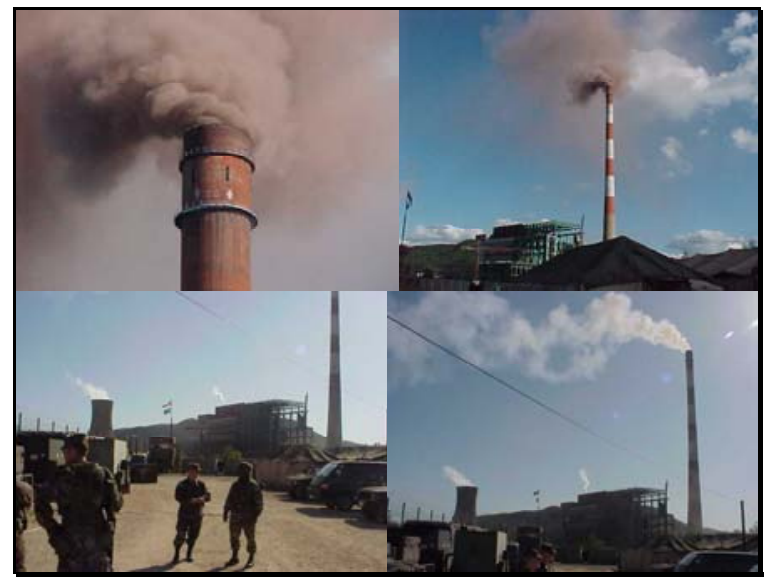

Slide 10

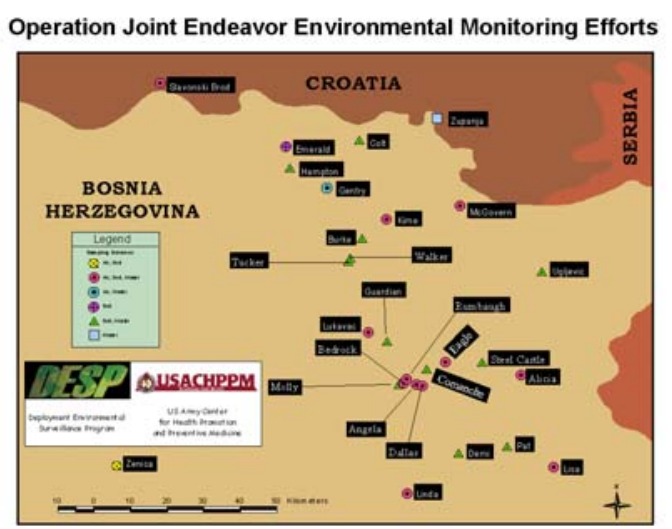

Slide 11

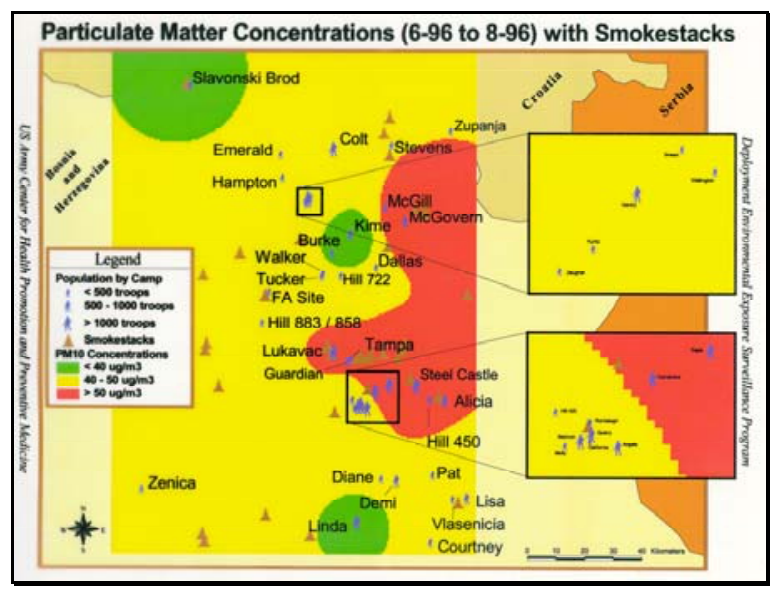

Slide 12 


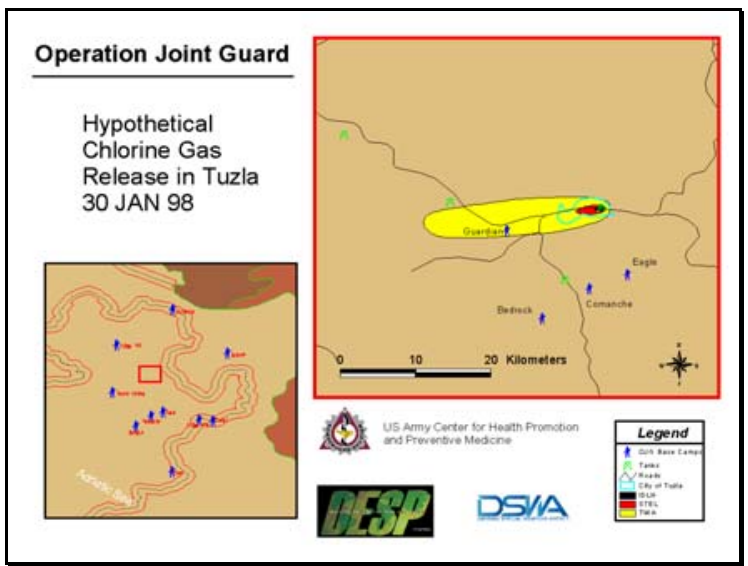

Slide 13

Deployment Occupational and Environmental Health Surveillance DOD Directive/Instruction

- DOD Directive 6490.2, Joint Medical Surveillance, 30 Aug 97.*

- DOD Instruction 6490.3 , Implementation and Application of Joint Medical Surveillance for Deployments, 7 Aug 97*

- Require the Department of Defense through the Joint Staff, Combatant Commands, and Military Services to:

- "identify and assess potential hazards, and evaluate and document actual exposures....

* Available at http://cba.ha.osd.mil/projects/other/depl-surv/depl-survmain.htm

Slide 14

Deployment Occupational and Environmental Health Surveillance Joint Environmental Surveillance Workgroup

- Formed at the direction of the Joint Preventive Medicine Policy Group to:

- review, develop, and recommend functional aspects of environmental surveillance policy.

- Executive Membership:

U.S. Army Center for Health Promotion and Preventive Medicine US Air Force Institute for Environment, Safety and Occupational Health Risk Analysis

U.S. Navy Environmental Health Center

Armed Forces Medical Intelligence Center

J-4 Medical Readiness Division
Deployment Occupational and Environmental Health Surveillance

\section{Current Activities}

- Amended DOD-I 6055.1 to include deployments

- Multi-service implementing instructions (Draft)

- Improved Environmental Health Intelligence for Operation Joint Guardian

- Improved Environmental Health Surveillance Equipment

- Deployment Health Risk Assessment Guidance
Slide 16

Deployment Occupational and Environmental Health Surveillance DOD Instruction 6055.1, DoD Safety and Occupational Health (SOH) Program August 19, 1998*

Applicability:

- Encompasses all DoD personnel and operations worldwide during peacetime and military deployments. These provisions consider limitations on the applicability of 29 U.S.C. 651 et seq., E.O. 12196 and 29 CFR 1960 (references (d), (f), and (g)) to the Department of Defense. These limitations include the exemntions or exceptions from Deforse. The Department or Labor (DoL) oversight for military personnel, military unique operations and workplaces, specific conditions governed by other statutory authorities, and, in certain overseas areas, conditions governed by international agreements.

- Includes risk management, aviation safety, ground safety, traffic safety, occupational safety, and occupational health.

*http://www.acq.osd.mil/ens

\section{Slide 17}

Deployment Occupational and Environmental Health Surveillance Draft Joint Service Instruction on Deployment Health Surveillance and Protection

- Establishes roles, responsibilities, and procedures for deployment health surveillance of Service personnel and applies Force Health Protection (FHP) concepts to the deployment setting

- Defines deployments ( $>30$ days OCONUS, no fixed MTF, under JCS direction.)

- Includes the collection, transmission, analysis, reporting, and storing of individual and population health data.

- Applies Operational Risk Management to Deployment Health Risk Assessment.
Slide 18 


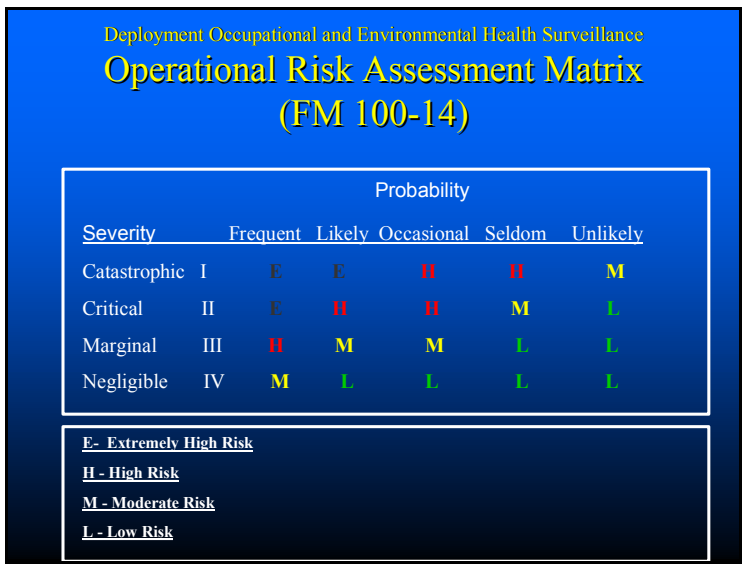

Slide 19

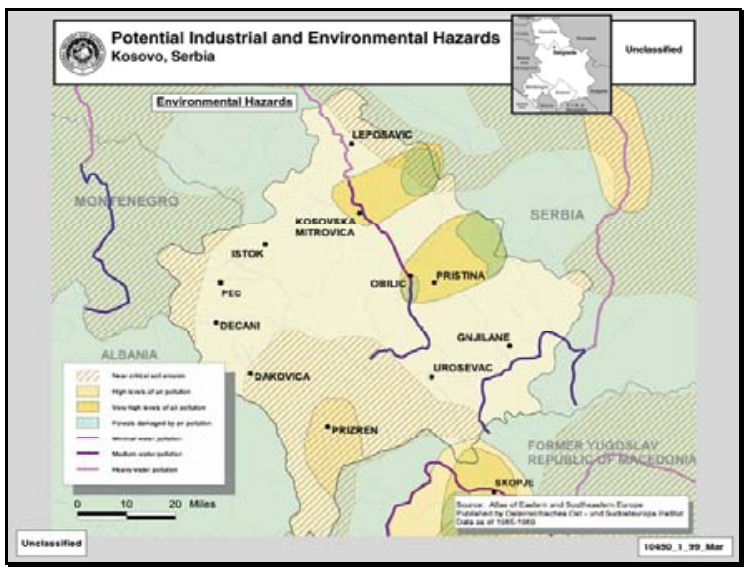

Slide 20

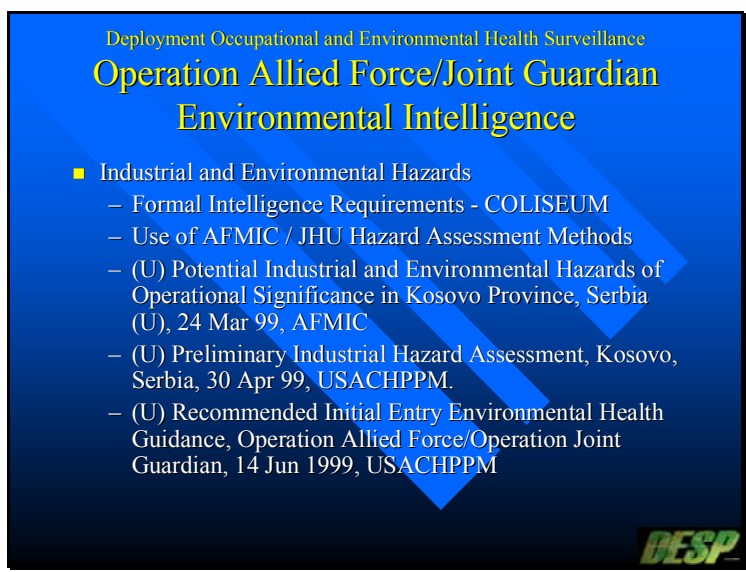

Slide 21

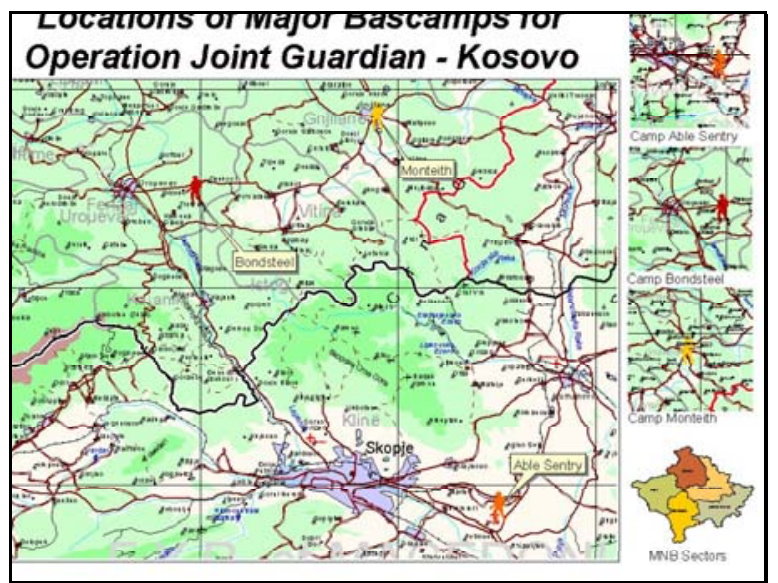

Slide 22

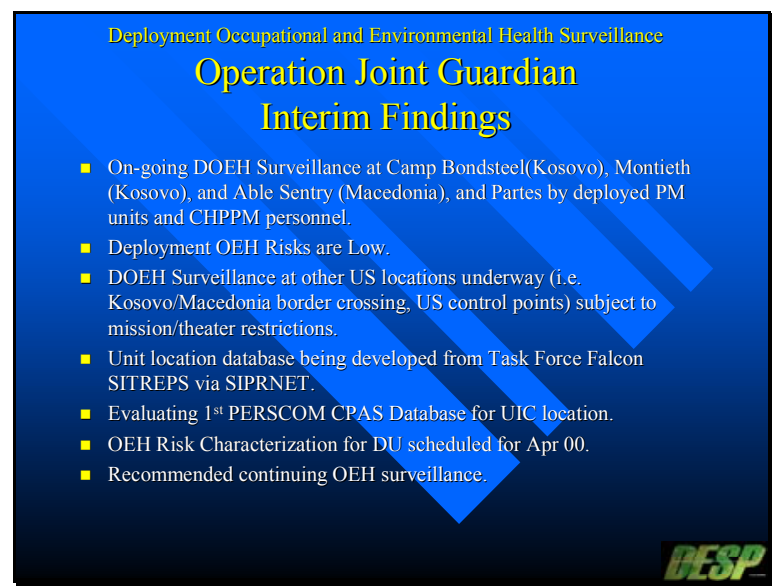

Slide 23

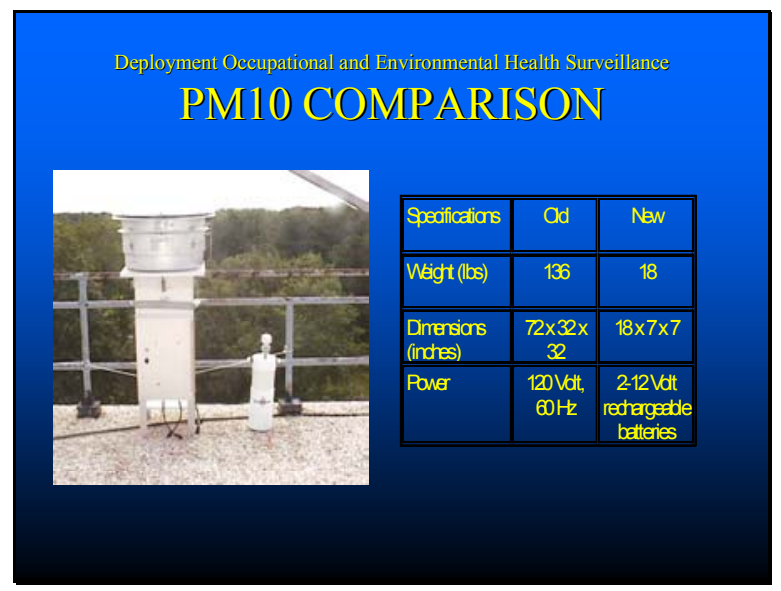

Slide 24 


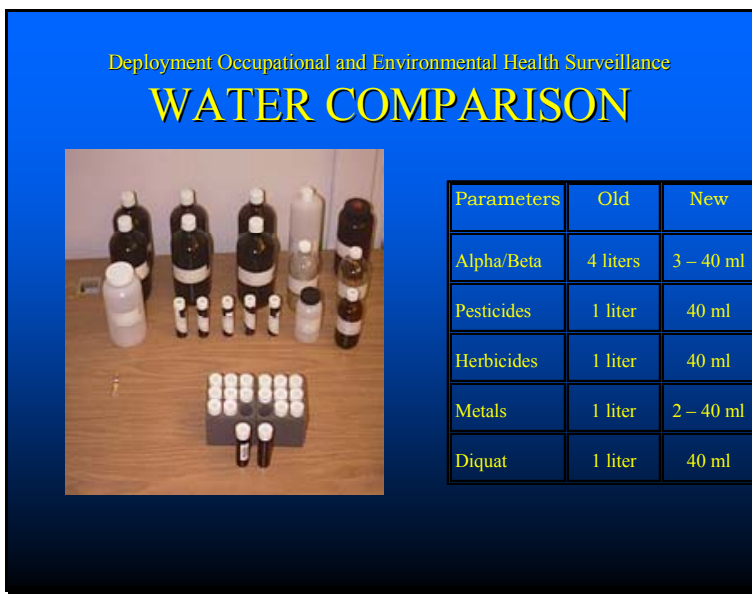

\section{Slide 25}

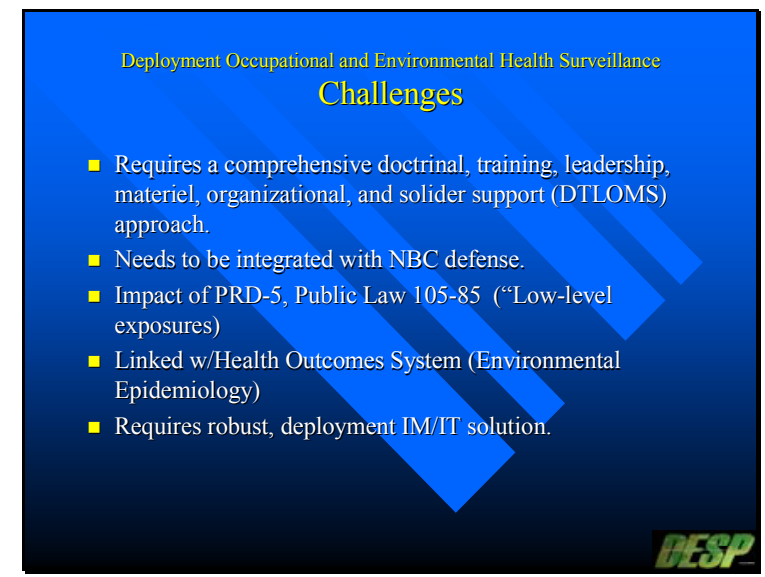

Slide 26

Deployment Occupational and Environmental Health Surveillance IM/IT Strategy

- Fundamental Strategy: Incorporate Deployment EOHS requirements into existing MHS Systems (DOHRS/TMIP)

- Accomplishments/Tasks:

- Deployment EOHS Functional requirements (Provided to DOHRS/TMIP 4QFY98).

- Use DOHRS Data Warehouse (3QFY00)

- MOU between TMIP/DOHRS for ITDB archiving

- Include Deployment EOHS in Block 2/3 TMIP

- Build data bridge between Block 1 TMIP (REOHM) and DOHRS Data Warehouse
Deployment Environmental Health Surveillance

Additional Information

- John J. Resta, CHPPM, DSN 584-5244/Comm 410.436.5244, John.Resta@apg.amedd.army.mil

- MAJ Bill Gooden, USAF-IERA, DSN 240-4687/Comm 210-536-4687, bill.gooden@esoh.brooks.af.mil

- CAPT Larry Betts, NEHC, DSN 864-5567/Comm 757.363.5567, betts1@nehc.med.navy.mil

- LTC Robert Thompson/LTC Larry Kimm, J-4, Medical Readiness Division, 703.693.5105,

larry.kimm@js.pentagon.mil

- MAJ Shanda Zugner, AFMIC, 301.619.3887 


\title{
HQ, Forces Command (FORSCOM) - Stu Cannon
}

\author{
Address: LTC (Ret), EN, USAR, HQ FORSCOM \\ ATTN: AFEN-ENE (Mr. Cannon) \\ 1777 Hardee Ave. SW \\ Fort McPherson, GA 30330-1062 \\ Email: $\quad$ Cannons@forscom.army.mil \\ Phone: 404-464-5762 \\ Fax: $\quad 404-464-7827$
}

The mission of HQ FORSCOM is to train, mobilize, and deploy forces to theater/JTF (Joint Task Force) CINCs (Commanders-in-Chief). It is responsible for Mission Planning Decision-Support tools, as a requirement identified by SELC 2000 Panel \#4. The agency perceives a need for links to existing data bases and fast imagery support.

HQ FORSCOM needs to know about environmental impacts beforehand because the mission planners need information. An example of this need is an instance in which contaminants ate through the boots of the troops. There was no appropriate protective gear in inventory, and it became necessary to go to Sweden to get protective suits. It is necessary to identify information sources and to reduce the cost of data gathering. This would mean using classified and unclassified data both.

\section{FORSCOM - Ted Reid}

Address: Deputy Chief of Staff for Operations, Commander FORSCOM ATTN: AFOPTE 1777 Hardee Ave. SW Fort McPherson, GA 30330-1062

Email: Reidt@forscom.army.mil

Phone: 404-464-7814

Fax: $\quad 404-464-6567$

The agency's mission is to train, mobilize, and deploy all Army forces in the United States. Army and Joint doctrine are woefully lacking; tools that are easily usable by commanders are needed, as are integration of data layers among users and identification of available data bases. The potential benefits are that Division and Corps G2 and G3 have GIS capability. FORSCOM most closely cooperates with TRADOC and ACSIM (Assistant Chief of Staff for Installation Management). 
From the point of view of a battlefield commander, there is not a lot of intelligence in the battlefield, at the user level, because of high security classification. Possibly, determining what is available should not be FORSCOM's role, but a Department of the Army [DA] role.

The CINCs are short on environmental doctrine, and DA Doctrine and Joint Doctrine are not adequate for what commanders need. Even what is under development in the Army is not adequate. There are no tools that are easily usable in the field by the commander and by people setting up advance camps (for operations ranging from things other than war to full scale combat). G3s, Corps, Divisions, and G2s do have GIS (ArcView, ArcInfo), so they do have the capability to use the data, but the data is not available for use in planning. Environmental divisions do not have GIS or CAD. They lack the capability within the office that is supposed to be handling environmental policy. They lack the doctrine to do what is asked for. There are a lot of capabilities out there, but the people at the unit level are not trained to use those capabilities. It might be a good idea to consider a joint team that is available to commanders for contingency operations. The team could deploy with the commanders. A vital question that needs to be answered is this: "Who is in charge of putting this all together and coming up with a system?"

\section{National Reconnaissance Office/National Support Staff (NRO/NSS) - Jerry Picantine}

Address: NRO

ATTN: Jerry Picantine (Room 15F20H)

14675 Lee Road

Chantilly, VA 20151-1715

Email: Picantj@nro.mil

Phone: 703-808-5395

Fax: $\quad$ 703-808-1184

The agency's mission is to acquire/operate reconnaissance satellites and address mission partners' need for satellite data. The NRO perceives a need for Essential Elements of Environmental Information for CINC:

- for country engagement

- planning for force deployment

- for support during operations.

The potential benefits include support for disaster/humanitarian activities and avoiding injury/death to deployed forces. The NRO most closely cooperates with the Director of Central Intelligence Environmental Center [DEC], USGS [U.S. 
Geological Survey], NOAA [National Oceanic and Atmospheric Administration], and TEC [Topographic Engineering Center].

Mr. Picantine is a CEDA contractor supporting the NRO National support staff, with Keith Elliot. He has provided 25 years of support relating to meteorology, space, weather, and global disasters. His purpose in attending the workshop was to determine what can be done to help the intelligence community.

\section{NRO/NSS, Civil Environmental Staff - Keith Elliott}

Address: $\quad$ No current information

Mr. Elliot works at the National Reconnaissance Office, where his title is Civil/ Environmental Account Manager.

The agency's mission includes the following:

- facilitating environmental support to DoD, civil, and intelligence

- promoting use of classified National Systems Data to address environmental issues, including disasters

- Environmental Assessment and Monitoring

- Humanitarian Assistance

- Environmental Intelligence.

The agency perceives an extensive list of needs. There is a need for documented requirements for strategic, tactical, and operational environmental information and data. An inventory/compendium of sources of environmental data and information would also be useful. It is necessary to support the environmental intelligence network for tactical and operational support to CINCs. There is also a need for GDIN and NDIN (leverage off these networks) - technology, data, and information transfer. Joint Intelligence Centers (JICs) and Joint Analysis Centers (JACs) - leverage tools, techniques from centers of excellence (such as $\mathrm{Pa}$ cific Disaster Center and the USGS Hazard Support System) with robust GIS, remote sensing, modeling and simulations, information processing technology, data distribution/networking are also needed. There should be leverage of lessons learned and technologies developed at the Pacific Disaster Center - currently under responsibility of USACE-Pacific Division - for Development and O\&M, as well as leverage of capabilities from around the DoD, Intelligence, and Civic Communities. NRO most closely cooperates with NOAA, USGS, DOE, EPA, Civil Applications Committee (CAC), DCI Environmental Center, ERDC/TEC (Topographic Engineering Center), DASD (ES), NIMA/IATE (Disaster Response and Environmental issues teams), CIA/Office of Transnational issues. Potential benefits include reduction of loss of lives and property. 
The NRO provides national systems support for environmental applications to the $\mathrm{DoD}$, the intelligence community, and the civil community. Its overseas deployment mission is facilitating the use of national systems data in support of environmental issues related to deployed forces for military operations and military operations other than war. Environmental questions for which the agency is responsible include promoting the use of classified national systems data to address environmental issues, including disasters, environmental assessment and monitoring, humanitarian assistance, and environmental intelligence. (Environmental intelligence is synonymous with environmental information and data, classified or unclassified.) The Pacific Disaster Center was to be modeled as a node, the first node, of a global disaster information network. GDIN includes a national disaster information network and a global disaster information network.

The first need is environmental information, data, and intelligence, which falls into three areas: [1] strategic, which is normally addressed by DCI Environmental Center, [2] tactical, and [3] operational, which includes issues that the CINCs have to be concerned about when it comes to force deployment for war, and for operations other than war.

There are a number of support activities related to environmental data/information/intelligence in support of the military, but they are not linked together. They do not have an environmental intelligence network, and there is an insufficient number of analysts trained in environmental related disciplines in joint intelligence centers that are deployed with the CINCs or at the JACs (joint analysis centers). There is a need for people specifically trained in environmental intelligence and information data gathering.

There is also a need for an inventory of sources of environmental information and data. It should be a sort of web-based tool where one can go to answer any type of environmental question. It would be possible to find out where the source of that information is, whether it points the user to the DEC, the armed forces medical information center, or CHPPM, etc. There needs to be an environmental intelligence network that links users to all the sources so that personnel can push and pull information across the network.

Regarding GDIN and NDIN, there is an opportunity to leverage off the technology, data, modeling and simulation, and R\&D, and bring it to the DoD community for use in places like JICs and JACs or CHPPM or elsewhere. Examples are the Pacific Disaster Center and Hazardous support system, and other nodes that have been in development as the GDIN architecture begins to evolve (primarily a civil activity, not military). 
One of the early concepts of GDIN was the need to establish "Centers of Excellence." The idea behind GDIN is that there are a lot of nodes that are existing sources of information that can be linked together. But linking them up does no good unless it is possible to push and pull that information in the Centers of Excellence and perform vertical integration and fusion of the data, and produce products that meet actual defined user needs.

One of the things missing is a documented set of environmental information data/intelligence needs. PACOM did this at the Pacific Disaster Center. There was a contractor working with the J2 and the J3 shops to develop a set of requirements for how the PDC could support them. The first set they could not support well because of the way the PDC mission was defined. However, the mission was redefined, and they are currently in the process of reassessing.

The Pacific Disaster Center will be brought up often because it is a fine example of the way things might be done. On the web it is www.PDC.org. The Army Corps of Engineers, Pacific Division is currently managing the continued development of PDC along with oversight from ASD C ${ }^{3} \mathrm{I}$.

At CINCPAC (Commander-in-Chief, Pacific), The Center of Excellence and Disaster Management, Humanitarian Assistance is a model for linking the NGOs, the United Nations, CEC, and the medical community. This may be a representation of a way in which things could be done (link to the sources of environmental data and information) for other theatre commands.

What is needed are the local networks (that exist because of the uniqueness of the local hazards [natural or manmade]) to link to a higher network of things that are common to all the CINCs.

The agencies that the NRO works most closely with include NOAA, USGS, DOE, and EPA on the civil side, because they are the premier earth science agencies. They have a level of environmental expertise not found in the DoD community or the intelligence (INTEL) community. INTEL does not have analysts trained in the earth sciences or analytical methods. They do not have analysts in the JICs and JACs who even know what to ask for as far as environmental intelligence requirements. There is an education problem. By showing them what is available, they can begin to think about what they might need. But it is necessary to start training analysts in the military and in INTEL on environmental intelligence issues. They also work with the Civil Applications Committee, which is the gateway through which the civil community gains access to classified national systems data. Until the DoD and INTEL communities develop analytical capability on their own, they will have to reach into the civil world for data col- 
lection, some analysis, and some product generation. They also work with DCI Environmental Center, NIMA, and the CIA. They have talked with the Deputy Assistant Secretary of Defense for Environmental Security when he worked on PDC and GDIN, and they have continued those through the conference at CENTCOM recently.

The potential benefits are a reduction in loss of lives and property. If a soldier dies from an environmental hazard, it is no different than if he or she had died from a bullet. The environment should be viewed as the same kind of risk as adversary forces.

* There is a need to view environmental information as intelligence, whether it is classified or unclassified. For example, the early images of the flow of the Venezuelan mudslide and the extent of the damage were taken by a commercial satellite system. The resolution was sufficient to do the analysis of where the mud went, and also to decide if deforestation exacerbated the problem. It was decided that deforestation did not exacerbate the problem, and the mudslides were natural. This is an example of the need for information to be unclassified so that it can be shared widely.

How does NRO use classified remote sensing data to address problems? The answer is the Imagery-Derived Products (IDP) Toolkit. It was developed by the CIA, and dissemination is controlled by NIMA legal and NIMA policy. The policy concerning how it will be distributed has not been fully formulated. The most recent information available indicates that a nonliteral version of the toolkit could be distributed to the commands. The difference between the literal and nonliteral versions is that a literal imagery-derived product is one that produces a picture, but not at a level at which the resolution might be classified. A nonliteral product is a GIS based data layer line drawing that is derived from inspection of the literal imagery. In both cases, they can be pushed down to the unclassified For Government Use Only (FGUO) level. Then they would not have a problem using it. There will be limitations in sharing outside of U.S. Government channels due to long-standing national policies, but a significant tool is brought into use. The issue is to get with NIMA to discover what is required for dissemination of the nonliteral tool set. This will probably depend on when the policy on that is finalized. It is a very significant tool set.

\footnotetext{
* The remainder is the result of an exchange between Keith Elliot and other participants.
} 
There are a lot of tools being developed all over the community. PDC did a lot of modeling and simulation work, GIS work, vertical integration, and fusion of data. At HSS they have a fusion engine that fuses weather data in a manner that is not available anywhere in the military or in the INTEL community. They built it for civilian purposes, for a mission that has to do with detecting fires and volcanic activity. What is important is talking to each other, and technology and information transfer, so that they can leverage each other's activities.

ERDC/CERL is trying to get some of the National Technical Means (NTM) products for military land manager capabilities (for installation and support). Policy says they should be able to get these things, but it is very slow and difficult. Is the environment a tactical issue? A death from hazardous waste is just as final as a death in action.

The problem of getting adequate priority for taskings associated with environmental applications of NTM has previously been alluded to. The requirements management system does not give that higher priority for this kind of tasking (national systems data). The bad news is that it will probably continue for some time. The good news is that the intelligence community recognizes this, and the Assistant Director of Central Intelligence for collection, Mr. Charlie Allen, is working to revamp the requirements management system for all intelligence community assets. The other good news is that (even though it was difficult) in

DCI's strategic intent from last year, environment is third on the list (the impact environment has on national security and the security of deployed forces). As the national policy people begin to realize the increased importance of this, things will change. On a day-to-day basis, the CINCs deal the most with humanitarian assistance problems. Even military problems create humanitarian assistance problems.

\section{ERDC/CRREL (Engineering Research and Development Center/Cold Regions Research and Engineering Laboratory) - Larry Gatto}

Address: ERDC/CRREL

72 Lyme Road

Hanover, NH 03755-1290

E-mail: lgatto@crrel.usace.army.mil

Phone: (603) 646-4273

Fax (603) 646-4785

Mr. Gatto is a research geologist from the U.S. Army Engineer Research and Development Center/Cold Regions Research and Engineering Laboratory. 
The agency's mission is cold region science and engineering research. Members volunteer for overseas deployment assignments; among other things, they provided snowmelt-forecasting technology for Bosnia BCCA (Base Camp Coordination Agency) in Kosovo.

The agency is responsible for the following environmental issues:

1. Frozen ground and freeze-thaw impacts on mobility

2. Snow melt runoff, snow loads

3. Infrastructure requirements (buildings, roads, etc.)

4. Cold-temperature effects on operations, structures, material

5. Training land resources and rehabilitation

6. RS/GIS research and application

7. Bio-remediation

8. Emergency/disaster operations.

It perceives a need for moving research results to the field and promoting user/researcher collaboration to improve the utility of research. It most closely cooperates with the following agencies: ERDC/CERL, ERDC/EL (Environment Laboratory), and ERDC/CHL (Coastal and Hydraulics Laboratory) (as research colleagues), Corps of Engineers Districts and Divisions, NASA, FHWA, FAA, FHA, and NSF.

ERDC/CRREL specializes in cold region science and engineering. It does not have a direct overseas deployment mission, but it has people from the labs volunteer to serve with those forces. The lab had people doing work on the snowmelt modeling on the Tusla River in Bosnia and people with the base camp coordination agency in Kosovo. The environmental questions researched range from the frozen ground effects on mobility to remote sensing and GIS research and applications in emergency and disaster relief operations. From the Corps of Engineers community, they are being asked to look more in depth and develop real connections between users and the research community. There is a real need to tighten the connections (from the researcher's point of view). ERDC/CRREL also worked on (support for) the Kuwait oil fires - from a remote sensing center.

\section{NRO/NSS-CE - Jerry Johnson}

\section{Address: NRO}

ATTN: Jerry Johnson

(Rm 15F2OH) 14675 Lee Road

Chantilly, VA 20151-1715 


$\begin{array}{ll}\text { E-mail: } & \text { Johnjerr@nro.mil } \\ \text { Phone: } & 703-808-5689 \\ \text { Fax: } & 703-808-1184\end{array}$

Jerry Johnson supports Keith Elliot at the National Reconnaissance Office as senior advisor in the Civil/Environmental program. He has been at NRO for 4 years. Previous to that he worked on the HQ Army DCSINT (DAMI) staff as a meteorologist/remote sensing advisor. Previous to that he worked on the Space Applications Technologies Program (SATP) for Space and Missile Defense Command (SMDC). He served in the U.S. Air Force, supporting joint Air Force and Army forces as an operational/tactical meteorologist and staff weather officer for 30 years.

The mission of the NRO/NSS-CE is Space Based Reconnaissance. Its overseas deployment mission is to provide reconnaissance data that supports force deployment, employment, and redeployment. The agency is responsible for spacebased reconnaissance. It perceives a need for better fusion of geophysical, meteorological, oceanographic, and biological data to support improved battle space characterization. The benefits include better understanding of environmental effects throughout the battle space, improved courses of action and informed decision making for friendly forces. It most closely cooperates with NIMA, CIA, DIA, NSA, CMO, OSD/Env Sec, ASD/C3I \& ASD/Environmental Security, Hq US Army/DCSINT (DAMI), AF/XOI/XOW, AFWA, CNMOC, Civil Applications Committee (CAC), TEC, DOI, DOE, DOC/NOAA, Department of Agriculture, Office of Science and Technology Policy (OSTP), DOT, Federal and military labs, FEMA, EPA, NSF, USCG, USGS, and NGB.

The remote sensing aspects of this are the most critical for support to tactical/operational forces. The United States has the greatest scientific gathering anywhere in the world. We are unrivaled. But when the United States deploys forces in harm's way, they do not have this unrivaled capability. Many times the war or mission is outside the seven industrialized nations, and the networks, meteorology, scientists, weather radars are not there. There is much that can bring troops into harm's way.

In terms of capabilities needed to safe up the troops, success has not yet been achieved. The United States is well developed, but on the plains of Africa, for example, the capability is not available. We need to look at bringing together the centers of excellence and operational capabilities, and develop better means to disseminate the information over multi-level security communications systems that connect the civil, national and military communities. We also need to look at how to fuse different geophysical data sets, including space based imagery and 
make a layered picture out of it that means something to a joint force commander. This is the challenge. It is everything combined (geophysics, medical, weather, climate, biology). The commander needs informed choices of what he can do.

An example of a situation in which something was needed is an incident that occurred at Fort Pickett, Virginia. During a joint force logistics exercise in the early 1980's the $24^{\text {th }}$ Infantry Division was field-testing a new briefing concept using an experimental, tactical closed-circuit television briefing system. Without benefit of a tactical weather radar, a lightning detection system, or any weather satellite receiving equipment that might have helped provide effective warning, a huge thunderstorm developed, creating a cloud-to-ground lightning discharge that fried the system. Needless to say, this accelerated ENDEX but made Mr. Johnson, the Division staff Weather officer, a target of opportunity for then Major General John Galvin, division commander.

This was in the United States, in a country with unquestionably the best weather and geophysical services (civil and military) in the world. Similar to that situation in rural Virginia nearly two decades ago, today in most countries outside the United States, the protection from natural and manmade disasters (even meteorological) that exists indigenously is not what is now taken for granted at home. It is necessary to look at how best to support deployed forces, not just how to support Fort Bragg. The capability, science, and technology may exist to adequately warn forces in CONUS, but not to warn those in a location somewhere in East Africa. U.S. Forces operating in the third world are at great risk from earthquakes, floods, volcanic activity, fires, severe weather, disease, and biological influences often exacerbated by local conditions and related hazards. The theater CINCs and Joint Task Force commanders need to understand this and make it one of their highest concerns. JCS needs to provide the doctrinal understanding that will promote a fix. Joint Intelligence Preparation of the Battlespace (JIPB) doctrine will help, when implemented. Data integration by multi-disciplined experts (new military specialties may be needed) is a key part of the answer. NRO believes that better integration of space-based reconnaissance with in-situ data, along with more effective all-source communications links and associative ties to the U.S. civil-scientific community will go far in providing effective solutions. Past, present, and future analyses of the total geophysical environment as a threat improves decision making and value-adds to combat effectiveness just as certainly as does the effective analysis of the enemy order of battle. 


\title{
U.S. Army Engineer School (USAES) Environmental Division TRADOC Training Proponent for Environment - Steve Flier, Environmental Specialist
}

\author{
Address: U.S. Army Engineer School \\ Dept. of Instruction \\ 320 Engineer Loop-Suite 370 \\ Ft. Leonard Wood, MO 65473-8926 \\ E-mail: FLIERS@WOOD.ARMY.MIL \\ Phone: $\quad 573-563-4122$ \\ Fax: $\quad 573-563-4127$
}

Mr. Flier is from the Engineer School at Fort Leonard Wood, the installation where MANSCEN is located. He is an environmental specialist.

The agency's mission is to train engineers. The environmental proponent of its mission is to develop doctrine and training products and to integrate and ensure integration of all Army Doctrine, training, and Leader. It was also TRADOC's training proponent for the environment, as well as their Environmental Proponent for development and integration of environmental considerations for doctrine, training, and leader development. The Engineer School's overseas deployment mission includes the following:

- Civil Infrastructure - Advise the commander on environmental considerations/issues

- Determine environmental impact from operations and integrate considerations into MDMP

- Work with G4 to perform site assessments and G2/S2 for IPB

- Developed the Center for Army Lessons Learned (CALL) Environmental Newsletter 9-99 on Military Environmental Protection, and will continue with database.

The environmental questions for which the agency is responsible include the following:

- Doctrinal

- Training - bringing together military and civilian leader development training

- Lessons Learned - development and maintenance of Database located at CALL

- Oversight role for Environmental Risk Assessment: New Doctrine: FM 20400, "Environmental Considerations in Military Operations" provides examples of environmental scenarios and applying risk assessment method from FM 100-14 "Risk Management." 
The agency perceives a need for coordination and integration of the database, including issues such as levels of data, kinds of data, differentiation of data term "environment" (e.g., adverse weather, conditions), and environmental integration of capstone doctrine. The Engineer School is now determining its future mission, organization, and costs. As environmental proponent, the Engineer School will be developing a lessons learned database, and ensuring collection, analysis, and dissemination of information. Compared with the GIS database information, this agency's database may be more anecdotal. It most closely cooperates with TRADOC Service Schools (for integration of doctrine and training), and ASA (I\&E) (to input for Army Environmental Campaign Plan).

The Engineer School has cooperated with other Army agencies over the past six years during the development of the FM 20-400 "Environmental Consideration in Military Operations," originally titled "Military Environmental Protection." This doctrine has been under development for almost 6 years, and has been reviewed by over 63 agencies, including FORSCOM and the Marines, but is still open to suggestions by those present to any shortfalls it may have. If there are any suggested changes within a year, the Engineer School could make changes to it.

For overseas deployment missions, what they have worked on is the Environmental Newsletter 9-99, which is disseminated by the CALL and the Engineer School.

The Engineer School was the training proponent for TRADOC until recently (throughout the 1990s). Recently at the Senior Environmental Leadership Conference 2000 (SELC 2000) they made a recommendation through Panel 2, Education and Training, Major General Robert B. Flowers, Commandant, U.S. Army Engineer School, for TRADOC to make the engineering school the Army Environmental proponent. A follow up to this workshop would be a good idea.

One of the other things that came out of SELC is that there should be a "lessons learned environmental database" developed and managed by TRADOC and the Engineer School. With the development of the Newsletter 9-99, they developed a collection term, "Military Environmental Protection," which is the key term for the database. In the future, the Newsletter can be linked to the other databases. The intent of CALL Newsletter 9-99, "Military Environmental Protection" is that it is to be used to establish a "call collection term" to be used by our services. It is relatively new, and as a result not much information about it is available yet.

The Engineer School is responsible for the doctrine and training. It brings together military and civilian leaders. There is a definite need to bring together 
civilian and military leadership. It has environmental vignettes, and examples that use FM 100-14, Risk Management.

The Engineer School perceives a need to include an integration of the capstone doctrine with what comes out of the workshop.

Benefits include developing the future mission, and deciding what the organization will look like (the environmental proponent). Costs are uncertain. They will be developing the database. They are looking at the training proponent integration office (TPIO).

The Engineer School dealt with TRADOC (to develop doctrine), and the Assistant Secretary's office, to input what their information requirements are to the environmental campaign plan, The Army Environmental Campaign Plan, that should come out with in the next 6 weeks. It has been coordinated with 63 agencies in the past 6 years while developing doctrine. It worked with TRADOC service schools to integrate environmental considerations across their doctrine and training. " In the past year there have been changes to the document, specifically, it has been reorganized in accordance with extensive comments received from Forces Command in April 1999. Forces Command was involved with a NATO Agreement that focuses on the planning of operation exercises. Military personnel know their duties when they arrive at the base camps. There are no mysteries about responsibilities or execution. In the Navy they have built a "pure" three-tier doctrine. The first tier is the big picture policy. The second tier is doctrine. The third tier is TTP. The document seems to be a classic example of TTP to him, as opposed to pure doctrine. The document's author has a problem with the word "doctrine." He thinks it seems to be more dominate at the operation level than at the execution level. TRADOC, on the other hand, has determined that the environmental campaign is doctrine. The Navy has NWP 411, and the Air Force has AFR 10-222. NWP 4-11 and 10-222 are similar to FM 20-400, which the Marine Corps use. These documents look at operations from an environmental perspective as far as predeployment, deployment, and postdeployment. That is the way they are interpreting doctrine in the services. The Joint Staff has no documentation.

* The remainder is the result of exchanges between Steve Flier and Larry Koss. 


\section{AEPI - Bob Jarrett}

Address: US Army Environmental Policy Institute

101 Marietta Street, NW, Suite 3120

Atlanta, GA

E-mail: jarrett@aepi.army.mil

Phone: $\quad 404-524-9364$

Fax: $\quad 404-524-9368$

Mr. Jarrett represented the director of AEPI, Dick Wright.

The abstract justification for why AEPI participated in the workshop can be laid out for anyone who is skeptical. Everyone has practical evidence, and AEPI has looked at some of the abstract justification.

AEPI is doing work for the Center of Army Analysis, formerly the Concept Analysis Agency. It was doing some modeling on predicting areas of instability in the world. It took on the task of trying to find the sources of environmental indices that would be relatively reliable when being used in models. The situation is sparse. That is the area that needs work. Everything will not be measurable from space. Some things will have to be measured on the ground. The space information will be important, however. Many of the countries they deal with are not contributors to the information because they are too poor. Much of the time they do not even remember where the contaminated sites are.

In tracing scandals, the motto is "Follow the money." In this case, chasing money is also a good idea. Nongovernmental Agencies (NGOs) handle information, a lot of space-based information, but much of the information is of questionable validity. It also may be very incomplete. For example, one of the pieces of information needed by USAREUR was the address of the environmental agency in Pristina. That information cannot be retrieved from a satellite, and sometimes the phone book does not have it either. Wide ranges of information types need to be considered. Chase the money. Legitimacy is building. There have been enough lessons learned that show that money has to be put into this. It is too big to do on a shoestring, in a worthwhile fashion. A culture change is that people need to begin signing off on financial planning-related documents that put resources into this. 


\title{
ODUSD (ES/FP) - Curtis Bowling, Assistant Deputy Under Secretary of Defense Environmental Security for Force Protection, DUSD-ES
}

\author{
Address: ODUSD (ES/FP) \\ 3400 Defense Pentagon, Rm 3E791 \\ Washington, DC 20301-3400 \\ Email: Bowlincm@acq.osd.mil \\ Phone: $\quad$ 703-604-1624 \\ Fax: $\quad$ 703-607-1244
}

The observations of other workshop participants reconfirmed what ODUSD (ES/FP) has been hearing all along: "Things are disjointed." There are a lot of needs, especially for timely information. The integrated environmental information and health data sets overlap (not completely, but they do overlap), so it is not smart to go after them in three separate communities. A problem is not to become overwhelmed with information. There is also a concern about how they will get the information to the field. A fire hose hooked up to a drinking straw is an appropriate analogy for the situation. "Centers of Excellence" are a good idea so that one can look at all the sources. The bottom line is getting the information to the decision makers using Operational Risk Management.

\section{Navy - Larry Koss}

Address: GEO-CENTERS

Attn: Lawrence J. Koss

1755 Jefferson Davis Highway

Crystal Square 5, Suite 910

Arlington, VA 22202

Email: $\quad$ kosslj@erols.com

Phone: 703-416-1023 ext 105

Fax: $\quad 703-416-1178$

Oil spills are an example of the kind of problem that the Navy would like to see modeled. Commanders have reported close encounters with oil spills. They need a network around the globe with contingency planning for oil spills, and this involves some expert modeling. In the Persian Gulf, the modeling did not work so well. What was predicted did not happen. Weather patterns, winds, and currents changed. There is a lot to be learned in terms of modeling.

The Navy started working with ESRI a long time ago to perfect models. The Black Sea is a good example of an area for which modeling would be very useful. Operations on the Black Sea involve a lot of third world countries that don't have 
sensitivity to NATO standards. What if there is a spill? Minimizing vulnerability and maximizing performance in the exercise then depend on environmental information. The Navy started looking at the concept of a GIS for the Black Sea, the Mediterranean, and the Baltic. They connected with the World Health Organization and used NOAA and NIMA information as well. A GIS tool for the Sixth Fleet was built. They were able to identify, using the GIS, areas where there would be minimum impact, should they have a spill. The final product was perfect for environmental planning.

Environmental modeling is particularly important because a young officer may know nothing about the environment. He has no tool to ask the right questions to determine his choices, and to figure out how to minimize his risk. He needs a way to document it and justify it.

On the other hand, back in the United States you have NEPA "kicking everybody's butt around the globe," spending huge dollars, and answering the same kinds of questions. There is an integration of cultures and scientific worlds, technical, political, and logistical worlds.

The Navy is starting to build an operational planning tool for the Sixth Fleet, so that they can actually look at the areas of operation in the Black Sea, Mediterranean, and Baltic. They are also considering doing this, for example, for the Second Fleet, in terms of training ranges. Tremendous headway has been made, and they are very close to delivering a product for the Sixth Fleet. In terms of the focus, listening to the dogma of the army, they are up in the operational planning level, not really down at the execution level. However, that is not far away. There are many bases that have been using GIS for a long time. They have built a whole pattern that overlaps, at Pax River, using Enterprise, Research and Management. There is one major, central set of information, from which they can extract information and apply it to a range of different needs. This system would be enhanced by remote imagery and taking advantage of realtime information from satellites. What they have could be integrated with realtime information, providing what is needed to make key decisions.

High-resolution satellite imagery is enhancing the process. There is no question that people have felt in the past that they could do whatever they wanted "inside the fence." Now all of a sudden everyone knows what they are doing inside the fence, and it is necessary to be defensive. That information should be used proactively to justify, minimize, change, and rethink, particularly in terms of minimizing the impact of a spill. Natural Resource Damage Assessment involves satellites and remote imagery, which are major factors influencing how we interpret information and apply it in a very strategic way. 
There needs to be a great deal of analysis and synthesis. This situation is like a Venn diagram with tremendous overlay in the center. Every agency can all benefit from sharing.

\title{
OADUSD(ES/FP) - Kurt Kratz
}

\author{
Address: OADUSD(ES/FP) \\ 3400 Defense Pentagon, Rm 3E791 \\ Washington, DC 20301-3400 \\ E-mail: $\quad$ KRATZKL@acq.osd.mil \\ Phone: (703)604-1621 \\ Fax: $\quad$ (703) 607-5422
}

Mr. Kratz works for Curtis Bowling on doctrine and policy for overseas deployment issues. His agency has the ability to affect policy, doctrine, and education, and they are interested in hearing what everyone thinks needs to be done. From their point of view, doctrine and education are key.

\section{NIMA/IATE (Environmental and Civil Issues Branch) - Neal Stewart}

Address: NIMA

Attn: Neal Stewart

Washington Navy Yard, Bldg 213

Mail Stop N31

1200 1st St SE

Washington, DC 20203-0001

Phone: 202-264-6497. This number is NIMA/IATE (Environmental and Civil Issues Branch).

Mr. Stewart is from NIMA, specifically the Environmental Solutions Branch. He represents the imagery side, as opposed to the mapping side. The purpose of his attendance at the workshop was to find out who potential new customers are, and what their needs are. They are encouraged to contact him so that he can find out how to help them.

The agency's mission is to provide imagery-derived environmental intelligence to policymakers, the Department of Defense, and U.S. civil agencies. It has no overseas deployment mission. The agency is responsible for responding to ad-hoc requests for information on environmental issues including deforestation, water scarcity and pollution, point sources of pollution, and natural disasters. Most of the requests have been from the disaster side, or potential threats to U.S. personnel. It perceives a need for more information on its customers and their 
needs. The potential benefits include wider dissemination of information and prioritization of customer needs and requirements, but there is the associated cost of acquiring and analyzing commercial imagery data. NIMA works most closely with FEMA (on information for disaster response), and U.S. policymakers, the Department of Defense, the intelligence community and a wide variety of civil agencies.

The mission of the imagery branch is to provide imagery derived from environmental intelligence. This is provided to policy makers, DOE at the command level, and to the civil agencies in the U.S. Government. Environmental intelligence deals with deforestation, water quality, desertification, and the ability to respond to natural disasters.

It is a small shop, so it does not have a standard product line worldwide. Between the environmental issues team and the disaster response team, there are only 18 people for the whole world. The work they do is incredible. They do have the ability to raise priority for taskings, particularly associated with significant disaster-related events that are going to impact military operations or military emergencies. It does not have contingency plans for environmental disasters around the world. The branch primarily responds to ad hoc requests for products, and for information on environmental hazards and environmental intelligence. Most of its products are classified. NIMA has an informal research program in-house but nothing formal. It does not have a general, broader database because it concentrates on specific issues in certain countries.

NIMA is working on the problems associated with disseminating some of their products. Most of their products on environmental intelligence are classified. They go out electronically, in blanket dissemination. The agency has access to classified products. They always try to produce unclassified products that mirror their classified products when they can; it is easy, for example, when working with unclassified base data, commercial unclassified satellite images. There is a way of taking classified NTM sources and producing an unclassified imageryderived product. There are established procedures for a map, line drawing, or a literal image. However, it is not always possible. The problem with imageryrequired products is that things take a long time to get approval, and will not meet the time lines. There is a need to respond quickly to disasters. Commercial imagery is a way of getting around the problems.

However, questions arise about disseminating that imagery digitally. It is a lot of information. How do you get it to the field at a certain bandwidth? Another question is the cost. Cost is an increasingly important element. For an environmental disaster, the cost could go into hundreds of thousands of dollars. That 
will be an issue in terms of subsidizing commercial data. One solution would be to use lower resolution images form SPOT or Landsat 7 (for something like flooding) because of the lower cost. NIMA has acquired commercial imagery for some of their customers. Another issue with commercial imagery is timeliness. As it stands right now, it could take several days, possibly a week or more to actually get the imagery disseminated.

There is a difference in the time frame, disaster response team vs. environmental issues team. The disaster response team is six people. They provide information with in 24 to 48 hours. That is an initial damage assessment. Normally environmental hazards, environmental intelligence issues, are considered more long-term, and get put into a category to respond to within weeks or months. The sooner NIMA receives a request about something, the more time it has to respond.

NIMA is interested in finding out what the problems and needs are. People are encouraged to visit the [Washington] DC office or a NIMA liaison officer to find out what kind of products are already available and what kind of products they might be able to create. Each command has a NIMA geospatial imagery liaison officer. Many also have imagery analysis officers (like Mr. Stewart, as opposed to the people on mapping side of NIMA).

From the intelligence community side, NIMA has good relationships with the J2. People are encouraged to check out the products available online, at the secret level. The agency is aware that there is a growing desire for unclassified products. It will meet the needs as well as it can, but ${ }^{*}$ priorities are based on NIMA resources and guidance from senior NIMA management.

\title{
Marine Corps Headquarters - Major Craig Eck
}

\author{
Address: Major Craig Eck \\ Environmental Compliance Officer \\ Headquarters, U.S. Marine Corps (LFL-6) \\ 2 Navy Annex \\ Washington, DC 20380-1775 \\ E-mail: $\quad$ eckcp@hqmc.usmc.mil
}

* The remainder is the result of exchanges between Neal Stewart and other participants. 
Phone: (703) 695-8302 x3327

Fax: (703) 695-8550

Major Eck is from Marine Corps Headquarters (HQ). Having been at his post for only 2 weeks, his purpose in attending the workshop is to intake information.

Marine Corps HQ deals with overseas-based compliance issues. It is responsible for inspection, determining whether rules are being followed. They get questions, when they are overseas, about hazardous waste and other things. Overseas environmental baseline guides are used overseas. For example, Japanese environmental guides are used in Japan.

Previous* experience showed that the big problem in the fleet is ignorance of laws. It is necessary to disseminate information concerning everything that needs to be done, whether personnel are operating at their own bases or overseas. The information needs to get to the lower levels. If an average guy is setting up a generator, for example, he does not care if there are any environmental problems. However, it would be overwhelming to go directly to the lowest levels. The information cannot be sent down to a corporal, but it is necessary to offer the help so they can call somebody. The engineering officers could help the lower units. They could have databases and CD-ROMs, easy to read products.

\section{DUSD-ES - Brian Smith}

Address: Evidence Based Research

1595 Spring Hill Road, Suite 250

Vienna, VA 22182

E-mail: BSmith@EBRInc.Com

Phone: (703) 287-0368

FAX: (703) $821-7742$

Mr. Smith is an analyst with Evidence Research for DUSD-ES, which is a practical research support contractor for the Deputy Under Secretary of Defense for Environmental Security.

\footnotetext{
* The remainder is the result of exchanges between Mr. Eck and other participants.
} 
The areas that DUSD-ES tends to work in are the "big picture" areas. It works in applied social science, not with GIS or remote sensing (which would be considered hard sciences). It works at the strategic level.

There is a problem of "environmental indices" because at the tactical and strategic levels there is nothing to work with. One source of data is the World Bank, but that data is highly aggregated. It is very difficult to find continuous time series types of data. Problems that the DEC tackles on a regular basis are difficult as a result. The data is simply not there on a regular aggregated basis. The agency has begun to study ways of getting this data, and where to get the data as well as how to get the aggregated tactical data that is available into some sort of coherent picture. In social science they have begun to look at GIS and remote sensing solutions. NASA's AVHRR system and data are available and are collected on a 1-kilometer basis. It is important for them to work at 1 kilometer because much of the other social science data is calibrated at that level. That is usually the smallest level of calibration available in the social sciences. There is a lot to be gained in this area. All the data that everyone else uses on a regular basis should be combined with the data that social sciences use on a regular basis.

One of the areas that DUSD-ES has looked at is "Environmental Engagement." There are a lot of tasks to be developed and a lot of areas that are potentially productive, but the problem has become one of moving the data into the field. Various points of contact - such as how to bring expertise into certain areas, how to at least set up points of contact for people in the CINC who are responsible for doing these things, how to find the people that they need to talk to on a regular basis to get the data, how to get the funding and the resources to be able to carry out the mission - seem to be lost in the "great haystack." DUSD-ES needs to be able to find them quickly. There is a need for coordination, integration, and information architecture to allow people to go in and navigate through to the people that they need to contact, to ask the questions to begin the process of getting the data and information that they need.

In one sense they are talking about integrating databases. They are talking about bringing remote sensing in so that analysts can use it on a regular basis. There is also another level they are beginning to consider, concerning people who are using this in the political and engagement realm. How can they access it, and how they can use it, not necessarily in interpretation and analysis, but rather, how can they use it as an extension for political and military deployments. 
When the database is finished, it will be placed on the DENIX system. However, many workshop participants expressed great displeasure over the use of the DENIX system, describing the system as slow, cumbersome, and difficult to use.

\section{MRJ Technology Solutions - Don Wells}

Address: 10560 Arrowhead Drive

Fairfax, VA 22030-7305

Phone: (703) 385-0700

Mr. Wells attended on behalf of Mark Launcher, who is the head of the operational/environmental planning office at Pax River.

Over the past 4 years, MRJ Technology Solutions has been building capabilities to construct a user-friendly information management system. The system pulls in information from an area covering 3 states, 33 counties, the Chesapeake Bay, and the operational area in the Atlantic and Key West Florida, which is 30,000 square miles.

Much of the work of MRJ Technology Solutions involves the NEPA (National Environmental Policy Act) problem. For example, it determines the impact of flying airplanes at various locations or putting people out there doing various things. The company has been building those kinds of information management systems. That sort of environmental database can also support many other things. For example, their system is supporting disaster preparedness emergency management for the whole area, and the company is also building a system to support public safety.

One of the other areas that MRJ Technology Solutions is working on right now for the Office of Secretary of Defense is an environmental system to support the country of Laos. It has a tremendous amount of information in it. The system contains all of the Vietnam era data from 1965 to 1974, which includes all the bombs and herbicides that were dropped. It has all of the NEPA data and Laos data in it, as well as data for Vietnam and Cambodia. There are lots of herbicides in all of those areas. The data have been taken down to the 1:50,000 scale level and put into an information management system that is very user friendly and allows people to query on it. The system is supporting the people who are doing the mining in Laos, the NGOs, etc. It allows them to create maps, bring that information out, and go out into the country. It is going to be expanded. It was started for people who were worried about what they were getting into; now they know what they are getting into. There may be herbicides in the area that are still active, and people are getting hurt. That is the information manage- 
ment system that is available. It is up and running now. It has been deployed into the capital city of Laos although the production facility is in Fairfax, VA.

State Department - Reid Daugherty (Bob Lozar summarized phone conversations with Mr. Daugherty)

The State Department is interested in using environmental data but has encountered the same problem as the military when developing data for overseas deployment. Their interests have been different, so there has been some suspicion between the two agencies. The State Department has an initiative to bring up a global coverage data set, hopefully of 1-kilometer resolution level. There is some hope for cooperation between the State Department and the Department of Defense. 


\section{Breakout Sessions}

Breakout Groups were asked to identify and prioritize:

- Problems

- Possible requirements to resolve:

- Policy and Doctrine

- Expertise and Personnel

- Technology and Data

- “The Way Forward” The Solution Breakout Groups:

- Policy

- Process

- Products

Each breakout group was given the flexibility to concentrate on issues it thought was most important.

\section{Report For Each Group}

\section{Breakout Group 1}

Major problems:

1. The major problem is there is currently no proponent for overseas deployment environmental concerns. It is not the medical folks, the engineering folks, or the chemical folks. This equals a lack of requirements, which then equals a lack of resources, and a lack of doctrine and funding.

2. The lack of proponent equals a lack of communication. People end up thinking in a box.

3. There is a lack of education.

4. There needs to be an overall integrated comprehensive plan. The purpose of a plan is to transfer from troops at an installation to troops as they are on a deployment.

5. Many people feel that environmental concerns are the same as "bugs and bunnies." However they need to look at the environment as a security issue. 
6. The problem is that we are in a reaction mode as opposed to a proactive mode of action.

7. How can get data in the effected countries?

8. How do we do the Tech transfer? Possibly by avoiding secure data, possibly by distributing via a CD-ROM.

\section{Solutions:}

1. Recommend action to the Defense Science Board that a study be done to develop a standard approach. This could be from the CINC to the JCS, from OSD to the JCS, from the Services to the JCS.

2. OSD Policy for example: a statement or directive on environmental policy would provide the impetus for the Joint Staff to include this in their discussion.

\section{Breakout Group 2}

Major problems:

1. The need for an environmental decision support tool.

2. The need for environmental data maintained by appropriate CINCs. This would include data held by all private and public sources.

3. No one is organizing overseas environmental support. Everyone is doing it (research labs, intelligence agencies), but no overall leadership.

Solution requirements:

1. The environmental decision support tool needs to modify contingency plans, to account for natural, industrial information.

2. The environmental decision support tool requires a modeling and simulation component, capable of doing risk assessment.

3. The environmental decision support tool must bring together joint planning, not stovepipe planning (individual planning at separate services).

4. The environmental decision support tool must bring together all software, and data related to environmental support.

5. Final product data must be unclassified. Currently, civilians and allied foreign nations are not allowed to see data.

6. The environmental decision support tool must be accessible to all levels of users. Users are not just strategic, can be platoon leaders. 
7. The environmental decision support tool must be an open system, with an open architecture, and be commercial off-the-shelf (COTS) software.

8. The environmental decision support tool must recognize that accidents will happen: an environmental exit strategy is needed.

Priority (lower item numbers are more important):

1. Who is in charge? Centralization is necessary.

2. Who is going to have spending authority? Again, centralization is necessary.

3. Training and awareness to all levels of military.

4. Developing a joint battle-space doctrine.

\section{Breakout Group 3}

Problems:

1. Doctrine is lacking. For example, Air Force Red Horse team is really a construction unit like a (Navy) Sea Bee. When the Red Horse team deploys, the main, and sometimes only, concern is to get the job done. Generally there is no thought of what the best alternatives may be; just where things can be put.

2. There is no implementation strategy. Currently there is a big policy and a sprinkling of implementation words throughout our documents. Some people thought a few words and doctrine would be sufficient.

3. Organizations have the data, the question is how do we get a handle on who has it and then how is it integrated. Who is the Czar who does all this?

4. The CINCs do not know where to go for expertise for environmental questions.

5. People are concerned about the environment in the United States because of the consequences of ignoring at. For overseas situations there are no consequences, therefore they pay less attention.

\section{Solutions:}

1. Deployments need to drive a list of Elements of Environmental Essential Information (E. E. E. I.).

2. Need to develop the protocol for environmental security (G3) and for force protection.

3. Civil Engineering Support To Overseas Deployment.

4. Joint staff working group has a target of opportunity. In EUCOM, Steve Hearn is the person to talk to. 
5. In policy there is an opportunity to be able to program money. Policy drives the requirement that the services use to generate doctrine. Doctrine carries no opportunity to program money.

6. Services will include environment as a part of planning process. Where? First in a DoD Directive (which then becomes a DoD Instruction) on environmental security, safety, personnel and readiness, NSS, and separate operational information. Where is the best place to use to begin this - the Joint Chiefs of Staff probably. This would support peacemaking and peace enforcement.

7. Commanders in the field need the resources (data) in order to do a risk assessment.

8. Need to impact perceptions on what is legitimate when we carry out missions.

9. The people who write the safety manuals have made a big impact and they have done this within a one-page document. Since they are so successful, maybe we should make a combined safety an environmental JOPS. The problem is that the CINCs need the information, what is the information that is needed in the JOPS?

10. In some places environment and environmental health are the same. Overseas at the OK Coral (I do not remember the name of the actual location) we placed our troops in a hazardous location. Once we realized that, we had to move them out again.

11. The development of policy leads to education and education is our goal.

12. To put an idea in front of a commander you need to express the idea in terms of health, safety, and... "By the way, if you have a choice please watch out for this concern...." For example, avoid this 800-yr old church please or avoid harming it if you have the option. This way you do not invite a retribution reaction. Beyond the question of your conscience there is the issue of long-term liability the United States may be entailing. In a deployment, operational concerns change. As an emergency situation lessens, the environmental questions become more important.

13. Currently, concern for the environment is not part of the culture for an overseas deployment. It would be useful for a commander to do a risk analysis. This way he knows what the real risk is.

14. Right now there are only 18 individuals supporting these environmental demands in NIMA. NIMA has it hands full simply generating camp base maps.

15. The first thing to do is to figure out what an environmental risk assessment would be for an operational commander. It needs to include policy, doctrine, training, and resources. There are different types of goals. Short-term are within the year, long-term maybe 12 years. You also need to include both cultural and physical questions. 
16. The policy needs to occur at the highest level. It needs to include a 20-hour block of training at the senior service schools for commanders. Years ago ERDC/CERL developed in environmental impact computer system that was a scoping system. This is the kind of support that field commanders need.

General Comments:

1. Ted Reid suggested that commanders are already convinced - they need guidance and a goal. They are determined to protect their troops, to protect their colleagues with whom they work, and protect the host country's resources.

2. TRADOC takes NSS and develops this into a statement of policy. Policy allows planning that is the important issue here.

3. There is no regulatory base to get the TDA slot for in-house expertise.

4. Only a few people have worked in the OPS section. This is a requirement to really know what goes on.

5. What drives the resources and overseas deployment is protection: protection of the resources, protection of the mission and, troops security. All of these exist for readiness reasons. 


\section{Workshop Observations and Recommendations}

Consensus: A soldier's death due to lack of an environmental risk analysis is just as fatal as a death due to enemy fire. It is possible to avoid this situation.

Desired End State: We wish to achieve information and space dominance in support of military missions overseas (including deployment planning, humanitarian, police, and training deployments). We have identified a hole in that dominance. The hole is the environmental information.

Recommendation: In our training we need to show to the commander the relationship between battlefield dominance and environmental security.

Observation: There is a strategic, as well as the tactical, level of concern for these deployment situations.

Recommendations: As stated in the SELC meeting (See Appendix D for a complete description): further discussions must be made on what tripwire mechanisms are in place to trigger a review of when environmental issues are in the national interest to remove these sensitive ecosystems. Also, soldier attitudes on the environment need to be refocused, requiring inspections of unit environmental performance, providing environmental resources, and enforcing existing environmental standards.

Problem: The field commanders often ask what is the state of the environment. Recommendation: We wish to give the commander the capability to do an environmental risk assessment.

Problem: Risk assessments may change over time.

Recommendation: There is a need to develop a continuous process as conditions change during the time horizon.

Problem: Operational CINCs need more resources.

Recommendation: The operational CINCs need scientific research. Civilian CONUS disaster management research is a model that can be applied to field commander environmental risk management. 
Consensus: Environmental health safety affects the soldier.

Recommendation: The Defense Science Board needs to look at this from all angles. This would provide a body of evidence for policy development. Good scientific research can support policy implementation.

Action: Identify the timing horizon for requesting a Defense Science Board study.

\section{Consensus:}

1. Critical issue is determining who is in charge.

2. Leadership must be taken in the policy arena.

3. There needs to be a high level of policy support. To provide the biggest bang for the buck, policy needs to be implemented at the highest level in order to bring things together in a uniform manner. High-level policy is the vehicle to ensuring resources is made available to accomplish the mission.

\section{Additional Observations:}

1. The use of environmental information has to be unclassified.

2. Actions within a stovepipe area might generate a 60 percent solution. This would be an improvement over the current situation.

3. Much of the discussion dealt with classical tactical situations, however the need for environmental risk analysis is also great in the planning, deployment, humanitarian, police, and training deployments.

4. The purpose of environmental characterization is to avoid risk and to take advantage of the environment for tactical purposes so environmental characterization can also be an ally to a commander (e.g., taking advantage of a stream that is flooding).

5. NRO will integrate Environmental Protection for Forces Deployment into their customer support plan for fiscal 2001. Actions:

- To educate communities

- To facilitate

- To fund studies with the DEC through the Directors Innovation Mission for Pilot Projects

- To provide a technology center exchange. 


\section{References}

Air Force Handbook (AFH) 10-222 (various volumes) Guide to Base Development, Secretary of the Air Force, 1 July 1996.

Army Regulation (AR) 200-1, Environmental Protection and Enhancement, Assistant Chief of Staff for Installation Management, 21 February 1997.

AR 200-1, Paragraph 1-40, 23 April 1997, “At OCONUS locations, commanders of Army activities will maintain cooperative relationships with the regulatory agencies in the host countries or jurisdictions. ... This regulation will be applied in fulfilling OCONUS environmental protection requirements, with special reference to paragraph 1-24 (see EO 12114 and AR 200-2, chapter 6).”

AR 200-2, Environmental Effects of Army Actions, Office of the Chief of Engineers, 23 December 1989.

Butts, Kent H., Environmental Security: What is DoD's Role? Strategic Studies Institute/U.S. Army War College, Carlisle Barracks, PA, May 28, 1993.

Department of Defense Directive (DODD) 6050.7, Environmental Effects Abroad of Major Department of Defense Actions, March 31, 1979; as incorporated in AR 200-2, Chapter 8, and reprinted.

Engineer Regulation (ER) 210-3-2, Army Range Programs, 1 October 1990. U.S. Army Corps of Engineers (USACE).

Executive Order (EO) 12114, "Environmental Effects Abroad of Major Federal Actions," 4 January 1979, (44 FR 1957).

EO 13151 “Global Disaster Information Network,” 27 April 2000 (65 FR 25619).

Field Manual (FM) 20-400, Draft Military Environmental Protection.

FM 100-14, Risk Management, HQ Department of the Army, April 1996.

Public Law (PL) 91-190, National Environmental Policy Act 42 U.S.C. 4321 to 4370c.

The responsibility of the Force Integration and Readiness Group, Architectural and Planning Group, Headquarters, U.S. Army Corps of Engineers.

Training and Doctrine Command (TRADOC) white paper, "Integrating U.S. Army Environmental Strategy into Operational Doctrine." 


\title{
Office Symbols and Acronyms
}

\author{
ACSIM Assistant Chief of Staff for Installation Management \\ AEPI Army Environmental Policy Institute \\ AF/XOI/XOW Air Force Office \\ AFR Air Force Regulation \\ AFWA Air Force Office \\ APG Aberdeen Proving Ground \\ AR Army Regulation \\ ARNG Air Reserve National Guard \\ ASA Assistant Secretary of the Army \\ ASD Assistant Secretary of Defense \\ AVHRR Advanced Very High Resolution Radometer (a NOAA satellite in- \\ strument) \\ BCCA Base Camp Coordination Agency \\ BDA Battle Damage Assessment \\ $\mathrm{C}^{3} \mathrm{I} \quad$ Command, Control, Communications, and Intelligence \\ CAC Civil Applications Committee \\ CAD Computer-Assisted Drawing \\ CALL Center for Army Lessons Learned \\ CEC Civil Engineer Corps \\ CENTCOM Central Command \\ CERL Construction Engineering Research Laboratory (part of ERDC) \\ CHL Coastal and Hydraulics Laboratory (part of ERDC) \\ CHPPM U.S. Army Center for Health Promotion and Preventive Medicine \\ CIA Central Intelligence Agency \\ CINC Commander-in-Chief \\ CINCPAC Commander-in-Chief, Pacific \\ CMO Civil Military Operations \\ CNMOC Civil Military Operations Center \\ CONOPS Concept of Operations \\ CONUS Continental United States
}


COTS Commercial Off-The-Shelf (software)

CRREL Cold Regions Research and Engineering Laboratory (part of ERDC)

DA Department of the Army

DASA Department of the Army, Secretary of the Army

DCI Director of Central Intelligence

DCSENGR Deputy Chief of Staff for Engineers

DCSINT Deputy Chief of Staff for Intelligence

DEC Director of Central Intelligence Environmental Center

DENIX Defense Environmental Network and Information eXchange

DIA Defense Intelligence Agency

DOC Department of Commerce

DoD Department of Defense

DODD Department of Defense Directive

DOE Department of Energy

DOI Department of Interior

DOT Department of Transportation

DUSD-ES Deputy Under Secretary of Defense for Environmental Security

E.E.E.I. Elements of Environmental Essential Information

EIA Environmental Impact Assessment

EIS Environmental Impact Statement

EL Environmental Laboratory (part of ERDC)

EO Executive Order

EPA Environmental Protection Agency

ERDC U.S. Army Engineer Research and Development Center

ESRI Earth Science Research Institute (a GIS software company)

EUCOM European Command, U.S. Army

EUD European District

FAA Federal Aviation Administration

FEMA Federal Emergency Management Agency

FGUO For Government Use Only

FM Field Manual

FORSCOM Forces Command

G2 Army component intelligence staff offices

G3 Army component operations staff offices 
G4 Army component logistics staff offices

GDIN Global Disaster Information Network

GIS Geographic Information System

HAZMAT Hazardous Materials

HQ Headquarters

HTRW Hazardous, Toxic, and Radiological Waste

IDP Imagery-Derived Products

INTEL Intelligence Command

IPB Intelligence preparation of the battlefield

ISA International Security Affairs

J2 Intelligence Directorate of a joint staff

J3 Operations Directorate of a joint staff

J4 Logistics Directorate of a joint staff

JACs Joint Analysis Centers

JCS Joint Chief of Staff

JICs Joint Intelligence Centers

JIPB Joint Intelligence Preparation of the Battlespace

JOPS Joint Operations

JTF Joint Task Force

MANSCEN Maneuver Support Center

MRJ company name

NASA National Aeronautics and Space Administration

NATO North Atlantic Treaty Organization

NEO noncombatant evacuation operation

NEPA National Environmental Policy Act

NGB National Guard Bureau

NGO Nongovernmental Organization

NIMA National Imagery and Mapping Agency

NOAA National Oceanic and Atmospheric Administration

NRO National Reconnaissance Office

NSA National Security Agency

NSF National Science Foundation

NSS National Security Strategy of the United States

NSS National Support Staff

NTM National Technical Means 


\begin{tabular}{|c|c|}
\hline O\&M & Operation and Maintenance \\
\hline ODCSENG & Office of the Deputy Chief of Staff for Engineering \\
\hline ODUSD-ES & $\begin{array}{l}\text { Office of the Deputy Under Secretary of Defense for Environ- } \\
\text { mental Security }\end{array}$ \\
\hline OPS & Operations \\
\hline OSD & Office of the Secretary of Defense \\
\hline OSTP & Office of Science and Technology Policy \\
\hline PACOM & Pacific Command \\
\hline $\mathrm{PDC}$ & Pacific Disaster Center \\
\hline PL & Public Law \\
\hline $\mathrm{R} \& \mathrm{D}$ & Research and Development \\
\hline S2 & Battalion or Brigade intelligence officer \\
\hline SATP & Space Applications Technologies Program \\
\hline SELC & Senior Environmental Leadership Conference \\
\hline SMDC & Space and Missile Defense Command \\
\hline SPOT & a commercial satellite \\
\hline TDA & Table of Distribution and Allowances \\
\hline TEC & Topographic Engineering Center (part of ERDC) \\
\hline TPIO & Training Proponent Integration Office \\
\hline TRADOC & Training and Doctrine Command \\
\hline TTP & Tactics \\
\hline U.S. & United States \\
\hline UN & United Nations \\
\hline USACE & U.S. Army Corps of Engineers \\
\hline USACHPPM & U.S. Army Center for Health Promotion and Preventive Medicine \\
\hline USAES & U.S. Army Engineer School \\
\hline USAREUR & U.S. Army Europe \\
\hline USGS & United States Geological Survey \\
\hline
\end{tabular}




\section{Appendix A: Executive Order on Global Disaster Information Network}

April 27, 2000

By the authority vested in me as President by the Constitution and the laws of the United States of America, and in order to establish a Global Disaster Information Network to use information technology more effectively to reduce loss of life and property from natural and man-made disasters, it is hereby ordered as follows:

Section 1. Policy.

(a) It is the policy of this Administration to use information technology more effectively to coordinate the Federal Government's collection and dissemination of information to appropriate response agencies and State governments to prepare for and respond to natural and man-made disasters (disasters). As a result of changing population demographics in our coastal, rural, and urban areas over the past decades, the loss of life and property (losses) from disasters has nearly doubled. One of the ways the Federal Government can reduce these losses is to use technology more effectively to coordinate its collection and dissemination (hereafter referred to collectively as "provision") of information which can be used in both planning for and recovering from disasters. While many agencies provide disaster-related information, they may not always provide it in a coordinated manner. To improve the provision of disaster-related information, the agencies shall, as set out in this order, use information technology to coordinate the Federal Government's provision of information to prepare for, respond to, and recover from domestic disasters.

(b) It is also the policy of this Administration to use information technology and existing channels of disaster assistance to improve the Federal Government's provision of information that could be helpful to foreign governments preparing for or responding to foreign disasters. Currently, the United States Government provides disaster-related information to foreign governments and relief organizations on humanitarian grounds at the request of foreign governments and where appropriate. This information is supplied by Federal agencies on an ad hoc basis. To increase the effectiveness of our response to foreign disas- 
ters, agencies shall, where appropriate, use information technology to coordinate the Federal Government's provision of disaster-related information to foreign governments.

(c) To carry out the policies in this order, there is established the Global Disaster Information Network (Network). The Network is defined as the coordinated effort by Federal agencies to develop a strategy and to use existing technical infrastructure, to the extent permitted by law and subject to the availability of appropriations and under the guidance of the Interagency Coordinating Committee and the Committee Support Office, to make more effective use of information technology to assist our Government, and foreign governments where appropriate, by providing disaster-related information to prepare for and respond to disasters.

Sec. 2. Establishment.

(a) There is established an Interagency Coordinating Committee (Committee) to provide leadership and oversight for the development of the Network. The Office of the Vice President, the Department of Commerce through the National Oceanic and Atmospheric Administration, and the Department of State, respectively, shall designate a representative to serve as Co-chairpersons of the Committee. The Committee membership shall comprise representatives from the following departments and agencies:

(1) Department of State;

(2) Department of Defense;

(3) Department of the Interior;

(4) Department of Agriculture;

(5) Department of Commerce;

(6) Department of Transportation;

(7) Department of Energy;

(8) Office of Management and Budget;

(9) Environmental Protection Agency;

(10) National Aeronautics and Space Administration;

(11) United States Agency for International Development;

(12) Federal Emergency Management Agency; and

(13) Central Intelligence Agency.

At the discretion of the Co-chairpersons of the Committee, other agencies may be added to the Committee membership. The Committee shall include an Executive Secretary to effect coordination between the Co-chairpersons of the Committee and the Committee Support Office.

(b) There is established a Committee Support Office (Support Office) to assist the Committee by developing plans and projects that would further the creation of the Network. The Support Office shall, at the request of the Co-chairpersons of the Committee, carry out tasks taken on by the Committee. 
(c) The National Oceanic and Atmospheric Administration shall provide funding and administrative support for the Committee and the Support Office. To the extent permitted by law, agencies may provide support to the Committee and the Support Office to assist them in their work.

Sec. 3. Responsibilities.

(a) The Committee shall:

(1) serve as the United States Government's single entity for all matters, both national and international, pertaining to the development and establishment of the Network;

(2) provide leadership and high-level coordination of Network activities;

(3) provide guidance for the development of Network strategies, goals, objectives, policies, and legislation;

(4) represent and advocate Network goals, objectives, and processes to their respective agencies and departments;

(5) provide manpower and material support for Network development activities;

(6) develop, delegate, and monitor interagency opportunities and ideas supporting the development of the Network; and

(7) provide reports, through the Co-chairpersons of the Committee, to the President as requested or at least annually.

(b) The Support Office shall:

(1) provide management and administrative support for the Committee;

(2) develop Network strategies, goals, objectives, policies, plans, and legislation in accordance with guidance provided by the Committee;

(3) consult with agencies, States, nongovernment organizations, and international counterparts in developing Network development tasks;

(4) develop and make recommendations concerning Network activities to the agencies as approved by the Committee; and

(5) participate in projects that promote the goals and objectives of the Network.

Sec. 4. Implementation.

(a) The Committee, with the assistance of the Support Office, shall address national and international issues associated with the development of the Network within the context of:

(1) promoting the United States as an example and leader in the development and dissemination of disaster information, both domestically and abroad, and, to this end, seeking cooperation with foreign governments and international organizations;

(2) striving to include all appropriate stakeholders in the development of the Network; and 
(3) facilitating the creation of a framework that involves public and private stakeholders in a partnership for sustained operations of the Network.

(b) Intelligence activities, as determined by the Director of the Central Intelligence Agency, as well as national security-related activities of the Department of Defense and of the Department of Energy, are exempt from compliance with this order.

Sec. 5. Tribal Governments. This order does not impose any requirements on tribal governments.

Sec. 6. Judicial Review. This order does not create any right or benefit, substantive or procedural, enforceable by law, by a party against the United States, its officers, its employees, or any other person.

WILLIAM J. CLINTON

THE WHITE HOUSE, April 27, 2000 


\section{Appendix B: List and Addresses of Attendees}

\begin{tabular}{|c|c|c|}
\hline Bowling, Curtis & $\begin{array}{l}\text { ODUSD (ES/FP) } \\
3400 \text { Defense Pentagon, RM 3E791 } \\
\text { Washington, DC 20301-3400 }\end{array}$ & $\begin{array}{l}\text { Bowlincm@acq.osd.mil } \\
\text { (703) 604-1624 } \\
\text { Fax (703) 607-1244 }\end{array}$ \\
\hline Cannon, Stu & $\begin{array}{l}\text { DCS for Personnel \& Install. Mgt. } \\
\text { ATTN: AFEN-ENE (Mr. Cannon) } \\
1777 \text { Hardee Ave SW } \\
\text { Fort McPherson, GA 30330-1062 }\end{array}$ & $\begin{array}{l}\text { Cannons@forscom.army.mil } \\
\text { (404) 464-5762 } \\
\text { Fax (404) 464-7827 }\end{array}$ \\
\hline Conrad, Chris & $\begin{array}{l}\text { Dept. of Army, Office of Assistant } \\
\text { Secretary, Installations \& Environment } \\
\text { ATTN: Chris Conrad, } 110 \text { ARMY } \\
\text { PENTAGON, Washington, DC 20310-0110 }\end{array}$ & $\begin{array}{l}\text { Chris.conrad@hqda.army.mil } \\
\text { (703) 614-9047 } \\
\text { Fax (703) 614-4057 }\end{array}$ \\
\hline Eck, Craig & $\begin{array}{l}\text { Major Craig Eck } \\
\text { Environmental Compliance Officer } \\
\text { Headquarters, U.S. Marine Corps (LFL-6) } \\
2 \text { Navy Annex } \\
\text { Washington, DC 20380-1775 }\end{array}$ & $\begin{array}{l}\text { eckcp@hqmc.usmc.mil } \\
\text { (703) 695-8302 x3327 } \\
\text { Fax (703) 695-8550 }\end{array}$ \\
\hline $\begin{array}{l}\text { Ehlschlaeger, } \\
\text { Charles }\end{array}$ & $\begin{array}{l}\text { Department of Geography } \\
\text { Hunter College } \\
695 \text { Park Ave. } \\
\text { New York, NY } 10021 \\
\end{array}$ & $\begin{array}{l}\text { chuckre@home.com } \\
\text { (212) 772-5321 } \\
\text { Fax (914) 407-2029 }\end{array}$ \\
\hline Elliot, Keith & No current information. & \\
\hline Flier, Steve & $\begin{array}{l}\text { U.S. Army Engineer School } \\
\text { Dept. of Instruction } \\
320 \text { Engineer Loop-Suite } 370 \\
\text { Ft. Leonard Wood, MO } 65473-8926\end{array}$ & $\begin{array}{l}\text { FLIERS@WOOD.ARMY.MIL } \\
\text { (573) 563-4122 } \\
\text { Fax (573) 563-4127 }\end{array}$ \\
\hline Gatto, Lawrence W. & $\begin{array}{l}\text { Research Geologist } \\
\text { Geological Sciences Branch } \\
\text { ERDC/CRREL } \\
72 \text { Lyme Rd. } \\
\text { Hanover, NH } 03755-1290 \\
\end{array}$ & $\begin{array}{l}\text { Igatto@crrel.usace.army.mil } \\
\text { (603) 646-4273 } \\
\text { Fax (603) 646-4785 }\end{array}$ \\
\hline Howard, Jackie & $\begin{array}{l}\text { USACHPPM, } 5158 \text { Blackhawk Road } \\
\text { Attn: MCHB-TS-EES } \\
\text { Building E1675 } \\
\text { APG-EA, MD } 21010-5403\end{array}$ & $\begin{array}{l}\text { Jackie.Howard@apg.amedd.army.mil } \\
\text { (410) 436-6096 } \\
\text { Fax (410) 436-2407 }\end{array}$ \\
\hline Hutchens, Brad & $\begin{array}{l}\text { USACHPPM, } 5158 \text { Blackhawk Road } \\
\text { Attn: MCHB-TS-EES } \\
\text { Building E1675 } \\
\text { APG-EA, MD } 21010-5403\end{array}$ & $\begin{array}{l}\text { Brad.Hutchens@apg.amedd.army.mil } \\
\text { (410) 436-8162/6096 } \\
\text { Fax (410) 436-2407 }\end{array}$ \\
\hline Jarrett, Bob & $\begin{array}{l}\text { US Army Environmental Policy Institute } \\
101 \text { Marietta Street, NW, Suite } 3120 \\
\text { Atlanta, GA } 30303-2720\end{array}$ & $\begin{array}{l}\text { jarrett@aepi.army.mil } \\
\text { (404) 524-9364 } \\
\text { Fax (404) 524-9368 }\end{array}$ \\
\hline Johnson, Jerry & $\begin{array}{l}\text { NRO, ATTN: Jerry Johnson } \\
\text { (Rm 15F2OH) } 14675 \text { Lee Road } \\
\text { Chantilly, VA } 20151-1715\end{array}$ & $\begin{array}{l}\text { Johnjerr@nro.mil } \\
(703) 808-5689 \\
\text { Fax (703) 808-1184 }\end{array}$ \\
\hline
\end{tabular}




\begin{tabular}{|c|c|c|}
\hline Koss, Lawrence J. & $\begin{array}{l}\text { GEO Centers } \\
1755 \text { Jefferson Davis Highway } \\
\text { Crystal Square 5, Suite } 910 \\
\text { Arlington, VA } 22202\end{array}$ & $\begin{array}{l}\text { kosslj@erols.com } \\
\text { (703) 416-1023 Ext } 105 \\
\text { Fax (703) 416-1178 }\end{array}$ \\
\hline Kratz, Kurt & $\begin{array}{l}\text { OADUSD(ES/FP) } \\
3400 \text { Defense Pentagon } \\
\text { Rm 3E791 } \\
\text { Washington, DC 20301-3400 }\end{array}$ & $\begin{array}{l}\text { KRATZKL@acq.osd.mil } \\
\text { (703) 604-1621 } \\
\text { Fax (703) 607-5422 }\end{array}$ \\
\hline Litynski, John & $\begin{array}{l}\text { USACHPPM, } 5158 \text { Blackhawk Road } \\
\text { Attn: MCHB-TS-EES } \\
\text { Building E1675 } \\
\text { APG-EA, MD } 21010-5403\end{array}$ & $\begin{array}{l}\text { John.Litynski@apg.amedd.army.mil } \\
\text { (410) 436-6096 } \\
\text { Fax (410) 436-2407 }\end{array}$ \\
\hline Lozar, Robert & $\begin{array}{l}\text { ERDC/CERL-CNN } \\
\text { P.O. Box } 9005 \\
\text { Champaign, IL } 61826-9005\end{array}$ & $\begin{array}{l}\text { r-lozar@cecer.army.mil } \\
\text { (217) 352-6511 Ext. } 6367 \\
\text { Fax (217) 373-7266 }\end{array}$ \\
\hline Nicholls, William & $\begin{array}{l}\text { ODUSD(ES)FP } \\
3400 \text { Defense Pentagon, RM 3E791 } \\
\text { Washington, DC 20301-3400 }\end{array}$ & $\begin{array}{l}\text { nicholwr@acq.osd.mil } \\
\text { 703-604-1798 } \\
\text { Fax (703) 607-1244 }\end{array}$ \\
\hline Parks, Roy & $\begin{array}{l}\text { USAREUR } \\
\text { CMR 410, Box 4, APO AE } 09096\end{array}$ & $\begin{array}{l}\text { Roy.parks@usace.army.mil } \\
336-2450 \\
\text { Fax 336-2453 } \\
\text { from outside US: } \\
\text { 011-49-611-816-2450 } \\
\text { Fax 011-49-611-816-2453 }\end{array}$ \\
\hline Picantine, Jerry & $\begin{array}{l}\text { NRO, ATTN: Jerry Picantine (Room } \\
\text { 15F20H) } \\
\text { 14675 Lee Road } \\
\text { Chantilly, VA 20151-1715 }\end{array}$ & $\begin{array}{l}\text { Picantj@nro.mil } \\
\text { (703) 808-5395 } \\
\text { Fax (703) 808-1184 }\end{array}$ \\
\hline Reid, Ted & $\begin{array}{l}\text { Deputy Chief of Staff for Operations, } \\
\text { Commander FORSCOM } \\
\text { ATTN: AFOPTE } \\
1777 \text { Hardee Ave SW } \\
\text { Fort McPherson, GA } 30330-1062\end{array}$ & $\begin{array}{l}\text { Reidt@forscom.army.mil } \\
\text { (404) 464-7814 } \\
\text { Fax (404) 464-6567 }\end{array}$ \\
\hline Rensema, Tim & $\begin{array}{l}\text { ARNG Readiness Center } \\
\text { ATTN: NGB-ARE } \\
111 \text { So. George Mason Dr. } \\
\text { Arlington, VA } 22204-1382 \\
\end{array}$ & $\begin{array}{l}\text { Timothy.Rensema@ngb.army.mil } \\
\text { (703) 607-7961 } \\
\text { Fax (703) 607-7993 }\end{array}$ \\
\hline Sadusky, Ninette & $\begin{array}{l}\text { ODUSD (ES/FP) } \\
3400 \text { Defense Pentagon, Rm 3E791 } \\
\text { Washington, DC 20301-3400 }\end{array}$ & $\begin{array}{l}\text { Saduskni@acq.osd.mil } \\
\text { (703)-604-1874 } \\
\text { Fax (703)-607-1244 }\end{array}$ \\
\hline Severinghaus, Bill & $\begin{array}{l}\text { USA ERDC/CERL } \\
\text { P.O. Box } 9005 \\
\text { Champaign, IL } 61826-9005\end{array}$ & $\begin{array}{l}\text { w-severinghaus@cecer.army.mil } \\
\text { (603) 646-4273 } \\
\text { Fax (217) 373-7222 }\end{array}$ \\
\hline Smith, Brian D. & $\begin{array}{l}\text { Evidence Based Research } \\
1595 \text { Spring Hill Road, Suite } 250 \\
\text { Vienna, VA } 22182\end{array}$ & $\begin{array}{l}\text { BSmith@EBRInc.Com } \\
\text { (703) 287-0368 } \\
\text { FAX: (703) 821-7742 }\end{array}$ \\
\hline Stewart, Neal & $\begin{array}{l}\text { NIMA } \\
\text { Washington Navy Yard, Bldg } 213 \\
\text { Mail Stop N31 } \\
12001^{\text {st }} \text { St SE } \\
\text { Washington, DC 20203-0001 }\end{array}$ & (202) 264-6497 \\
\hline Wells, Don & $\begin{array}{l}\text { MRJ Technology Solutions } \\
10560 \text { Arrowhead Drive } \\
\text { Fairfax, VA } 22030-7305\end{array}$ & (703) 385-0700 \\
\hline
\end{tabular}




\section{Appendix C: Agency Introduction Form}

Environmental Protection for Forces Deployment

Welcome to the Environmental Protection for Forces Deployment Workshop. We are delighted that you are interested in today's topic. We will be asking for your active participation today. After the initial presentations, we will be asking attendees to spend a

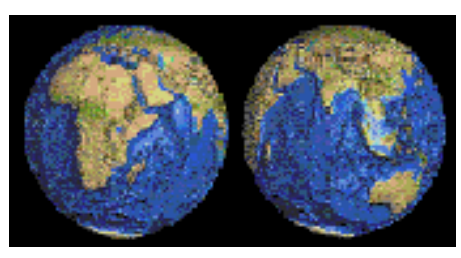
few minutes presenting their agency's mission and concerns regarding environmental protection for forces deployment. Since the presentation time is limited (five minutes per agency) we request that you use this outline to organize your presentation. Also, before lunch could you please leave the filled out form with us so we have a document that reflects your presentation. Thank you.

1. Attendee Name/Office

2. Agency Mission

3. Overseas Deployment Mission

4. Environmental Questions for which Agency is Responsible

5. Perceived Needs

6. Potential Benefits and Costs

7. Agencies with which you currently most closely cooperate/how

CERL POC: Mr. Robert C. Lozar CN-N

Phone: 217-352-6511 Extension 6367

Fax: 217-373-7222

E-mail: r-lozar@cecer.army.mil 


\section{Appendix D: Senior Environmental Leadership Conference Issue Papers}

The SELC issue papers presented here discuss the following issues:

1. The Army must include environmental concerns into all aspects of operations.

2. The Army must ensure it has sufficient usable land and facilities to conduct its training, mobilization, and deployment missions under maximum surge conditions for both the current and Objective Force structure.

3. There is no uniform policy on standards for hazardous waste storage and disposal by deploying forces.

4. Environmental Factors Effecting Staging Area in the AOR (APOD/SPOD) "Enforcing Army Environmental Standards"

5. Environmental Factors Effecting Staging Area in the AOR (APOD/SPOD) "Existing environmental conditions at the APOD/SPOD due to heavy industrial development"

6. There is a general lack of environmental information about APOD/SPODs in the areas of probable conflict. An environmental database is needed to assist in the IPB.

ISSUE \#1: The Army must include environmental concerns into all aspects of operations.

DISCUSSION: Military operations encompass a number of distinct phases, starting with home station training and ending with redeployment and demobilization. Environmental concerns can, and have had significant impact on each of the phases of the operations cycle. The failure to consider and plan for environmental concerns presents a real vulnerability for and execution of the Army's principle mission - the ground component of our national military defense team. Environmental issues need to be imbedded within the planning and execution process.

\section{ACTION:}

- Institutionalize throughout training and doctrine how to properly plan for Environmental Security concerns. (TRADOC) 
- Ensure Mobilization Plans accurately capture mobilization requirements and all necessary environmental documentation (e.g., NEPA analysis and permits) have been completed. (FORSCOM)

- Develop a comprehensive environmental Decision-Support tool for mission planning which contains links to existing databases containing worldwide environmental data maintained by appropriate CINCs. (FORSCOM)

- Modify contingency plans to take into account natural obstacles and potential industrial environmental threats in the AOR. (DCSOPS)

- Design a nontactical BASEOPS type of engineer support element that includes environmental management and oversight responsibilities for contingency operations. This team would be composed of environmental experts, either GS, contractor, or a combination of the two, which would handle all "garrison-level" environmental actions such as Haz Mat storage in order to relieve pressure from the base Camp Commander. (TRADOC)

- Ensure that all environmental After Action Reports are captured by the Center for Army Lessons Learned (CALL) in a manner that is readily accessible by mission planners and operators. (FORSCOM)

- Ensure adequate acclimatization periods for reserve component soldiers are built into the time required for postmobilization trainup. (FORSCOM)

ISSUE \#2: The Army must ensure it has sufficient usable land and facilities to conduct its training, mobilization, and deployment missions under maximum surge conditions for both the current and Objective Force structure.

DISCUSSION: Environmental and urban encroachment pressures will continue to reduce and restrict the availability of Army land and facilities. As the Army transforms into the Objective Force, requirements for usable land will increase. In addition to maintaining the current land base, the Army will likely require additional maneuver land to train the Total Army upon mobilization. The land requirements must be calculated at the height of mobilization surge strength. Additional land purchases or maneuver rights will be very difficult in the future.

\section{ACTION:}

- Develop a comprehensive Training Land Strategy. The strategy must:

- Consider the early use of Reserve Component forces in the TimePhased Force Deployment Data. 
- Examine and establish the true delta between the steady-state land and facility requirements and those required at the height of mobilization surges.

- Address the needs of the Objective Force Brigade as they transform to a structure of four maneuver battalion-equivalents.

- Consider dual utilization of training and testing lands on a corporate basis.

- Include a proactive information campaign to describe the Army's environmental ethic and to create or reinforce the perception of the Army as a good land steward.

- Reinforce the importance of the ITAM program.

ISSUE \#3: There is no uniform policy on standards for hazardous waste storage and disposal by deploying forces.

DISCUSSION: A major goal of the transformation process is to reduce the size of the logistical tail. Units must take more than needed to the AOR, and what they take must be more easily stored, handled, and disposed of.

\section{ACTION:}

- Ensure that contracted resources such as LOGCAP include a full range of capabilities to support handling, storage, and disposal of NBC contaminated materials. (DCSLOG)

- Remove all hazardous material items from GSA catalogs when there are acceptable substitutes that are nonhazardous. (DCSLOG)

Require materiel developers to consider the life-cycle costs of disposal when they create and field new products. (ASA [ALT])

Issue \#4: Environmental Factors Effecting Staging Area in the AOR (APOD/SPOD) "Enforcing Army Environmental Standards"

Background: During a 1994 build up of forces in the Gulf region, we deployed equipment from the Brigade-a-float package to support contingencies in Kuwait. The objective was to download combat vehicles in Saudi Arabia and deploy them North into Kuwait; to support the forward deployed ground forces. Environmental supplies were not on hand for the down loading of equipment. Focus was on going to war, not maintaining the environment. 
Facts: As vehicles are downloaded from the ships, they had to be processed and prepared for issue to the deploying units. The personnel focused on getting the vehicles issued out in combat sets as fast as possible. Environmental issues are secondary concerns because "We are going to War!"

The personnel have spent 2 days flying to the AOR. They are tired but keyed up and ready to support the mission. The focus - "How many tanks and Bradley companies can be ready for issue in the next 48 hours?"

The mechanics are working 12-hour shifts changing batteries, replacing starters, fixing broken seals, testing brakes, replacing hydraulic fluids and ensuring the vehicles are ready to fight.

When the environmental engineers and safety managers showed up, it was as if the troops had discarded their training. Batteries were stacked without pallets, no eye protection was being used, and many other unsafe and unhealthy conditioned were noted.

We all have good intentions but sometimes we take the wrong approach. Our soldiers, GS employees, and contractors all want to succeed and ensure mission success. However, we have to help and provide them with the resources, guidance, and command emphasis needed to inspire and motivate them to do so safety and in an environmentally sound manner. We, as senior leaders have to set the tone in our actions to ensure that the issues that may haunt us all later are not over looked in the desire to "get the mission done."

Our Soldiers can do the mission. We know that. We need to reinforce to them that environmental sustainment and safety concerns are a part of the daily operations, not just something to slowdown the process. Environmental concerns affects soldier safety and it can affect soldier health. It can also affect the attitude of local population toward our forces and the way the world looks at us as a Nation.

Recommendations: We need to refocus soldier attitudes on the environment, follow up and inspect unit environmental performance, provide environmental resources and enforce existing environmental standards, not create new ones.

Refocus attitudes: Ensure that environmental standards are incorporated as part of every soldier's training; not as a separate course but an integral part of all our training. 
Follow up: We have to follow up, with units and staffs, ensuring that they understand that we consider environmental planning and execution as a part of normal operations. We have to ask the right questions of the G3/S3s and G4/S4s to ensure that they know we want environmental issues considered in the planning and decisionmaking process. "Soldiers do, what the Commander checks!"

Provide Resources: We should ensure that environmental supplies are included with prepositioned equipment and that personnel are trained on how to use it.

Enforce standards: The Army has policies in place to ensure mission success while meeting environmental standards. If we enforce environmental compliance standards now, we will save money on cleanup in the future and ensure the safety and health of our forces.

Issue \#5: Environmental Factors Effecting Staging Area in the AOR (APOD/SPOD) "Existing environmental conditions at the APOD/SPOD due to heavy industrial development"

Background: Throughout history, deep-water ports were developed to support commerce with other areas of the world. The arrival of the industrial age brought factories around the seaports that have had a long-term affect on our environment ever since. Today as then, goods are produced next to distribution systems for ease of transportation. This has lead to the development of heavy industries around Aerial Port of Debarkation (APOD), as air cargo capabilities increased. We are now faced with this inherent situation around the globe. Heavy industry's use of toxic and hazardous materials for production further threatens the environment and increases the safety, health, and environmental concerns that we face during a deployment.

Facts: When we deploy, we now have to consider and plan for hazardous material accidents or environmental terrorism at or near the SPOD/APOD. The maturity of host nation assets to respond to, control, and cleanup industrial accidents, environmental catastrophes, and terrorism varies by country. Adequate distance must be meet to ensure force protection from these hazardous material accidents and industrial terrorism. All of these considerations must be planned and included in Intelligence Preparation Battlefield (IPB).

Shu'yabah Port is a Seaport of Debarkation (SPOD) located south of Kuwait City. The port is surrounded by several heavy industrial facilities. They include a petroleum refinery, cement plant, chlorine plant, and a power plant. Marshalling areas are required for the off load of vehicles and equipment. A reconnais- 
sance of the initial site marshalling area and port discovered a green to yellow film that covered the soil. The Center for Health Promotion and Preventive Medicine (CHPPM) was requested to perform a risk assessment utilizing soil and air samples. Air monitors confirmed high levels of sulfur dioxide, carbon monoxide, and high particulate matter (PM10) levels. Today's force structure relies on reserve units, which tend to be a more mature population, more susceptible to respiratory injuries. The active duty average age is less than the reserve component.

Toxic and hazardous substances produced by local factories:

a. Petroleum Refinery: Volatile Organic Compounds (VOC), Carbon Monoxide $(\mathrm{CO})$

b. Cement Plant: Particulate Matter less than ten microns (PM10).

c. Chlorine Plant: Chlorine

d. Power Plant: Sulfur Dioxide $\left(\mathrm{SO}_{2}\right)$

Agencies are collecting intelligence information that relates to environmental security. Some intelligence sources are open while others are closed. CHPPM supports the AOR with a Deployment Environmental Surveillance Program; sharing their reports with Defense Intelligence Agency Armed Forces Medical Intelligence Center (DIA/ AFMIC), and Oak Ridge Labs. NIMA, the National Imagery and Mapping Agency has the capability to image environmental damage. CIA has the DCI Environmental Center (DEC). The National Reconnaissance Office (NRO) can furnish data, intelligence, and analysis of the environmental changes in our AOR. USAID office of foreign disaster assistance can also be of assistance during environmental disasters. Although these many sources provide information and intelligence, no one is task to put it all together and furnish it to the component commanders.

Recommendations: Operational Plans should take into account the unseen and potential environmental threats. New courses of action can be developed to protect our soldiers from environmental hazards. Use risk assessment tools. Prioritize the areas to be assessed. Pinpoint a single resource by classification as a data depository; one that is open, the other is closed.

Issue \#6: There is a general lack of environmental information about APOD/SPODs in the areas of probable conflict. An environmental database is needed to assist in the IPB.

Background: During the planning phase for Native Atlas it was determined that a coral reef obstructed the entry way to the JLOTS site at the Kuwaiti Na- 
val Base (KNB). This was the only site available and offered to ARCENT by the local Host Nation Commander. Third Army identified the requirement for a study done on the feasibility to remove all or a partial section of the reef to have a permanent site to do JLOTS.

Facts: Despite the cancellation of Exercise Native Atlas, Third Army G3 sees a continuing need for the JLOTS site that will require the demolition or destruction of the coral reefs in front of the KNB.

Coral reefs can be a hazard for U.S. forces in conducting operations in coastal areas, during exercises, contingencies other than war, and war; but coral reefs are considered an important resource to the global commons as a fish hatchery for rare and endangered species. Coral reefs only exist near approximately 2 percent of the world's seashores.

In 1994, Vice President of the United States, Al Gore, founded the International Coral Reef Initiative to mobilize efforts to protect and restore fragile coral reefs throughout the world.

In 1997 the United States joined the world in declaring the International Year of the Coral Reef, to bring support to saving the worlds diminishing coral reefs.

In 1998, President of the United States, Bill Clinton, published Executive Order 13089 "Coral Reef Protection". The order established a Coral Reef Task Force of various departments, including the Secretary of Defense and the Secretary of State. Their task is to "assess the U.S. role in international trade and protection of coral reef species and to implement appropriate strategies and actions to promote conservation and the sustainable use of coral reef resources worldwide...".

DoD Coral Reef Conservation Guide for the Military states that the U.S. Military shall "Maintain and improve the sustainability and native biological diversity to terrestrial and aquatic, including marine ecosystems while supporting human needs including the DoD mission."

The Local Host Nation Commander has stated that he does not care about the reef and plans to have the entire reef removed sometime in the future as it is a hazard to ship navigation at KNB. He was also interested in the possibilities to a Joint Coalition training effort (KU/USN/USA) to eliminate it.

The Army Environmental Center (AEC) has reviewed the issue from a legal standpoint of the U.S. regulations OEBGD, and the FGS. AEC's verbal legal opinion is that U.S. forces can participate in the removal of the reef, due to the 
fact that U.S. regulations don't apply overseas and that Kuwait does not participate in the International Coral Reef Initiative.

Recommendations: That further discussions be made on what tripwire mechanisms are in place to trigger a review of when it is in the national interest to remove these sensitive ecosystems.

Who makes the decision to remove these obstacles? Is it the local Commander, CINC, Ambassador; at what level does approval authority lie?

What are the political ramifications on removing such sensitive ecosystems when a national emergency is not declared (i.e., exercises and contingencies)?

Are we willing to test GreenPeace and World opinion on such an operation in peace time? 


\section{Appendix E: Overseas Deployment Land Management}




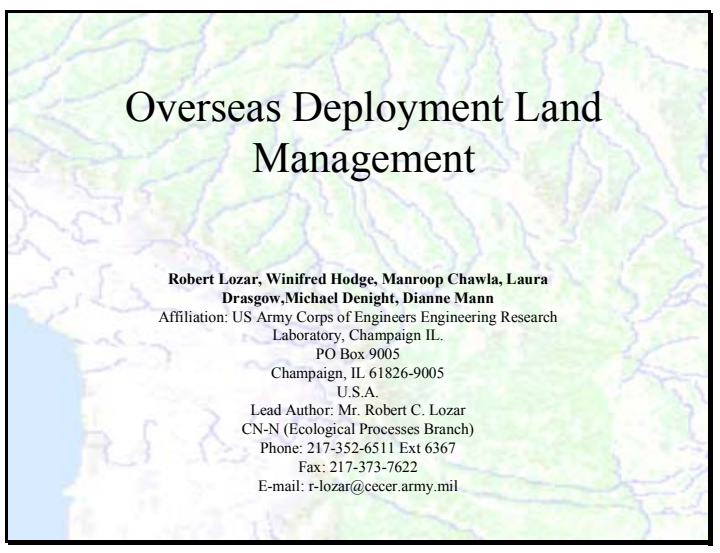

Slide 1

\section{Background: 1}

- DoD carries out

emergency and humanitarian response,

training or tactical on lands of other countries.

- Host counties expect that the U.S. agencies observe CONUS level environmental oversight

- Planning for avoidance

desirable

is normally less expensive to the U.S. mission than mitigation.

Knowledge can avoid potentially controversial issues.

10 August 1999

$$
\begin{gathered}
\text { Arizona Geographic Information } \\
\text { Conference }
\end{gathered}
$$

Slide 2

\section{Background: 2}

U.S. Executive Branch support:

- National Environmental Policy Act of 1969 \{NEPA PL91-190\}. Documentation:

Environmental Impact Assessment -EIA

the more robust Environmental Impact Statement -EIS)

- Presidential Executive Order $\{$ EO 12114 $\}$ : actions in areas beyond territorial limits.

"This directive provides policy and procedures to enable Department of Defense (DoD) officials to be informed and take account of

environmental considerations when authorizing or approving certain major federal actions that do significant harm to the environment of places outside the United States."

10 August $1999 \quad$ Arizona Geographic Information

Slide 3

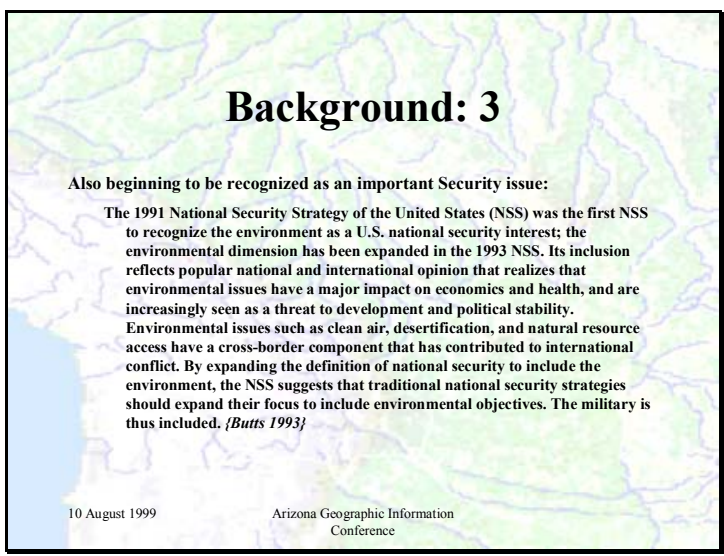

Slide 4
GIS Applications to Overseas Non Combat Deployment

We propose an approach utilizing integrated data from a number of sources into a single package that supports the initial environmental, political, engineering and
cultural awareness. This capability can reside on a PC Notebook hardware platform and be serviced by a combination of a data base manager and GIS providing both tabular and graphical output.

At each step of this process, the background data accessed and the resulting decisions would be saved for integration into an EIA style document which would

Normally the first step in any EIA would be a scoping process in which the universe of possibilities is pared to a few which are relevant to the user. The scoping capability helps a user to quickly identify likely potential problems and assign relative priotics to them from among the mith tude of potential possible .

10 August 199 Arizona Geographic Information

Slide 5
GIS Applications to Overseas Non Combat Deployment - 1

- Example 1: To deployment troops to a humanitarian aid mission.

The planner needs to become familiar with concerns which might affect deployment.

- First filter to establish the nature of the action, identify relative priorities, provide objective documentation.

- Within the Overseas Environmental Red Flag system the planner establishes Bolivia as the place for a yearlong deployment to in support of disaster relief. Arizona Geographic Information

Slide 6 


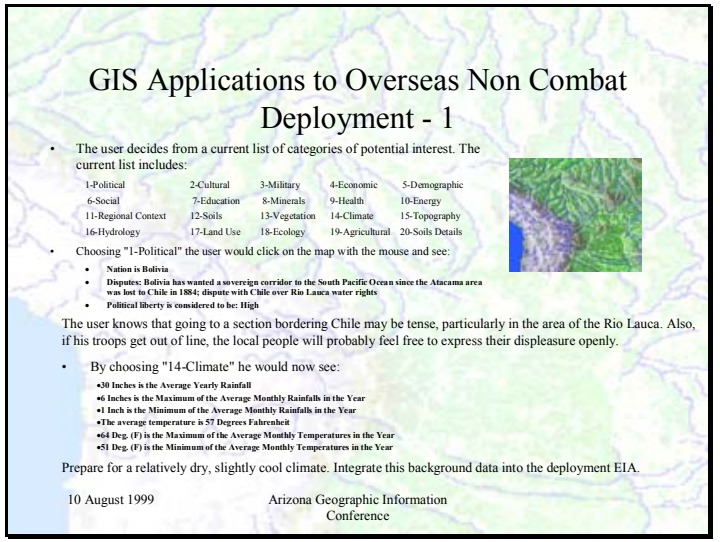

Slide 7

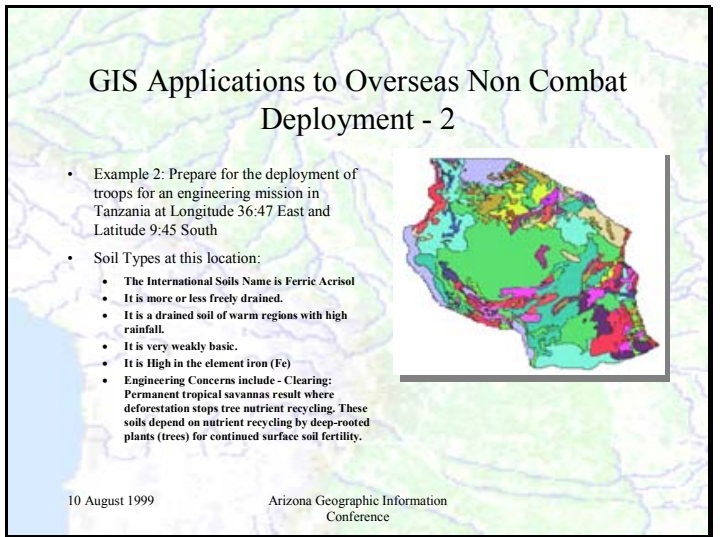

Slide 8

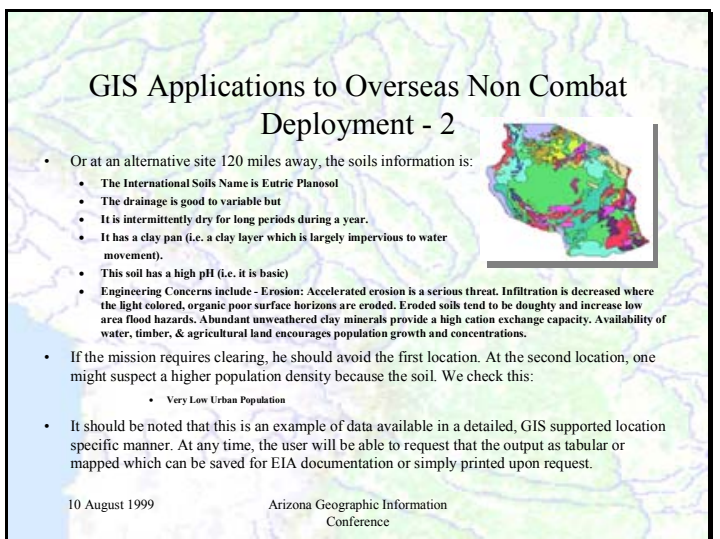

Slide 9

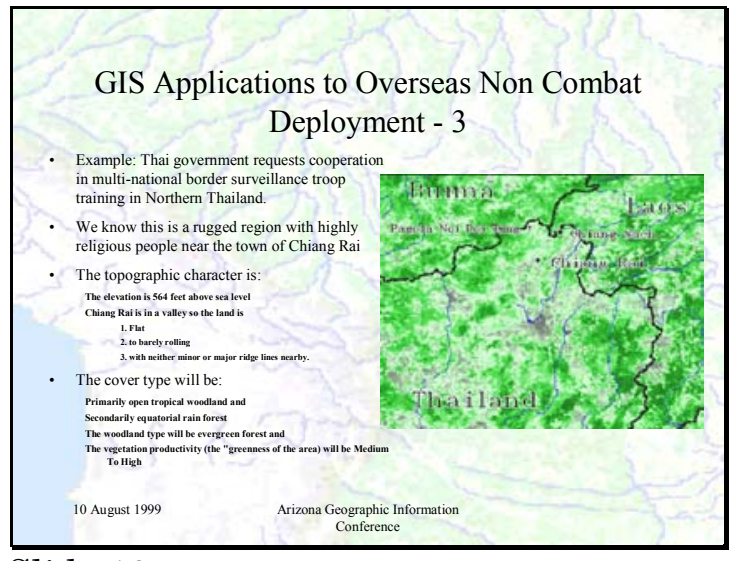

Slide 10

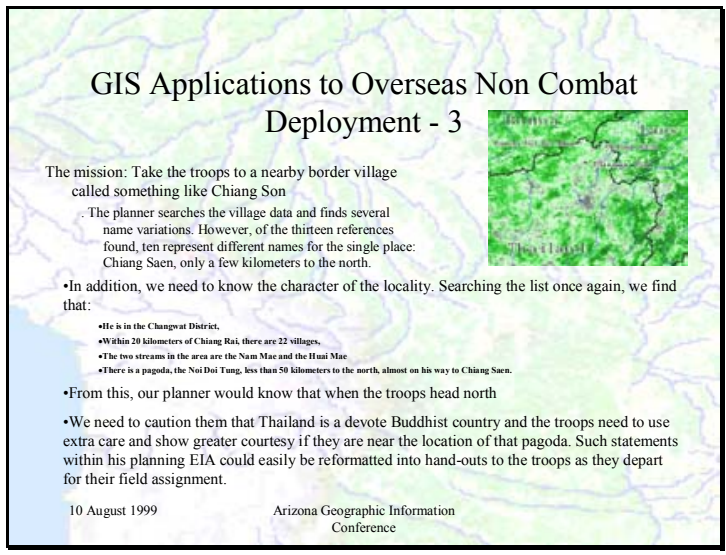

Slide 11

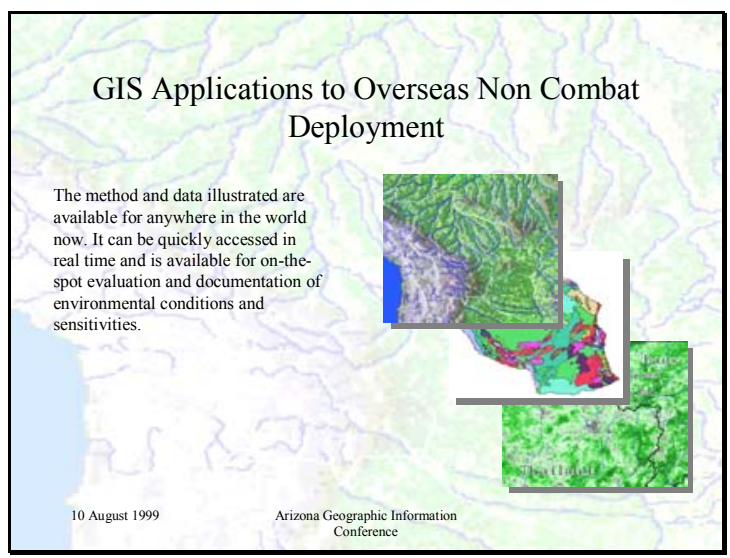

Slide 12 


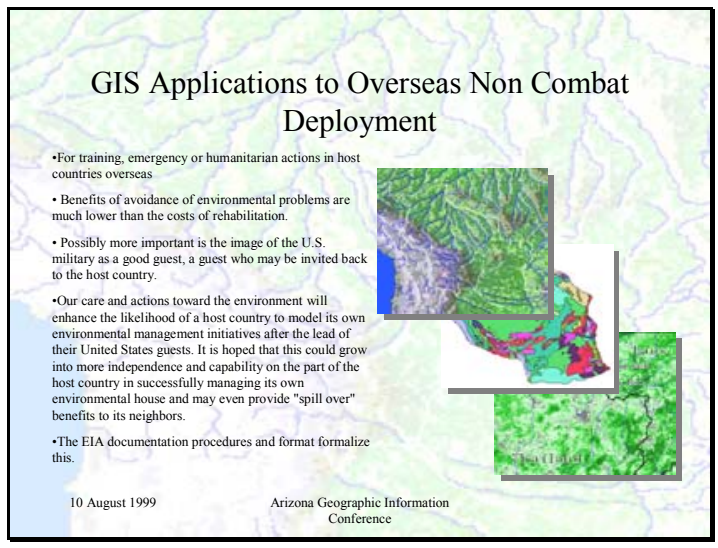

Slide 13 


\title{
Appendix F: Agenda
}

\author{
Environmental Protection for Forces Deployment Workshop \\ Final Agenda - May 1, 2000
}

8:00

Welcome, Administrative Announcements

What we want to accomplish

Product by the end of the day/month

Pass out Introduction Forms

Facilitator Responsibilities

8:15 Setting the Stage: Panel Discussion

DoD Overview and History: DUSD-ES - Gary Vest

Deployment Issues on the Ground: USAREUR - Roy Parks

Deployment Policy Concerns and SELC: AEPI - R. Jarrett/LTC Rensema

Technological Expertise: ERDC - Dr. Severinghaus

9:00 Participant Mission Introductions - Five minutes maximum

Name/Office

Agency Mission

Overseas Deployment Mission

Environmental Questions

Perceived Needs

10:30 Break

10:40 Breakout into 3 Groups to identify and prioritize:

$>$ Problems

$>$ Possible requirements to resolve:

Policy and Doctrine

Expertise and Personnel

Technology and Data

11:30 Report out group findings: 10 minutes each

12:00 Lunch

1:00 Observations/Response/Reality Check

ODCSENG Environmental Division: William Nicholls

1:30 "The Way Forward" The Solution Break out Groups:

Policy

Process

Products

3:00

Break

3:15 Report for each group - 20 minutes

4:15 Workshop Wrap-up and Validation:

Assessment of what the Workshop has accomplished

What still needs to be done?

Who will do what by when?

Participant Consensus

Summary of Next steps

4:30

Adjournment 


\title{
Appendix G: Increasing Environmental Awareness During Overseas Deployments, an Outsider's Perspective
}

\author{
by Dr. Charles R. Ehlschlaeger, Hunter College
}

The goal of this essay is to focus on overseas deployment environmental policy issues not discussed in detail during the May $1^{\text {st }}$ workshop. Please do not interpret this essay as a criticism of the ideas presented at the workshop. The ideas and goals stressed at the workshop, if implemented, will greatly benefit the US military's overall mission objectives. Many of the ideas presented in this essay compliment arguments presented at the workshop. This essay will focus on three elements: 1) Perceiving environmental policy during overseas deployments as a means to prevent an enemy from achieving their objectives, 2) Implementation strategies of overseas environmental policy at the personnel level, and 3) Technical issues of implementing environmental policy during overseas deployments. While the author claims no special insight to the specific issues of overseas deployment, he has participated in the implementation of environmental solutions at military bases for twelve years.

The most important goal of any policy is to relate it to the objectives of the organization. In this case, the organization is the US military. Ultimately, the military must understand how increased environmental awareness benefits its overall mission. The following is a reasonable argument, in their language, why the military should increase environmental awareness.

The military is deployed whenever an opponent does not want US policy to be implemented. Whether an oversea deployment is called a war, or a peacekeeping mission, the principles of war will still be in force. Carl Von Clausewitz, in his book "On War" declares war to be "an act of violence intended to compel our opponent to fulfill our will." Even a peace-keeping mission is considered an act of violence to some people within the country or region being deployed to. While the popularity of Von Clausewitz's ideas rise and fall on a regular basis, military conflicts almost always can be reduced to his principles. An opponent 
will proportion his efforts to the US powers of resistance. The powers of resistance is the product of two factors: the sum of available means, and the strength of will. For all practical purposes, the US can always (or more precisely: should always) deploy enough force to overwhelm an opponent. An opponent's only hope at victory lies in reducing the will of the US to continue the deployment.

While the greatest strength of the US military is it's all-volunteer force, from the perspective of an opponent, the all-volunteer force is also its greatest weakness. The loss of every soldier adversely affects the perception of any peace-keeping mission, reducing the will of the American people to support an overseas deployment. Ironically, an opponent need not directly confront US forces. Casualties will occur whether troops are in hostile conditions, or during training exercises. In fact, World War I is reportedly the first major war in history where most casualties were caused by enemy forces and not by environmental factors. When considering the ability for US forces to deploy overwhelming force, most future oversea deployments casualties will likely be caused by environmental factors.

Depending on the circumstances, environmental factors may be the most important factor determining whether or not a future overseas deployment will be considered a success. It is now nearly a decade after the Gulf War. Using CNN as a guide, the mainstream media is usually analyzing health issues when discussing the Gulf War. All unit commanders wants to bring home every soldier that is sent into the field. The commander doesn't care whether a soldier died from a sniper or from being exposed to toxic waste.

Relatively speaking, it is far easier for an Army Commander to plan for tactical and strategic operations than understand environmental implications of military actions. Army civil engineers assigned to deployment forces, as a rule, do not have training to collect and analyze environmental hazards while combat engineers have extensive training and detailed maps of potential deployment sites. Thus, whenever issues of location are analyzed, the decisions are made based solely on combat issues.

The most critical decision determining adverse environmental exposure is the location of military base camps. As the workshop attendees clearly articulated, commanders are advised by combat engineers and civil engineers when determining the location of base camps. At the very least, civil engineers require accurate maps of potential health hazards to minimize troop exposure. If possible, US military forces should preserve the environment, cultural, and historical landmarks in the deployment region. 
Note that the term Geographic Information System has not been specifically stated as a requirement for deploying civil engineers to accomplish their mission. In fact, a set of analog or digital maps describing "GO - SLOW GO - NO GO"* environmental conditions might be preferable to a complex GIS database for several reasons: 1) Classified data should be filtered to make identifying the original sources difficult, 2) Maps can quickly be transferred to the appropriate civil engineers to allow planning within a rapid deployment, and 3) Extensive training in environmental issues will not be required of all military civil engineers.

The first reason involves the nature of the data itself. Some of the data required can easily be collected from the public domain. Cultural and historic landmarks, for example, can be collected from travel guides and national maps. Other data, such as sites polluted by industrial waste, may be impossible to collect openly within some nations. Difficult to collect data may require clandestine operations, making the data classified. As articulated by several workshop participants, classified data is difficult to use. Often, it is difficult to prove a "need to know" for specific data, especially for data that civil engineers do not know exists, or of what quality. In order for classified data to more easily be used, it should be filtered by cartographic techniques eliminating clues about the data's sources. For example, suppose an industrial waste site containing heavy metals was identified in a country with a policy of hiding information about it's contaminated areas. In order to "hide" the leak that made the waste site information available, the NO GO polygon containing the contaminated area could be much larger than the actual site with polygon borders related to some other environmental factor, such as forest boundaries. If a region is relatively free from environmental and combat hazards, the environmental maps could be sprinkled with randomly located SLOW GO and NO GO polygons that may prevent someone from seeing patterns specific to secret maps. If a region is so littered with environmental hazards that it would be impossible to set up a base camp, the hazards can be combined into one huge polygon removing any specific evidence.

The second reason maps may be more useful than a complete GIS database is that maps can easily transferred to the appropriate personnel. Many deployment issues must be made within days or even hours of notification. Several case studies discussed at the workshop described environmental maps and data taking weeks to arrive, long after significant decisions were already made. A database, even in the hands of a trained professional, takes time to study the vari-

\footnotetext{
* In this context, SLOW GO might be replaced by HASTILY GO or AVOID UNLESS TACTICALLY CRITICAL.
} 
ous data layers and decide the relevance of attributes particular to that region. A civil engineer within a deploying unit needs to be able to make recommendations at a moment's notice.

The third reason maps may be more useful than a complete GIS database during a deployment is that maps require less training to use than a GIS. Training in environmental issues IS a good thing, but understanding all of the ramifications of environmental issues is a full time job while military civil engineers already have many duties and responsibilities.

One of the unstated goals of this essay's recommendations is to minimize any organizational changes that must be made. However, as Tim Reid recommended during his introduction, the military should create a unit to provide environmental support to deploying units. This deployment information support unit (DISU) should provide three critical tasks: 1) Deploy cartography expert(s) * and the appropriate maps and GIS databases with oversea deployments, 2) Build environmental databases for all potential deployment areas, 3) Maintain a liaison with military intelligence organizations to maximize the utility of sensitive information and help intelligence organizations acquire the appropriate data.

Of the three tasks, only DISU's liaison task requires clarification. The largest problem facing the use of classified data is that unit commanders do not know what sensitive data is available while the intelligence community has no incentive to assist the military. The DISU would be responsible for articulating specific military needs to the intelligence community as well as demonstrating techniques to prevent data sources from being compromised. The intelligence community would be expected to provide the DISU with information about available data. The DISU would then devise cartographic techniques to combine classified information with unclassified information to map products which hide the specific content of the classified data. When the combined maps are created, the intelligence community should be given an opportunity to provide timely suggestions for specific changes to the environmental "No-Slow-Go" maps before these maps be releasable to deploying forces.

In summary, while the military has reduced environmental impacts during overseas deployments, there is potential to improve environmental awareness and

\footnotetext{
* The term cartography expert is used instead of GIS technician to emphasize the main role as communicator of environmental information, not the creation of environmental data.
} 
reduce troop casualties. This workshop brought together separate groups of researchers and military planners dealing with environmental problems. It is obvious that these separate measures, while worthwhile separately, require organization in a specific unit responsible and accountable for the dissemination of environmental data to overseas deployments to multiply the potential benefits. 


\section{CERL Distribution}

Chief of Engineers

ATTN: CEHEC-IM-LH (2)

ATTN: CERD-ZA

Engineer Research and Development Center (Libraries)

ATTN: ERDC, Vicksburg, MS

ATTN: Cold Regions Research, Hanover, NH

ATTN: Topographic Engineering Center, Alexandria, VA

Defense Tech Info Center 22304

ATTN: DTIC-O

7

$3 / 01$ 


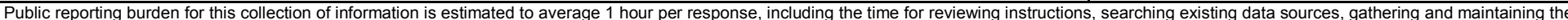

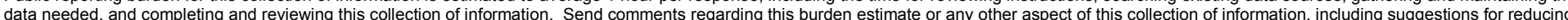

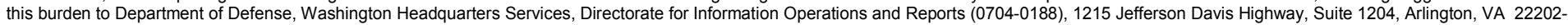

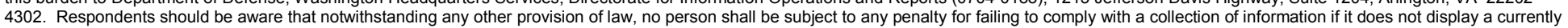
valid OMB control number. PLEASE DO NOT RETURN YOUR FORM TO THE ABOVE ADDRESS.
1. REPORT DATE (DD-MM-YYYY) $12-2001$ 2. REPORT TYPE

4. TITLE AND SUBTITLE

Proceedings of the Workshop on Environmental Protection for Forces Deployment

Robert C. Lozar and Charles R. Ehlschlaeger
3. DATES COVERED (From - To)

5a. CONTRACT NUMBER

5b. GRANT NUMBER

5c. PROGRAM ELEMENT NUMBER

5d. PROJECT NUMBER

622720A896

5e. TASK NUMBER

5f. WORK UNIT NUMBER

TY9

8. PERFORMING ORGANIZATION REPORT NUMBER

ERDC/CERL SR-01-21

U.S. Army Engineer Research and Development Center (ERDC)

Construction Engineering Research Laboratory (CERL)

P.O. Box 9005

Champaign, IL 61826-9005

\section{SPONSORING / MONITORING AGENCY NAME(S) AND ADDRESS(ES)}

Commander, U.S. Army Corps of Engineers

$441 \mathrm{G}$ Street, NW

Washington, DC 20314-1000

NUMBER(S)

12. DISTRIBUTION / AVAILABILITY STATEMENT

Approved for public release; distribution is unlimited.

\section{SUPPLEMENTARY NOTES}

Copies are available from the National Technical Information Service, 5285 Port Royal Road, Springfield, VA 22161.

\section{ABSTRACT}

The Department of Defense often must carry out actions beyond United States territorial limits. By Presidential Executive Order, regulation, and international treaty agreement, agencies of the government may be responsible for assessing the environmental affects of actions that are carried out in host countries. Environmental resource concerns an overseas mission planner may take into account when establishing an overseas deployment for troop training purposes. On 1 May 2000, the Workshop for Environmental Protection for Forces Deployment was held at the Holiday Inn Washington Dulles. The purpose of the workshop was to explore possible solutions to providing required spatial and nonspatial environmental management information to support planning and operations of deployed forces. The U.S. Army Engineer Research and Development Center/Construction Engineering Research Laboratory (ERDC/CERL), the Army Environmental Policy Institute (AEPI), and the USAREUR ODCSENG Environmental Division sponsored the workshop. This paper documents the participant's mission responsibilities, perception of needs, and consensus recommendations.

\section{SUBJECT TERMS}

Camp Bondsteel Kosovo, environmental protection, military training, workshops, environmental planning, forces deployment

\section{SECURITY CLASSIFICATION OF:}

\section{a. REPORT}

Unclassified

\section{b. ABSTRACT}

Unclassified c. THIS PAGE

Unclassified

\section{LIMITATION OF ABSTRACT}

SAR
18. NUMBER OF PAGES

97 19a. NAME OF RESPONSIBLE PERSON Robert C. Lozar

19b. TELEPHONE NUMBER (include area code)

(217) 352-6511 x6367 